\title{
mTOR CONTROLS LYSOSOME FUNCTION BY MODULATING THE RAB7 GTPASE
}

\author{
by \\ Zechariah Martin, HBSc (with High Distinction) \\ University of Toronto, Trinity College, 2015
}

\author{
A thesis \\ presented to Ryerson University \\ in partial fulfillment of the \\ requirements for the degree of \\ Master of Science \\ in the Program of \\ Molecular Science
}

Toronto, Ontario, Canada, 2017

(C) Zechariah Martin 2017 


\section{AUTHORS DECLARATION FOR ELECTRONIC SUBMISSION OF A THESIS:}

I hereby declare that I am the sole author of this thesis. This is a true copy of the thesis, including any required final revisions, as accepted by my examiners.

I authorize Ryerson University to lend this thesis to other institutions or individuals for the purpose of scholarly research.

I further authorize Ryerson University to reproduce this thesis by photocopying or by other means, in total or in part, at the request of other institutions or individuals for the purpose of scholarly research.

I understand that my thesis may be made electronically available to the public. 


\title{
Abstract: \\ mTOR CONTROLS LYSOSOME FUNCTION BY MODULATING THE RAB7 GTPASE
}

\author{
Zechariah Martin
}

Master of Science, Molecular Science, Ryerson University, 2017

Mammalian target of rapamycin (mTOR) is a protein kinase that integrates signals including stress and nutrient availability, to modulate the metabolic state of the cell. Interestingly, mTOR complex 1 (mTORC1) is specifically found on lysosomes where it regulates lysosome function, trafficking and morphology. However, little is known about how mTOR interfaces with lysosomal regulators, like the Rab7 GTPase, the canonical mediator of lysosome function, including biogenesis and trafficking to lysosomes to control processes such as antigen presentation and cell signaling. Rab7 can exist in two states. GDP-bound Rab7 is inactive but can be converted to GTP-bound Rab7, the catalytically active form of Rab7. Guanine nucleotide exchange factors (GEFs) are responsible for this conversion. Conversely, GTP-hydrolysis activating proteins (GAPs) facilitate Rab7 GTP hydrolysis, resulting in the conversion of GTP to GDP, rendering Rab7 inactive. We hypothesized that mTOR and Rab7 are functionally linked. Here we show that mTOR negatively controls Rab7. mTOR inhibition through the use of torin, EBSS (an amino acid deprived media) and A-769662 (an AMPK activator), increased levels of both total and active Rab7 (Rab7-GTP) on the lysosomal membrane. This was observed through fractionation, fluorescence microscopy and biochemical pulldown assays. This negative regulation is specific to mTOR, acting through TBC1D15, a Rab7 GAP. mTOR inhibition resulted in a significant reduction in levels of TBC1D15 via 
ubiquitination, which can be restored upon inhibition of the proteasome. Additionally, mTOR inhibition increased lysosomal proteolytic activity, and enhanced trafficking of material toward the lysosome. Our work suggests that under starvation conditions, trafficking to the lysosome is accelerated, re-establishing nutrient homeostasis. This research could provide a novel link between membrane regulation (Rab7) and metabolic stress sensors (mTOR), allowing insight into the pathogenesis of several metabolic diseases, including certain forms of cancer. 


\section{Acknowledgments:}

To my colourful supervisor, Dr. Roberto Botelho, you encouraged me to do more than simply scratch the "science surface". The last two years have been challenging, rewarding and maturing, and I have you to thank for that. I leave here much more confident than when I began, knowing that the skills I have acquired will serve me well in my future. Thank you for the opportunity to pursue this research project in your lab under your tutelage.

To my committee members, Dr. Greg Fairn and Dr. Sarah Sabatinos, your suggestions have been immensely helpful and your friendly dispositions have served to ease my nerves.

Dr. Kimberley Gilbride, doing directed studies under your leadership was a pleasure. Your guidance throughout my journey here has been invaluable.

To some of the friends I have gained during this experience:

Erika Ospina-Escobar, thank you for providing me with words of encouragement and making me smile. I admire your tenacity, diligence and fortitude. Your work ethic and dedication have consistently inspired me.

Victoria Hipolito, you helped me with most (if not all) of the experiments contained in this research dissertation, and for that I am perpetually grateful. I appreciate your advice, along with a seemingly endless supply of Tim Horton's coffee and laughter.

Dr. Monica Dayam, your humour, positivity, perspective and brilliance have made pursuing this graduate degree enjoyable. I look forward to many more years of friendship.

Dr. Matthew Gray, you mentored me throughout my time here. I have enjoyed our insightful, thought-provoking conversations, and wish you nothing but success in your new career.

Lastly, and most importantly, to my parents: thank you for your unwavering and unrelenting support. You believed in me when I lost faith in my abilities and stamina. I am grateful to have you healthy, happy and hilarious. Your success and intelligence are inspiring, and hopefully I have made you proud.

The words of Robert Frost resonate with me:

"Two roads diverged in a wood and I, I took the one less traveled by, and that has made all the difference."

$\sim$ Robert Frost 


\section{Table of Contents:}

$\begin{array}{ll}\text { Abstract } & 3\end{array}$

Acknowledgements $\quad 5$

Table of Contents $\quad 6$

$\begin{array}{ll}\text { List of Figures } & 10\end{array}$

List of Abbreviations 11

1. Introduction 14

$\begin{array}{ll}\text { 1.1. Metabolism and nutrient homeostasis } & 14\end{array}$

1.2. Sensing and controlling metabolism: the mammalian target of $\begin{array}{ll}\text { rapamycin (mTOR) } & 14\end{array}$

1.3. Sensing and controlling metabolism: AMP-activated protein kinase (AMPK)

1.4. Relationship existing between metabolic sensors and the lysosome

1.5. Lysosomes and the endomembrane system 20

1.6. Endocytosis and endosomal trafficking 23

$\begin{array}{ll}\text { 1.6.1. Phagocytosis } & 24\end{array}$

$\begin{array}{lr}\text { 1.6.2. Autophagy } & 24\end{array}$

1.7. Protein degradation and the 26S proteasome 25

1.7.1 Ubiquitin serves as a strong signal for protein destruction $\quad 28$

1.8. Rab GTPases and the endomembrane system 29

1.9. Rab7 34

1.9.1. Functional role of TBC1D15 39

1.10. Connection between mTOR and Rab7 40

1.11. Hypothesis 42 
1.12. Macrophages and the innate immune system

1.13. Objectives of this research project

2. Materials and Methodology

2.1. Cell culture and Treatments

2.1.1. Cell culture

2.1.2. Pharmacological treatments

2.1.3. Plasmid transformation

2.1.4. Plasmid DNA purification and extraction

2.1.5. Plasmids and transfection

2.2. Biochemistry Techniques

2.2.1 Western blotting and SDS-PAGE

2.2.1.1. PhosTag SDS-PAGE

2.2.2. Subcellular fractionation assay

2.2.3. Affinity Purification of GST-RILPc33

2.2.4. Affinity Precipitation of GTP-bound Rab7

2.2.5. Immunoprecipitation

2.3. Functional Assays and Imaging

2.3.1. Fc $\gamma$-mediated endocytosis assay using aggregated IgG and immunofluorescence

2.3.2. Dye Quenched-Bovine Serum Albumin (DQ-BSA) proteolysis assay

2.3.3. Lysosomal labeling

2.3.4. Spinning disc confocal microscopy and image quantification 52 
3.1. Suppression of $m$ TOR activity results in a significant reduction in levels of phosphorylated S6K

3.2. Lysosomal trafficking is upregulated under conditions of mTOR inhibition

3.3. Lysosomal proteolytic activity is enhanced by mTOR inhibition

3.4. mTOR inhibition enhances total Rab7 lysosomal-membrane association

3.5. mTOR inhibition increased levels of GTP-bound Rab7 on the lysosomal membrane

3.6. Inhibiting mTOR results in more GTP-bound, active Rab7

3.6.1. AMPK hyper-activation increased levels of active Rab7 (Rab7GTP)

3.7. Increased levels of Rab7-GTP are specific to mTOR inhibition not AMPK activation

3.8. mTOR does not seem to directly phosphorylate Rab7

3.9. Two Rab7 GAPs and One Rab7 GEF contain the mTOR consensus sequence

3.10. mTOR does not seem to directly phosphorylate TBC1D15

3.11. mTOR inhibition results in decreased levels of TBC1D15 and this depletion was restored via proteasome inhibition

4. Discussion and Future Directions

4.1. Summary of findings

4.2. Role of Rab7 in autophagy

4.3. The Rab7 GAP TBC1D2A, is involved in autophagy maintenance

4.4. The effects of starvation on endocytosis 
4.6. $\mathrm{mTOR}$ inhibition and protein degradation

4.7. E3 ubiquitin ligases and endo-lysosomal function

4.8. E3 ubiquitin ligase identification

4.9. Identification of ubiquitination site(s) on TBC1D15

4.10. Functional implications of TBC1D15 silencing

4.11. Proteasome inhibition and levels of active Rab7 (Rab7-GTP)

4.12. Additional Functional Tests

4.12.1. Using peroxisomes as a cargo "molecule" as opposed to aggregated IgG 


\section{List of Figures:}

Figure 1. The dynamic interplay between mTOR and AMPK regulates energybalance

Figure 2. Lysosome convergence pathways

Figure 3. Ubiquitin and protein degradation

Figure 4. Rab GTPase cycle

Figure 5. Rab7 GEFs and GAPs

Figure 6. Suppression of mTOR activity results in a significant reduction in levels of phosphorylated S6K

Figure 7. Trafficking to the lysosome is accelerated under conditions of mTOR inhibition

Figure 8. mTOR inhibition enhances lysosomal proteolytic activity

Figure 9. mTOR inhibition enhances total Rab7 lysosomal-membrane association

Figure 10. mTOR inhibition increases levels of RILPc33 (active Rab7) on the lysosomal membrane

Figure 11. Inhibiting mTOR results in more active Rab7 (Rab7-GTP)

Figure 12. Increased levels of Rab7-GTP are specific to mTOR inhibition not AMPK activation

Figure 13. mTOR does not directly phosphorylate Rab7 or TBC1D15

Figure 14. Rab7 GEF and GAP amino acid sequences containing the mTOR consensus sequence

Figure 15. mTOR inhibition results in decreased levels of TBC1D15, which can be restored upon inhibition of the $26 S$ Proteasome

Figure 16. mTOR inhibition results in enhanced ubiquitination of TBC1D15 75

Figure 17. Overall model of research dissertation 


\section{List of Abbreviations:}

4E-BP1 - 4E-binding protein 1

AMPK - AMP-activated protein kinase

APC - Antigen presenting cell

Arl - Arf-like

Atg13 - Autophagy-related protein 13

ATPase - Adenosine triphosphatase

BORC - Bloc-1 organelle related complex

cDNA - complementary DNA

deptor - DEP domain-containing mTOR-interacting protein

EGFR - Epidermal growth factor receptor

eIF-4E - eukaryotic initiation factor 4E

ER - Endoplasmic reticulum

ESCRT - Endosomal sorting complexes required for transport

FYCO1 - FYVE and coiled-coil domain-containing protein 1

GAP - GTP-hydrolysis activating protein/GTPase activating protein

GDF - GDI displacement factor

GDI - GDP dissociation inhibitor

GEF - Guanine-nucleotide exchange factor

GTPase - Guanosine triphosphatase

HECT - Homologous to the E6-AP Carboxyl Terminus domain.

HOPS - Homotypic fusion and Protein Sorting complex

IgG - Immunoglobulin G 
Lamp1 - Lysosome-associated membrane protein 1

LC3 - Light Chain 3

LKB1 - Liver kinase B1

MHC - Major histocompabibility complex

mLST8 - mammalian lethal with SEC13 8

mSin1 - stress-activated MAP-kinase interacting protein 1

MTOC - Microtubule organizing center

mTOR - Mammalian target of rapamycin

mTORC1/mTORC2 - mTOR complex 1/2

MVB -Multivesicular body

ORP1L - Oxysterol-binding protein-related protein 1L

PAMP - Pathogen-associated molecular pattern

PI3K - Phosphatidylinositol 3-kinase

PRAS40 - Proline-rich Akt1 substrate

protor $\mathbf{1 / 2}$ - protein observed with rictor

PRR - Pattern recognition receptor

RabGGT - Rab geranylgeranyl transferase

Rabring7 - Rab7-interacting RING-finger protein 7

raptor - regulatory associated protein of mTOR

REP - Rab escort protein

Rheb - Ras homolog enriched in the brain

rictor - rapamycin insensitive component of TOR

RILP - Rab7-interacting lysosomal protein 
RING - Really Interesting New Gene domain

S6K - S6 kinase

SDS-PAGE - Sodium dodecyl sulfate-polyacrylamide gel electrophoresis

siRNA - small interfering RNA

SKIP - SifA and kinesin-interacting protein

SNARE - Soluble N-ethylmaleimide sensitive fusion protein-attachment protein receptor

TSC1/2 - Tuberous sclerosis complex $1 / 2$

Ulk1/2 - Unc51-like autophagy activating kinase 1/2

v-ATPase - vacuolar $\mathrm{H}^{+}$-ATPase

VSV - Vesicular stomatitis virus 


\section{Introduction}

\subsection{Metabolism and nutrient homeostasis}

In order for cells to maintain homeostasis, they must accurately and reliably sense the nutrient status of their microenvironment. Nutrients refer to a class of molecules that are active participants in biochemical reactions necessary for energy production and liberation (Pang, Xie, Chen, \& Hu, 2014). Vital cellular nutrients include compounds such as amino acids, lipids and glucose and companion sugars. Not only do these nutrients perform different essential cellular functions, but also their mechanisms of detection are distinct. Nutrient sensing can result in the immediate physical binding of the nutrient(s) to the sensor, or through the use of a secondary molecule able to assess cellular nutrient-status. Nutrients play many crucial roles intracellularly including use as sources of energy for growth and development and the maintenance of health (Palacios, 2006). Cells need to detect nutrients and their abundance in order to determine if conditions are suitable for proliferation, degradation or steady-state equilibrium.

\subsection{Sensing and controlling metabolism: the mammalian target of rapamycin (mTOR)}

In order for cells to maintain optimal function, they must identify the nutrient condition(s) of the cellular environment and initiate anabolic or catabolic processes accordingly. Two particularly important metabolic sensors are mammalian target of rapamycin (mTOR) and AMP-activated protein kinase (AMPK). mTOR responds to a variety of external cues and initiates several anabolic processes including mRNA translation and lipid synthesis, while inhibiting catabolic processes like autophagy (Yang \& Guan, 2007). mTOR has been implicated in a massive number of cellular pathways 
with a diverse array of functional implications and consequences. mTOR is a $280 \mathrm{kDa}$ serine/threonine kinase belonging to the phosphoinositide-3-kinase (PI3K)-related kinase family (Porta, Paglino, \& Mosca, 2014). mTOR contains a kinase domain in its Cterminus that is structurally similar to the kinase (catalytic) domain of PI3K. This structural homology characterizes mTOR as a PI3K-related kinase.

mTOR associates with many different proteins, resulting in the formation of two distinct complexes: mTOR complex 1 (mTORC1) and mTOR complex 2 (mTORC2) (K. Huang \& Fingar, 2014). These two complexes have different sizes, downstream targets and upstream proteins that they elicit responses to. Six proteins comprise mTORC1 and seven proteins comprise mTORC2 (Laplante \& Sabatini, 2012b). Both complexes share certain protein interaction partners including the mTOR kinase catalytic subunit, Tti/Tel2 complex, DEP domain containing mTOR-interacting protein (deptor) and mammalian lethal with sec-13 protein 8 (mLST8) (Laplante \& Sabatini, 2012b). Proteins specific for mTORC1 include proline-rich Akt substrate 40 (PRAS40) and regulatory-associated protein of mTOR (raptor) (Laplante \& Sabatini, 2012b). Proteins specific for mTORC2 include rapamycin-insensitive companion of mTOR (rictor), protein observed with rictor 1 and 2 (protor 1/2) and mammalian stress-activated map kinase-interacting protein 1 (mSin1) (Laplante \& Sabatini, 2012b).

mTORC1 and mTORC2 perform different functional roles intracellularly. More extensive research has been done on mTORC1, showing that mTORC1 is responsive to a plethora of stimuli including growth factors, amino acids, glucose and cellular energy status (Wang \& Proud, 2011). The detection and integration of these signals causes the initiation of several processes including protein synthesis, lipid synthesis, ribosome 
biogenesis and mitochondrial metabolism (Morita et al., 2015). Conversely, the functional implications of mTORC2 activation have been relatively unexplored (Ebner, Sinkovics, Szczygieł, Ribeiro, \& Yudushkin, 2017). It is known that the activation of Akt by insulin occurs in a mTORC2-dependent fashion (Polak \& Hall, 2006). This suggests that mTORC2 may be involved in growth-sensing pathways. mTORC2 activation has effects on cytoskeletal dynamics/reorganization and cell proliferation (W. Huang et al., 2013). Unsurprisingly, aberrant mTOR activity has been identified in a vast number of diseases, ranging from cancers to type II diabetes to certain forms of neurodegeneration (Alzheimer's disease and Parkinson's disease) (Dazert \& Hall, 2011).

A well-characterized process regulated by mTOR is protein translation. mTOR phosphorylates two protein substrates involved in protein translation initiation, the ribosomal protein S6K (S6 kinase) and 4E-BP1 (4E-binding protein 1), a translational repressor. The phosphorylation of S6K by mTOR results in phosphorylation of the S6 ribosomal protein in addition to core translational components (Magnuson, Ekim, \& Fingar, 2012). 4E-BP1 binds the eukaryotic initiation factor 4E (eIF-4E). Unbound, eIF4E interfaces with the 5' cap of newly transcribed mRNA, leading to the localization of translation machinery. The phosphorylation of 4E-BP1 causes its dissociation from eIF4E, facilitating translation initiation (Hara et al., 1997).

\subsection{Sensing and controlling metabolism: AMP-activated protein kinase (AMPK)}

AMP-Activated Protein Kinase (AMPK) is a heterotrimeric protein complex consisting of a catalytic alpha subunit $(\alpha)$, scaffolding beta subunit $(\beta)$ and regulatory gamma subunit $(\gamma)$ (Xiao et al., 2011). AMPK plays the reciprocal role to mTOR inside 
of cells, being potently activated under conditions of nutrient deprivation, low glucose, tissue ischemia and hypoxia. AMPK is intimately regulated by the energy status of the cell (Shock, 2005). Under conditions of low energy (low ATP:AMP ratio), the binding of AMP to the $\gamma$ subunit results in the allosteric activation of the heterotrimeric complex, causing its phosphorylation in the $\alpha$ subunit at Threonine 172 (Thr172) by LKB1, an AMPK kinase (Mihaylova \& Shaw, 2011). Phosphorylation and subsequent activation of AMPK serves to induce signaling pathways responsible for energy replenishment. This includes processes like autophagy and fatty acid oxidation. In conjunction with this, AMPK serves to inhibit energy-depleting processes such as protein synthesis, lipid synthesis and gluconeogenesis. AMPK activation inhibits mTOR, through enhanced TSC1/2 activity, phosphorylating the Raptor component of mTORC1 (Steinberg \& Kemp, 2009). In its phosphorylated form, Raptor cannot engage with the other core components of mTORC1. The inhibited assembly of mTORC1 prevents its activity. Clearly, the dynamic interplay existing between AMPK and mTOR is necessary for the maintenance of cellular homeostasis and energy balance (Figure 1). 


\section{Figure 1:}

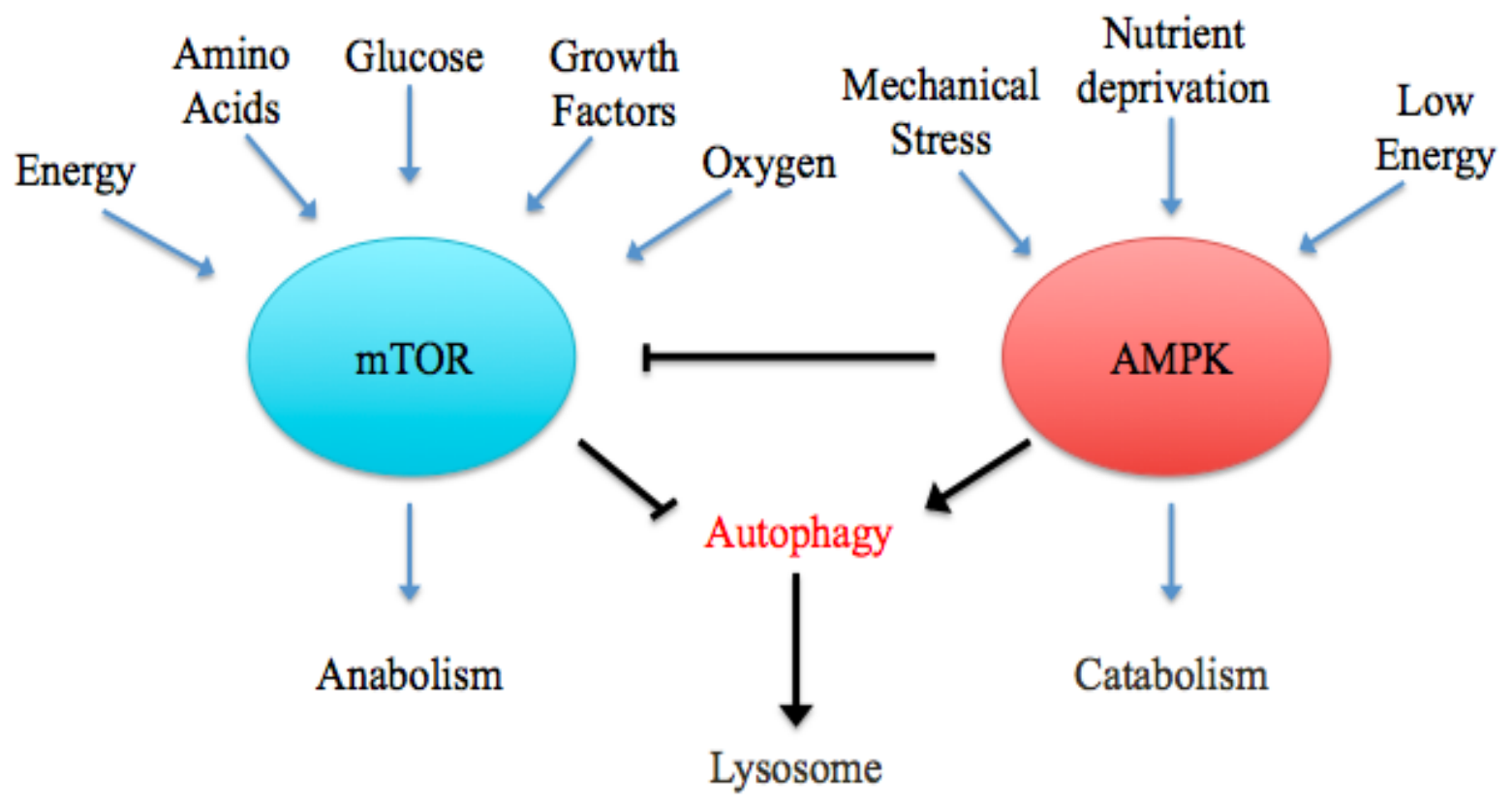

Figure 1. The dynamic interplay between mTOR and AMPK regulates energybalance: The reciprocal relationship existing between mTOR and AMPK is important for homeostatic maintenance. mTOR is active under conditions of amino acid satiety, growth factor presence and high energy (high ATP:AMP ratio). mTOR activation results in the induction of anabolic processes intracellularly. This includes activities like protein and lipid synthesis. Conversely, AMPK is optimally functional during conditions of low energy (high AMP:ATP ratio), nutrient deprivation and cellular stress. These stressors initiate catabolic processes. 


\subsection{Relationship existing between metabolic sensors and the lysosome}

Lysosomes are dynamic, adaptable organelles that orchestrate several responses upon the detection of nutrient levels. Interestingly, mTORC1 and AMPK appear to localize, be regulated, and function on the surface of the lysosome (Poüs \& Codogno, 2011). The connection between mTORC1 and the lysosome is outlined below.

Mammalian target of rapamycin complex 1 (mTORC1) senses and responds to cellular energy levels, growth factors and amino acids. High levels of these three sensors (particularly leucine and arginine amino acids) initiate the translocation of mTORC1 to the membrane of the lysosome. This process is prompted by amino acid signaling within the lysosome. The interaction between amino acids and the vacuolar ATPase proton pump (v-ATPase) potently activates Ragulator, a multisubunit protein complex (Sancak

et al., 2010). Ragulator functions as a GEF of Rag GTPases. These small GTPases function to draw mTOR to the membrane of the lysosome (Narita \& Inoki, 2012). At this docking site, coined the Ragulator docking site, mTOR resides spatially in close proximity to Rheb, a GTPase responsible for mTOR activation (Long, Lin, Ortiz-Vega, Yonezawa, \& Avruch, 2005). The interaction between mTORC1 with Rheb at the Ragulator docking site on the lysosomal membrane, leads to protein phosphorylation. This phosphorylation inhibits autophagy and regulates cell metabolism.

The mechanistic action of mTOR is still developing. mTOR has been found to control the function of a number of GTPases. Tuberous sclerosis complex 1 (TSC1) and tuberous sclerosis complex 2 (TSC2) are upstream regulators of mTORC1. These proteins act as GAPs for the Rheb GTPase (Byles et al., 2013). When Rheb is bound to GTP, mTORC1 activation occurs, initiating its kinase activity. Conversely, TSC1 and 
TSCS2 convert Rheb into its GDP-bound, inactive state. TSC1 and TSC2 are also responsible for detecting a variety of other cellular stressors including DNA damage and low levels of oxygen. Many signals are integrated through the TSC1/2-mTOR axis, however, researchers are still uncertain about which inputs have a more prominent impact and the particular cell-specific mechanisms responsible for this type of regulation.

\subsection{Lysosomes and the endomembrane system}

Eukaryotic cells have an endomembrane system composed of a wide variety of membrane-bound organelles (Mishev, Dejonghe, \& Russinova, 2013). These membranebound organelles include the nuclear envelope, endoplasmic reticulum (ER), Golgi apparatus, endosomes, lysosomes and the plasma membrane. The endomembrane system functions to transport, package, modify, tag and target lipids and proteins (Glick, 2000). Many of these transported/modified lipids and proteins converge at the lysosome.

In the early 1970s a Nobel Prize was awarded to Christian de Duve for his discovery of the lysosome (de Duve, Pressman, Gianetto, Wattiaux, \& Appelmans, 1955). He identified this organelle as a membrane-bound compartment containing a variety of different enzymes, that function in degradation and other lytic-like properties.

Lysosomes are small, membrane-bound organelles housed in the cytoplasm of almost all mammalian cells, with the exception of erythrocytes. The lumen of the lysosome contains many hydrolytic enzymes including lipases, proteases, glycosidases, sulfatases, phsophatases, phospholipases and nucleases (Lübke, Lobel, \& Sleat, 2009). The luminal environment of the lysosome is highly acidic, ranging from between a $\mathrm{pH}$ of 4.5-5 (Xu \& Ren, 2015). This highly acidic luminal environment enables protein degradation, 
processing and subsequent presentation. This acidic $\mathrm{pH}$ is maintained by the vacuolar ATPase (v-ATPase) proton pump, which releases protons $\left(\mathrm{H}^{+}\right)$into the lumen of the lysosome, against their concentration gradient (Schumacher \& Krebs, 2010). Other components of the lysosome that serve an important role include glycosylated lysosomalassociated membrane proteins (Lamp's; Lamp1 and Lamp2) that participate in lysosomal motility, integrity and structure (Gyparaki \& Papavassiliou, 2014).

Pathogens, macromolecules, organelles and surface receptors are targeted to the lysosome for degradation and processing. This wide heterogeneity makes the lysosome a convergence point for a number of distinct degradative pathways including the processes of endocytosis, phagocytosis and autophagy (Figure 2). 


\section{Figure 2:}

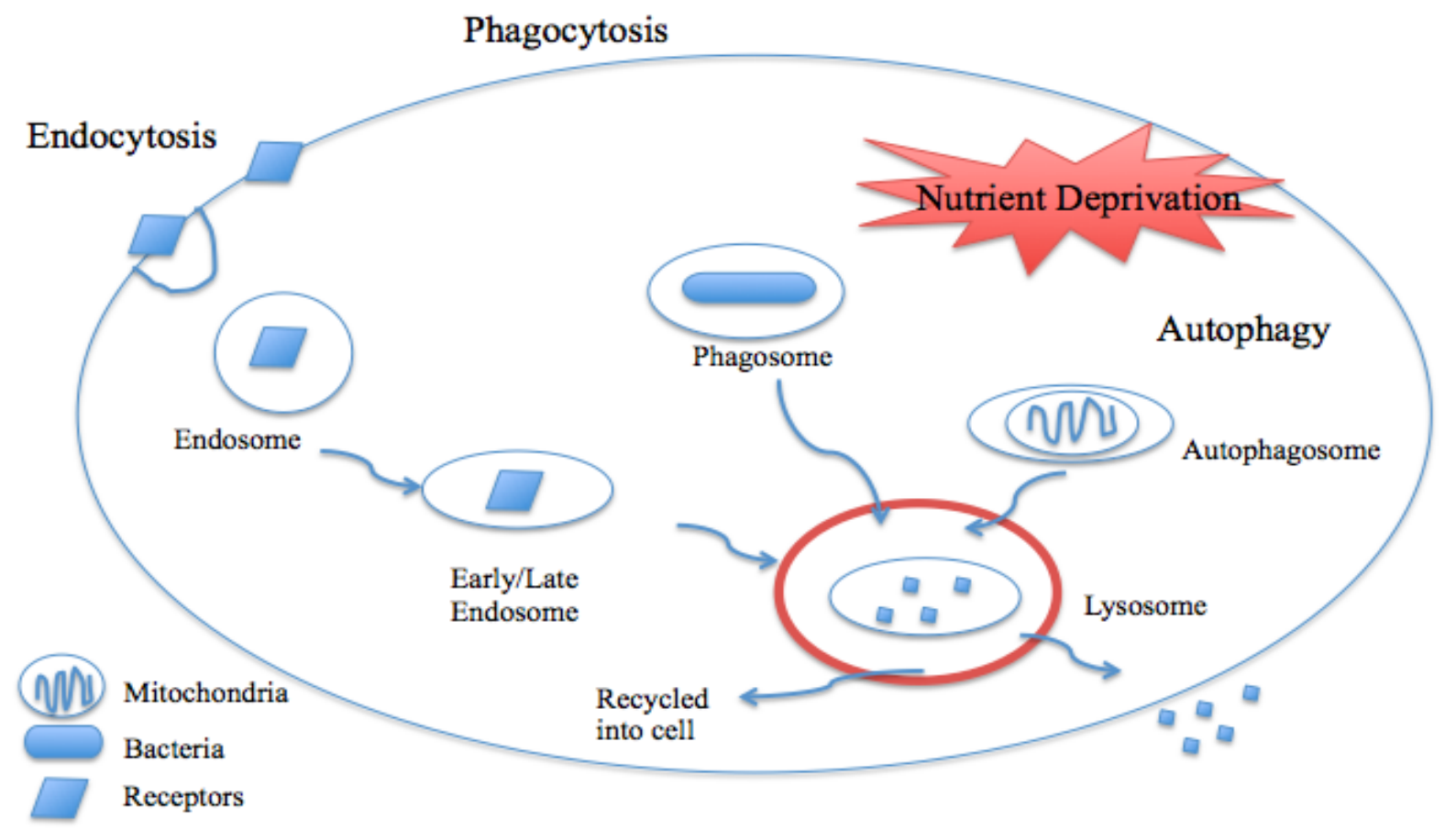

Figure 2. Lysosome Convergence Pathways: Inside all mammalian cell types with the exception of erythrocytes exists an organelle called the lysosome. The lysosome serves as a terminal organelle for a number of distinct degradative pathways include endocytosis, phagocytosis and autophagy. Cargo molecules in these crucial intracellular processes converge at the lysosome (receptors/fluid-phase material in endocytosis, bacteria/pathogens in phagocytosis and organelles/damaged proteins in autophagy). This organelle facilitates the degradation and recycling of delivered components for subsequent re-use. 


\subsection{Endocytosis and endosomal trafficking}

During endocytosis, fluid-phase material from the extracellular environment (and receptors) is internalized from the plasma membrane to then be sorted to different destinations in the cell, including recycling or degradation in lysosomes (Mukherjee, Ghosh, \& Maxfield, 1997). The formation of plasma membrane invaginations can be initiated with the aid of certain coat proteins, including clathrin (Ungewickell \& Hinrichsen, 2007). These invaginations place cargo in an endocytic cup, eventually forming a membrane-bound vesicle. Newly formed vesicles mature, forming early endosomes. The early endosome serves as a sorting compartment where delivered material is sequestered into specific micro-domains (Huotari \& Helenius, 2011). Material (mainly receptors) pinches off from the early endosome, resulting in trafficking to a variety of different destinations. The diversity in cargo sorting is reliant on the identity of the cargo molecule present in the vesicle. A subset of material delivered to the early endosome is recycled to the cell surface (Scott, Vacca, \& Gruenberg, 2014). An example of a protein with this trajectory is transferrin bound to transferrin receptor (TfR), an ironbinding glycoprotein present in the blood, responsible for tempering iron levels in the human body (Grant \& Donaldson, 2009).

Material required for degradation is often ubiqutitinated (See "Ubiquitin serves as a strong signal for protein destruction" below). Covalent ubiquitin tag(s) on the surface of a protein interface with proteins of the ESCRT (endosomal sorting complexes required for transport) complex (Henne, Buchkovich, \& Emr, 2011). This machinery partitions material into a series of vesicles, forming multivesicular bodies. This compartmentalization guarantees the fate of the material (degradation at the lysosome). 
Early endosomal maturation is marked by the liberation of early endosomal markers and the acquisition of late endosomal identity-markers. Late endosomes eventually fuse with lysosomes (Luzio, J. P.; Rous, B. A.; Bright, N. A.; Pryor, P. R.; Mullock, B. M. \& Piper, 2000). The acidic environment of the lysosome is responsible for breaking down the contents delivered from the late endosome into precursor molecules. These precursor molecules can then be re-used by the cell or released into the extracellular environment via exocytosis.

\subsubsection{Phagocytosis}

Phagocytosis refers to a specialized form of endocytosis in which particulate matter (including pathogens) are internalized by phagocytic immune cells. Conserved regions of pathogens, known as pathogen associated molecular patterns (PAMPs) are recognized by pattern recognition receptors (PRRs) on the surface of phagocytic cells. Binding of the PAMP to the PRR triggers its phagocytosis (Flannagan, Jaumouillé, \& Grinstein, 2012). The engulfed microbe is sequestered into a phagosome, which goes through a series of maturation steps eventually fusing with the lysosome, forming a phagolysosome (Botelho \& Grinstein, 2011). The acidic nature of the phagolysosome provides an optimal environment for the induction of pathogen killing and clearance.

\subsubsection{Autophagy}

Autophagy involves the degradation of the internal components of a cell. Under conditions of nutrient deprivation, low energy and cellular damage, certain proteins and organelles are sequestered into a double-membrane structure known as an 
autophagosome (Rubinsztein, Shpilka, \& Elazar, 2012). The process of autophagy is marked by the presence of certain molecular mediators. The formation of the autophagosome is reliant on the nucleation of an isolation membrane. This isolation membrane contains the protein LC3 (light Chain 3), which associates with the membrane of the autophagosome facilitating its formation and extension. (Tanida, Ueno, \& Kominami, 2008). The autophagosome undergoes a series of maturation events, eventually fusing with the lysosome, forming an autolysosome. The highly acidic nature of the autolysosome initiates recycling and degradation of the delivered components (Reggiori \& Ungermann, 2017). The end products produced from this recycling and degradation are used to drive cellular anabolic processes.

Control of autophagy is accomplished through mammalian target of rapamycin (mTOR), specifically mTOR Complex 1 (mTORC1), a serine/threonine protein kinase and master growth regulator and nutrient sensor, found spatially located on the surface of the lysosome (Puertollano, 2014). During nutrient abundance, mTOR is active and serves to inhibit the production of autophagosomes. Mechanistically, this is accomplished through phosphorylation of Atg13 (Autophagy-related protein 13) and Ulk1/2 (Unc51like autophagy activating kinase 1 and 2) (Laplante \& Sabatini, 2012a). Phosphorylation of these proteins suppresses their activity, preventing autophagosome production and nucleation.

\subsection{Protein degradation and the $26 \mathrm{~S}$ proteasome}

The information outlined above showcases the lysosome as being the prominent physiological hub for macromolecular recycling and degradation. However, not all 
cellular material that must be discarded (and properly disposed of) is targeted to the lysosome. The $26 \mathrm{~S}$ proteasome plays an integral role in the clearance of protein debris including molecules such as transcription factors, cyclins, virally encoded proteins, and proteins which are improperly folded (Smalle \& Vierstra, 2004). The 26S proteasome serves as an additional route for the disposal of unwanted (or unnecessary) material for more efficient allocation.

The $26 \mathrm{~S}$ proteasome is a barrel-like structure, which is divided into two component complexes, the 19S Regulatory Particle and the 20S Core Particle (Da Fonseca, He, \& Morris, 2012). The 19S Regulatory Particle recognizes ubiquitinated proteins. Six ATPases reside in the basin of the 19S Regulatory Particle (HartmannPetersen, Seeger, \& Gordon, 2003). The action of ATP hydrolysis initiates unfolding of the ubiquitinated protein (an important post-translational modification) and subsequent translocation into the cavity of the 20S Core Particle. Inside the Core Particle, multiple catalytic residues are responsible for facilitating the degradation of this substrate protein into a series of small peptides (Voges, Zwickl, \& Baumeister, 1999). From here, these small peptides (approximately eight amino acids in length) exit the Core Particle and are then degraded by cytosolic peptidases or presented as antigens to cells of the adaptive immune system in the context of the Major Histocompatibility Complex (MHC) (Gallastegui \& Groll, 2010). Ubiquitin peptides are expelled from the Regulatory Particle and can then be re-used intracellularly (Figure 3). 


\section{Figure 3:}

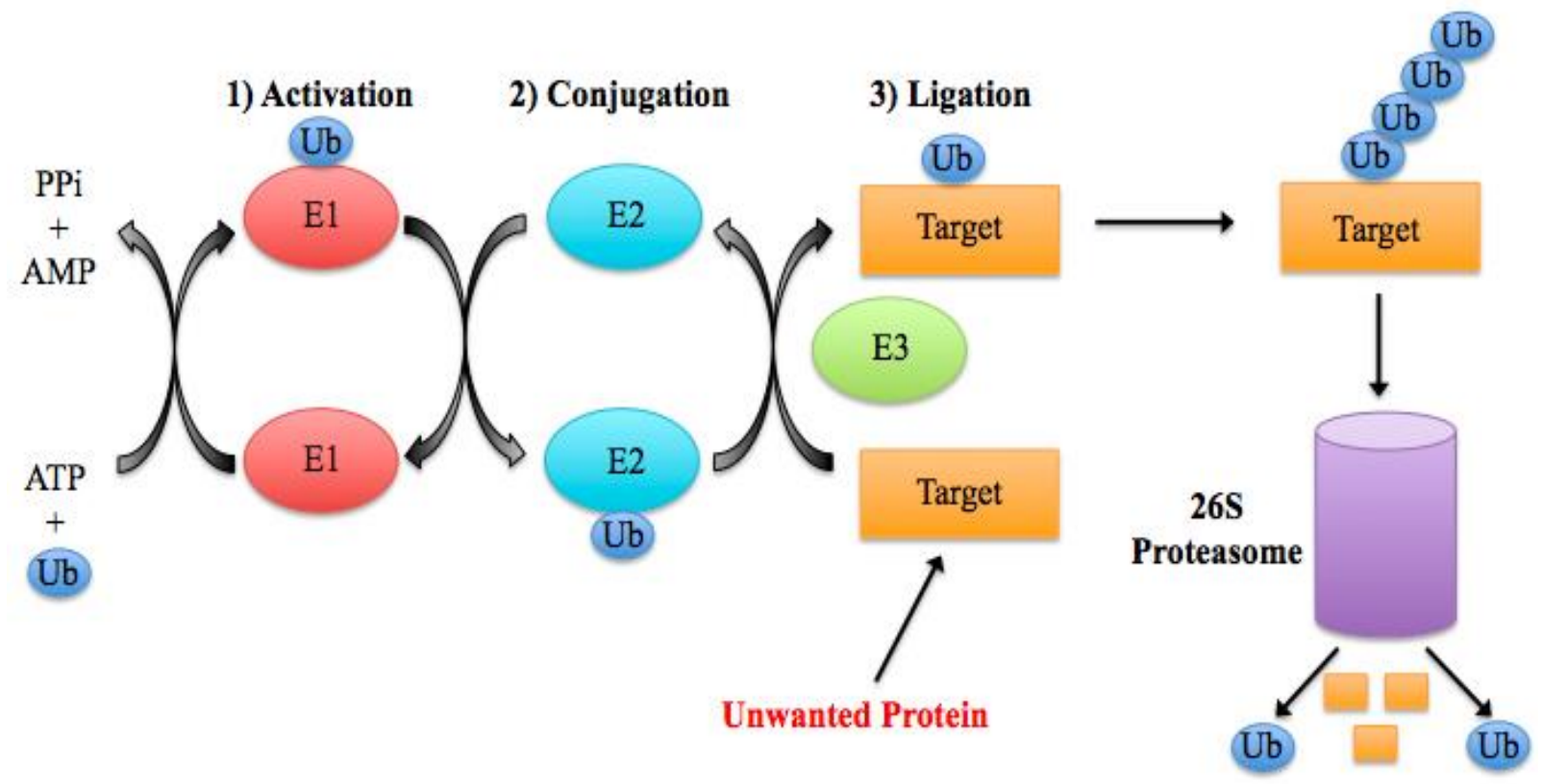

Figure 3. Ubiquitin and Protein Degradation: The addition of ubiquitin to certain proteins is catalyzed through a three-step reaction of activation, conjugation and ligation steps. The presence of ubiquitin poly-covalent chains serves as a strong signal for the targeted degradation of a protein by the $26 \mathrm{~S}$ proteasome (Adapted from: https://www.ebi.ac.uk/interpro/potm/2004_12/Page2.htm). 


\subsubsection{Ubiquitin serves as a strong signal for protein destruction}

The maintenance of cellular homeostasis and protein turnover is reliant on the differentiation of "healthy" proteins from those that are damaged and need to be removed. A crucial protein mediator separating useful proteins from ones targeted for destruction is the peptide ubiquitin. Ubiquitin is a seventy-six amino acid $(8.5 \mathrm{kDa})$ peptide that is added to certain proteins in a three-step reaction of activation, conjugation and ligation steps (Komander \& Rape, 2012). The addition of ubiquitin to target proteins in poly-covalent chains serves as a strong signal for that proteins targeted degradation by the $26 \mathrm{~S}$ proteasome. During ubiquitin activation, an E1 activation enzyme (E1) catalyzes the hydrolysis of ATP, resulting in the acyl-adenylation of the carboxyl terminus (Cterminus) of ubiquitin (Swatek \& Komander, 2016). This produces a thioester bond between a cysteine residue in the active site of the E1 enzyme and the C-terminus of ubiquitin. During conjugation, E2 conjugating enzymes (E2s) facilitate ubiquitin's transfer from the active site of the E1 activating enzyme to a cysteine residue in the active site of the E2 (forming an additional thioester bond). E2 conjugating enzymes have the ability to transiently bind both ubiquitin and the E1 activating enzyme. Approximately thirty-five E2 enzymes are present in eukaryotic cell types, all of which are characterized by containing a ubiquitin-conjugating catalytic (UBC) fold (Ye \& Rape, 2009). Ubiquitin ligation is accomplished by E3 ubiquitin ligases (E3s). This is done by the formation of an isopeptide bond between the C-terminal glycine of ubiquitin and a lysine residue present on the target protein of interest (Figure 3). Approximately seven hundred putative E3 ubiquitin ligases have been identified in literature (Morreale \& Walden, 2016). E3 ubiquitin ligases contain one of two evolutionarily conserved domains, either the Really 
Interesting New Gene (RING) domain or the Homologous to the E6-AP Carboxyl Terminus (HECT) domain. RING E3 ubiquitin ligases facilitate the transfer of ubiquitin from the E2 conjugating enzyme directly to a lysine residue on the target protein (Deshaies \& Joazeiro, 2009). Conversely, HECT E3 ubiquitin ligases bind ubiquitin temporarily during the ligation process (Rotin \& Kumar, 2009).

Ubiquitin elongation is essential for protein recognition by the $26 \mathrm{~S}$ proteasome. Ubiquitin contains seven lysine residues, which can be ubiquitinated. At least four ubiquitin residues must be covalently added to a single lysine residue on ubiquitin for targeting to the $26 \mathrm{~S}$ proteasome and subsequent recognition. The nature of the lysine to which ubiquitin is added has implications for its destination inside the cell. Poly-ubiquitin chains contained at Lysine 11, Lysine 29 and Lysine 48 residues serve as strong signals for proteasomal degradation of that protein (Jacobson et al., 2009). Conversely, Lysine 6 and Lysine 63 linkages function to alter protein trafficking, localization and activity (Jacobson et al., 2009).

\subsection{Rab GTPases and the endomembrane system}

Lysosomes are components of the endomembrane system. An extensive amount of research has been conducted on the endomembrane system focusing on concepts including:

1) How specific cargo is selected to become part of a vesicle.

2) The process of vesicle budding or detachment from a particular membrane.

3) The mechanisms through which vesicles are transported around the endomembrane system (the associated protein coats and regulatory 
machineries).

4) The processes induced when vesicles come in contact with a target membrane of interest (vesicle tethering and fusion).

Proteins called Rab GTPases are implicated in all of the aforementioned processes (Stenmark, 2009). Rab GTPases are members of the Ras superfamily of GTPases, consisting of approximately one hundred and fifty different protein-members in humans. They are responsible for not only ensuring the accuracy and fidelity of transport but also the establishment of organelle identity, with certain Rab GTPases localized to distinct compartments in the endomembrane system (Zerial \& McBride, 2001). This includes Rab5 being localized to early endosomes, Rab11 on the surface of recycling endosomes (multivesicular bodies) and Rab32 on the mitochondrial membrane.

Rab GTPases are small molecular switches involved in many cell-signaling pathways. Structurally, Rab proteins contain a GTPase fold, hyper-variable region, CAAX box and two Switch regions (Switch I and Switch II) (S. R. Pfeffer, 2005). The GTPase fold is made of a beta-sheet composed of six strands and five alpha helices. Proximal to this is a hyper-variable region (consisting of between 35-40 amino acids), involved in targeting the Rab GTPase to particular membranes (An et al., 2003). The CAAX box (residing adjacent to the hyper-variable region) contains two cysteine residues, which serve as sites for the covalent addition of geranylgeranyl moieties. These geranylgeranyl groups facilitate Rab GTPase insertion to target membranes of interest. Additionally, Rab GTPases have two Switch regions (Switch I and Switch II), which come in contact with the gamma $(\gamma)$ phosphate of GTP (S. Pfeffer \& Aivazian, 2004). In the GTP-bound state, these Switch regions are highly ordered. Conversely, in the GDP- 
bound state, the Switch regions are highly disordered. The region that undergoes the greatest structural change between its GDP and GTP bound states is the $\alpha 3 / \beta 5$ loop in the Switch II domain (Hutagalung \& Novick, 2011). This structural transition marks a change in activation state (ON in the GTP-bound form and OFF in the GDP-bound form). GTP-bound Rab proteins engage with protein effectors, initiating biological activity. GDP-bound Rab proteins do not have this ability.

Immediately after Rab protein translation, an association occurs between the Rab protein and Rab Escort Protein (REP). REP is responsible for presenting the Rab protein to Rab Geranylgeranyl Transferase (RabGGT) (Seabra, 1996). The interaction between the Rab protein and RabGGT catalyzes the addition of two geranylgeranyl lipid moieties to the carboxyl terminus of the Rab protein (Alory \& Balch, 2000). This modification is termed prenylation. Post-prenylation, the Rab protein enters its GTPase cycle. In the cytoplasm, Rab GTPases are bound to GDP. In the GDP-bound state, Rab proteins interact with GDP Dissociation Inhibitors (GDIs) (Dirac-Svejstrup, Sumizawa, \& Pfeffer, 1997). In order for Rab protein translocation and insertion to the membrane (where interaction with protein effectors occurs), GDIs must be recruited and bound to Rab proteins in their GDP-bound state.

The function of GTPases are tightly regulated and connected to their nucleotidebinding state. GTPases only interact with downstream effector molecules when they are in a guanosine triphosphate (GTP)-bound state. Specific proteins are responsible for mediating the conversion of Rab GTPases from their active to inactive forms (and inactive to active forms). GTP-hydrolysis Activating Proteins (GAPs) enhance the rate of GTP hydrolysis, in which a water molecule is used to produce GDP from GTP, liberating 
a molecule of inorganic phosphate in the process $\left(\mathrm{GTP}+\mathrm{H}_{2} \mathrm{O} \rightarrow \mathrm{GDP}+\mathrm{Pi}\right)(\mathrm{Barr} \&$ Lambright, 2010). This is done through the use of a glutamine or arginine finger, a binding motif, that interacts with the location of nucleotide binding. This conversion inactivates GTPases Conversely, Guanine-nucleotide Exchange Factors (GEFs) mediate the exchange of guanosine diphosphate (GDP) to guanosine triphosphate (GTP) (GDP $\rightarrow$ GTP) (Barr \& Lambright, 2010). This process activates GTPases. When Rab proteins are in the GTP-bound state, they can engage with effector proteins, enabling downstream biological functioning (Figure 4). The nucleotide status of Rab GTPases has an impact on Rab-dependent cycling and membrane insertion. Rab GTPases bound to target membranes in the GDP-bound state are susceptible to removal by GDI Displacement Factors (GDFs). Membrane removal renders Rab proteins inactive in the cytosol. This highly complex and dynamic Rab GTPase network is regulated at several different checkpoints. Rab GTPases have been implicated not only in trafficking inside the endomembrane system (and organelle identity), but have important roles in development, cell growth and cell signaling. 


\section{Figure 4:}

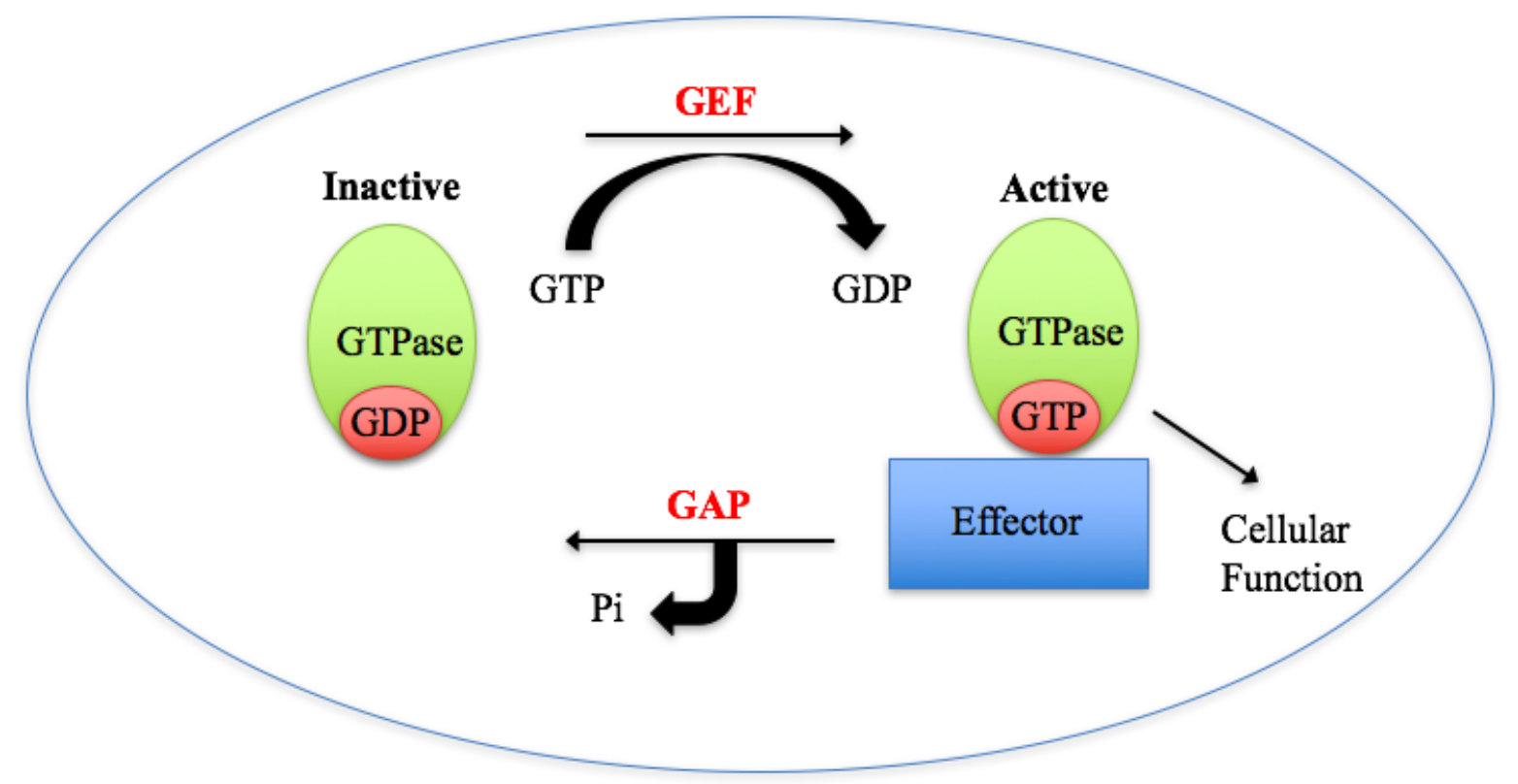

Figure 4. Rab GTPase Cycle: Proteins called GEFs (Guanine-nucleotide Exchange Factors) mediate the exchange of GDP to GTP, activating Rab GTPases. In their active form (Rab GTPase-GTP), these proteins are capable of interacting with effector proteins, which enables downstream cellular functions. In contrast, proteins called GAPs (GTPhydrolysis Activating Proteins) carry out GTP hydrolysis, where GTP is hydrolyzed to GDP and inorganic phosphate (Pi). This reaction inactivates Rab GTPases (Rab GTPaseGDP), preventing interaction with protein effectors and the performance of biological functions. 


\subsection{Rab7}

Even though an extensive amount of cargo is trafficked throughout the endomembrane system constitutively, organelles have the ability to keep their identity intact. The maintenance of organelle integrity is reliant on sequential shedding and accrual of molecular mediators. For instance, the displacement of Rab5 with the acquisition of Rab7 is indicative of a change in organelle identity, converting from an early endosome to a late endosome. The recruitment of Rab5 to the membrane of the early endosome along with its subsequent activation (Rab5-GDP $\rightarrow$ Rab5-GTP) is dictated by Rabex-5, a Rab5 GEF (Poteryaev, Datta, Ackema, Zerial, \& Spang, 2010). The activity of Rabex-5 is enhanced by the presence of Rabaptin-5, a Rab5 effector (binding exclusively to Rab5-GTP). The binding of Rabaptin-5, Rabex-5 and Rab5 produces a positive feedback loop, resulting in the recruitment of more active Rab5 (Rab5-GTP) to the membrane of the early endosome (in addition to more Rab5 effectors). To numb this positive feedback loop, the protein Mon1-Ccz1 displaces Rabex-5, preventing further Rab5 activation (M. Zhang, Chen, Wang, \& Wang, 2009). Mon1-Ccz1 acts as both a recruiter of Rab7 to the membrane of the early endosome and a GEF for Rab7 (Rab7-GDP $\rightarrow$ Rab7-GTP) (Nordmann et al., 2010). The change in presence of Rab GTPase $($ Rab5 $\rightarrow$ Rab7) reflects a transition from an early endosome to a late endosome and marks a change in organelle function.

A large amount of research has focused on the small GTPase Rab7. Rab7 is found predominantly on late endosomal and lysosomal structures, serving as the canonical mediator of tethering and fusion. Tethering and fusion reactions happen through the Homotypic fusion and Protein Sorting (HOPS) complex (also known as class C Vps 
protein complex) (Solinger \& Spang, 2013). Mechanistically, this occurs via a component of the HOPS complex, Vps33. Vps33 is capable of interacting with soluble Nethylmaleimide sensitive fusion protein-attachment protein receptors (SNAREs) on the surface of endosomes, facilitating fusion. HOPS, specifically the Vps39 subunit, behaves as a Rab7 GEF (Auffarth, Arlt, Lachmann, Cabrera, \& Ungermann, 2014), although this has been disputed (Peralta, Martin, \& Edinger, 2010).

Rab7 exerts its biological functions through the action of protein effectors, exemplified through the Rab7 Interacting Lysosomal Protein (RILP). The interaction between active Rab7 (Rab7-GTP) and RILP results in minus-end directed endolysosomal trafficking, through the formation of the Rab7-RILP-Dynein-Dynactin protein complex (Jordens et al., 2001). Lysosomal migration is intimately connected to the microtubule-based motor proteins dynein and kinesin. Dynein is a minus-end directed microtubule motor transporting cargo to the microtubule-organizing center (MTOC) in the perinuclear region of the cell. Kinesin plays the reciprocal role, serving as a plus-end directed microtubule motor, initiating transport towards the cell periphery. Optimal RILP activity is essential for lysosomal phenotypic properties and lysosomal distribution (Progida et al., 2007). RILP overexpression causes a change in lysosomal morphology and clustering, where lysosomes become enlarged and essentially solely perinuclear in distribution (De Luca et al., 2015). Conversely, RILP silencing fragments the lysosomal population, leading to peripheral scattering and a drastic increase in lysosomal $\mathrm{pH}$. Lysosomal alkalizing upon RILP silencing connects RILP to the vacuolar ATPase proton pump (v-ATPase). RILP co-immunoprecipitates with the V1G1 subunit of v-ATPase, a component required for proton translocation and the maintenance of acidity (De Luca et 
al., 2015). RILP serves to recruit V1G1 to the membrane of the lysosome. The linkage of Rab7 to kinesin-1 occurs through FYCO1, another Rab7 effector. Other Rab7 effectors include ORP1L (OSBP (oxysterol-binding protein)-related protein 1), Rab7-interacting RING-finger protein 7 (Rabring7), proteasome alpha subunit XAPC7 and Rac1, another small GTPase (Rocha et al., 2009).

Rab7 is a crucial regulator for cargo destined for the lysosome. Two Rab7 dominant negative mutants (Rab7-N125I and Rab7-T22N) prevent the migration of vesicular stomatitis virus (VSV) through the endomembrane system (particularly transport from the early endosome to the late endosome) (Vanlandingham \& Ceresa, 2009). Furthermore, dominant negative Rab7 expression leads to the accumulation of mannose-6-phosphate receptor and cathepsin D in early components of the endomembrane system and impairs the decomposition of low density lipoprotein (LDL) (Girard et al., 2014).

Aberrant Rab7 activity is implicated in the pathogenesis and progression of many diseases including Charcot Marie Tooth Disease Type 2B, an autosomal recessive neuropathy, and certain forms of cancer, particularly melanoma and prostate cancer (Cogli, Piro, \& Bucci, 2009). Understanding the interplay that exists between Rab7 and the endomembrane system has the potential to elucidate therapeutic targets and strategies for the treatment of the previously listed diseases. The importance of the Rab7 GTPase is over-indexing, making it necessary to understand its function, morphology, dynamics and downstream effectors.

Rab7 activity is reliant on specific GEFs and GAPs. Three Rab7 GAPs have been characterized in literature, all belonging to the TBC (Tre2/Bub2/Cdc16) domain- 
containing family of proteins. These include TBC1D2A (Armus), TBC1D10 and TBC1D15 (Guerra \& Bucci, 2016). Two Rab7 GEFs are known, the Vps39 subunit of the HOPS tethering complex and Mon1-Ccz1 (Guerra \& Bucci, 2016) (Figure 5). 


\section{Figure 5:}

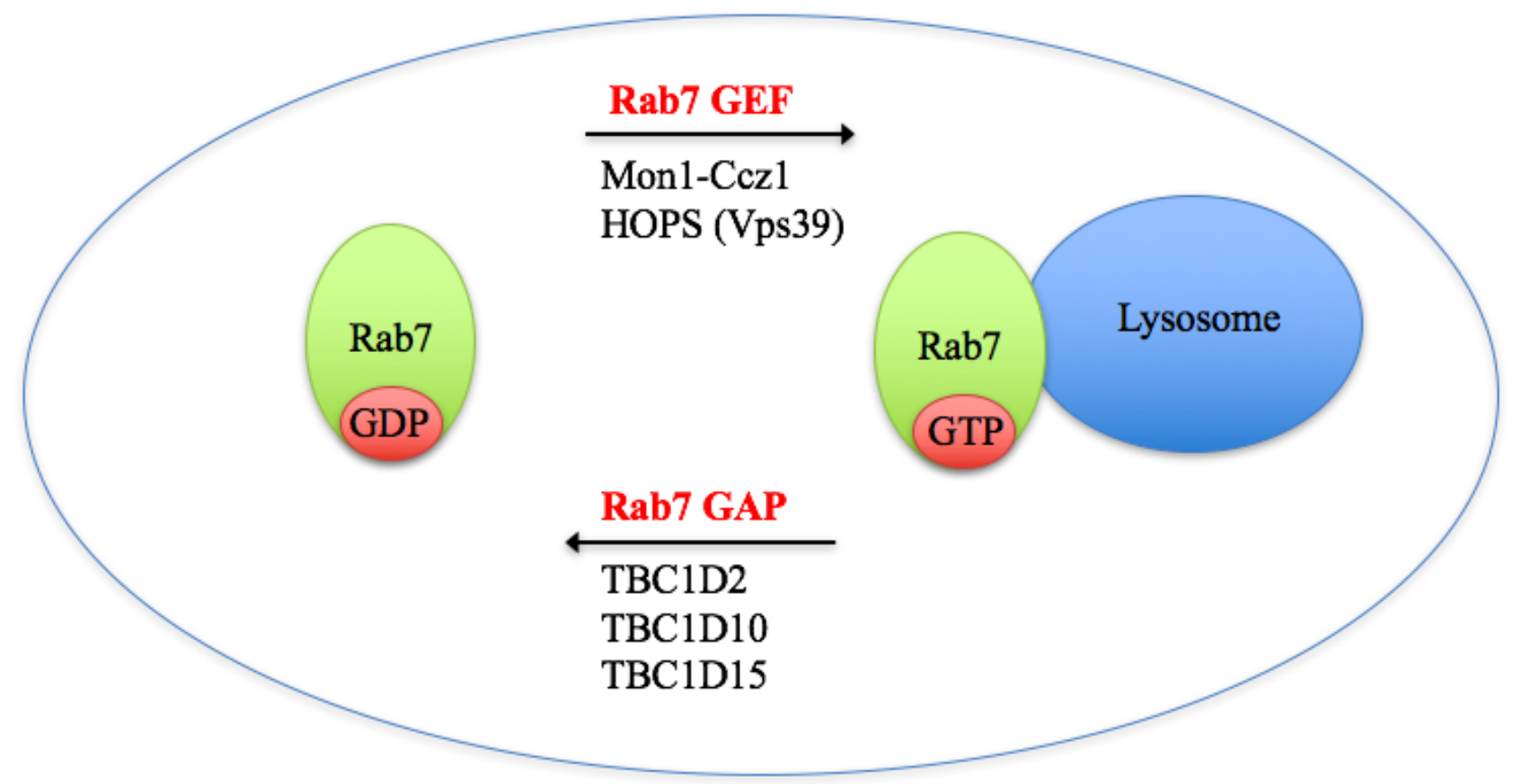

Figure 5. Rab7 GEFs and GAPs: Two Rab7 GEFs and three Rab7 GAPs have been characterized in literature. Mon1-Ccz1 and one subunit of the HOPS tethering complex (Vps39) have been identified as Rab7 GEFs. Three members of the TBC family of proteins, TBC1D2, TBC1D10 and TBC1D15 have been shown to exhibit GAP activity. 


\subsubsection{Functional role of TBC1D15}

Several Rab7 GEFs and GAPs are involved in the dynamic cycling between active and functional Rab7 (Rab7-GTP) and dormant, cytosolic Rab7 (Rab7-GDP). TBC1D15 is a Rab7 GAP responsible for promoting GTP hydrolysis rendering Rab7 inactive, resulting in its dissociation from the lysosomal membrane (X. M. Zhang, Walsh, Mitchell, \& Rowe, 2005). Minimal research has focused on the importance of this protein.

TBC1D15 has been implicated in mitophagy induction (Yamano, Fogel, Wang, van der Bliek, \& Youle, 2014). PINK1 (a protein kinase) and Parkin (an E3 ubiquitin ligase) serve as crucial upstream molecular mediators in mitophagy initiation, however, the mechanisms involved in the formation of the autophagosomal membrane (engulfing mitochondria), remain to be elucidated. TBC1D15 acts downstream of Parkin activation, limiting the activity of Rab7 (Yamano et al., 2014). TBC1D15 silenced cells have drastically enlarged autophagosomes that extend bi-directionally along microtubule tracts. The autophagosomal populations in TBC1D15 silenced cells have impaired fusion with the lysosomal population and lose their directionality (Yamano et al., 2014). TBC1D15 forms a complex with Rab7, the mitochondrial protein Fis1 and TBC1D17. This complex interacts with LC3/GABARAP proteins ultimately resulting in mitochondrial restriction to the autophagosomal isolation membrane. TBC1D15 serves to temper Rab7 activity, facilitating proper mitophagy commencement (Yamano et al., 2014).

Research pinpoints TBC1D15 as being important in cancer pathogenesis and progression. TBC1D15 acts as an oncoprotein, particularly important in stem cell 
proliferation and multipotency (Feldman, Chen, Punj, \& Machida, 2013). The protein complex Numb-p53 is a crucial control mechanism in tumor progression. p53 is a wellcharacterized tumor suppressor. The association of Numb with p53 is destabilized by the action of PKC $\zeta$ (a kinase of Numb). Douglas Feldman and colleagues (lab of Dr. Keigo Machida) showed that the amino terminus of active TBC1D15, independent of Rab7, causes the dissociation of p53 from Numb, leading to the degradation of p53 and heightened cell proliferation (Feldman et al., 2013). Additionally, this research showed that levels of TBC1D15 are diminished during conditions of nutrient deprivation (Feldman et al., 2013). This illustrates a potential connection between TBC1D15 and growth-sensing pathways (particularly mammalian target of rapamycin), considering aberrant mTOR activity is a hallmark of several cancer subtypes.

\subsection{Connection between mTOR and Rab7}

Three pieces of evidence currently exist showing a potential connection between mTOR and Rab7. In 2009, Kimberly Rosales and colleagues (lab of Dr. Aimee Edinger) explored the relationship between Rab7 and conditions of growth factor withdrawal. This research showed that Rab7 activity was modulated in response to the presence or absence of growth factors. Under conditions of growth factor withdrawal, RILP (a Rab7 effector) migrated from the cytosol to the membrane of the lysosome (Romero, Peralta, Guenther, Wong, \& Edinger, 2009). Additionally, cells experiencing growth factor withdrawal showed elevated levels of Rab7-GTP (evidenced through biochemical pull-down assays) (Romero et al., 2009). This provided evidence that extrinsic growth factor signaling impacts Rab7 activity. 
In 2015, evidence connecting the function of mTOR to the activity of Rab7 came from Jing Pu and colleagues (lab of Dr. Juan Bonifacino). The focus of this research was BORC (Bloc-1 organelle related complex). This research identified BORC as being responsible for recruiting Arl8b, another small GTPase, to the lysosome (Pu et al., 2015). Arl8b is known to interact with an effector SKIP, which links to the microtubule motor protein Kinesin-1, resulting in lysosomal migration towards the cell periphery. BORC acts as a promoter of Arl8b-SKIP-Kinesin-1 lysosomal transport, mirroring the role of the Rab7-RILP-Dynein-Dynactin complex, involved in lysosomal transport towards the microtubule-organizing center (MTOC) (Pu et al., 2015). siRNA knockdown of BORC subunits prevented association of Arl8b with lysosomes, causing the peripheral lysosomal population to collapse into the perinuclear region ( $\mathrm{Pu}$ et al., 2015). BORC serves to facilitate a series of interactions that initiate lysosomal transport to the cell periphery. Additionally, a link between Ragulator and BORC was established. When mTOR activity was compromised (using torin), Arl8b recruitment to the lysosome was reduced (Pu et al., 2015). Since Arl8b and Rab7 are involved in reciprocal pathways, this suggests that Rab7 recruitment to the lysosome and minus-end directed transport, may be elevated during conditions of mTOR inhibition.

The final piece of evidence came from a paper published in 2016 by Amra Saric and colleagues (lab of Dr. Roberto Botelho). This paper focused on understanding the role of mTOR in lysosomal trafficking and morphology, through the alteration of microtubule-motor activity (Saric et al., 2016). Under conditions of lipopolysaccharide (LPS) stimulation, lysosomes undergo a change in morphology, converting from small punctate structures to vast tubular networks. mTOR is required for this phenotypic 
change. When mTOR was inhibited, through the use of torin, levels of Arl8b drastically decreased on the membrane of tubular lysosomes, and preliminary evidence showed that levels of Rab7 increased on the tubular lysosomal membrane (Saric et al., 2016). These points of knowledge allowed us to generate the corresponding hypothesis.

\subsection{Hypothesis}

We hypothesized that mTOR and Rab7 are functionally linked. More specifically, we propose that mTOR serves as a negative regulator of Rab7, whereby loss of mTOR function upregulates Rab7.

\subsection{Macrophages and the innate immune system}

To carry out the experiments contained in this dissertation, the cell type RAW 264.7 macrophages were used. Macrophages are a type of white blood cell of the innate immune system known as a leukocyte, and are professional phagocytes responsible for pathogen clearance, garbage disposal and antigen presentation (Banchereau \& Steinman, 1998). The immune system serves as the body's line of defense against foreign pathogens and microbes and is divided into two different branches: the innate immune system and the adaptive immune system (Dunkelberger \& Song, 2010). The innate immune system includes non-specific defenses that serve as physical and chemical barriers to infectious material. The adaptive immune system elicits a fine-tuned response based on antigenic priming. Macrophage biology has traditionally been investigated in the context of infection. It is known that upon an encounter with a foreign microbe, macrophages (and other phagocytes) are recruited to the site of infection (Silva \& Correia-Neves, 2012). At 
this location, macrophages interact with these foreign pathogens, breaking them down (processing them) into antigenic derivatives (Harvey, Gee, Haberman, Shlomchik, \& Mamula, 2007). These antigenic derivatives are subsequently loaded on the surface of the macrophage in the context of the Major Histocompatibility Complex (MHC) (Mantegazza, Magalhaes, Amigorena, \& Marks, 2013). From here, macrophages present these antigens to cells of the adaptive immune system, specifically $\mathrm{T}$ lymphocytes and B lymphocytes, known as the process of antigen presentation. $\mathrm{T}$ lymphocyte cytokine production and B lymphocyte antibody production helps clear the infectious agent and provides the body with immunological memory. The aforementioned processes represent canonical macrophage cell biology. However, macrophages have also been implicated in processes of muscle and limb regeneration, iron and nutrient homeostasis and tissue maintenance (Ganz, 2012). This makes it essential to not only understand the role of the macrophage in the context of infection, but also the fundamentals of basic macrophage cell biology. Additionally, macrophages are an ideal cell type for studying endomembrane system dynamics due to the rapid membrane flux exhibited by these cells. This makes them more sensitive to environmental perturbations. For example, macrophages internalize their membrane surface within thirty minutes (Cox, Lee, Dale, Calafat, \& Greenberg, 2000). Exploring and characterizing the intricate nature of macrophage biology serves as a platform for deeper insight into the immune system and potentially, the treatment of a number of immune-mediated and metabolic diseases.

\subsection{Objectives of this research project}

It is known that mTOR, specifically mTORC1, is located on the surface of the 
lysosome at the Ragulator docking site and that mTOR inhibition results in autophagy induction, a process that converges at the lysosome. This research project aims to investigate if crucial energy sensing circuits are involved in coordinating the trafficking of material toward the lysosome for degradation, ultimately resulting in nutrient liberation for re-use. This project aims to:

i) investigate the functional implications of mTOR inhibition at the lysosome by employing trafficking and lysosomal proteolytic assays.

ii) explore the recruitment of Rab7 to the lysosomal membrane upon mTOR inhibition, using membrane fractionation, imaging and affinity precipitation of GTPbound Rab7.

iii) determine how mTOR interfaces with Rab7 regulatory machinery. 


\section{Materials and Methodology}

\subsection{Cell culture and Treatments}

\subsubsection{Cell culture}

Unless indicated otherwise, RAW 264.7 macrophages were used as the cell-type for all of the experiments contained in this dissertation. They were grown in Dulbecco's modified Eagle's medium (DMEM), supplemented with 5\% fetal bovine serum (FBS), glucose, sodium pyruvate and L-glutamine. These conditions were maintained at $5 \% \mathrm{CO}_{2}$ and $37^{\circ} \mathrm{C}$.

\subsubsection{Pharmacological treatments}

Cells were treated with one of two mTOR-specific inhibitors, either torin at a final concentration of $200 \mathrm{nM}$ or Earle's Balanced Salt Solution (EBSS, Gibco). AMPK activation was performed using A-769662 at a final concentration of $100 \mu \mathrm{M}$ (Abcam) and AMPK inhibition was done using Compound $\mathrm{C}$ at a final concentration of $40 \mu \mathrm{M}$ (Abcam). All pharmacological treatment groups were incubated at $37^{\circ} \mathrm{C}$ for two hours.

\subsubsection{Plasmid transformation}

The deoxyribonucleic acid (DNA) plasmids used in this study were RFP-Rab7, RILPc33-GFP, GST and GST-RILPc33. Plasmid transformation occurred in DH5 $\alpha$ competent cells. $50 \mu \mathrm{L}$ of DH5 $\alpha$ competent cells were used in conjunction with ten nanograms (10 ng) of plasmid DNA. Cells were heat-shocked for forty-five seconds at $42^{\circ} \mathrm{C}$ and subsequently placed on ice for five minutes. The transformation reaction was incubated at $37^{\circ} \mathrm{C}$ for one hour with one millilitre $(1 \mathrm{~mL})$ of Luria Bertani (LB) broth. 
Two hundred and fifty microliters $(250 \mu \mathrm{L})$ of transformed cells were added to LB agar plates containing either $50 \mu \mathrm{g} / \mathrm{mL}$ of kanamycin or $100 \mu \mathrm{g} / \mathrm{mL}$ of ampicillin, and placed in a $37^{\circ} \mathrm{C}$ incubator for sixteen hours.

\subsubsection{Plasmid DNA purification and extraction}

One colony of transformed bacteria was grown in $50 \mathrm{~mL}$ of $\mathrm{LB}$ broth at $37^{\circ} \mathrm{C}$ for sixteen hours, while shaking (containing the appropriate antibiotic concentration). The post-sixteen hour culture was centrifuged at $5500 \mathrm{xg}$ for fifteen minutes at $25^{\circ} \mathrm{C}$. Plasmid DNA extraction and purification was performed using EZNA Plasmid Midiprep Kit according to the manufacturer's instructions.

\subsubsection{Plasmids and transfection}

Prior to transfection, cells were seeded onto coverslips in the wells of a twelve well plate to reach $50 \%$ confluency. Plasmid DNAs were transfected into cultured cells using Fugene HD Transfection Reagent (Promega) as per manufacturer's instructions and analyzed 24 hours later.

\subsection{Biochemistry Techniques}

\subsubsection{Western blotting and SDS-PAGE}

To prepare whole cell lysates, cells were homogenized in lysis buffer, including phosphatase inhibitors and protease inhibitors (Bio Basic), made in PBS containing 0.1\% Triton X-100. Clearing of cell lysates was accomplished via centrifugation at 15000xg

for ten minutes. $2 \mathrm{X}$ Laemmli buffer was subsequently added to cellular supernatant and 
heated at $95^{\circ} \mathrm{C}$ for five minutes. Samples were added to a $10 \%$ SDS-PAGE gel and transferred to a PVDF membrane. The PVDF membrane was blocked using 5\% non-fat milk or bovine serum albumin (BSA) in Tris Buffered Saline $+0.1 \%$ Tween-20 (TBST) for one hour at room temperature. Membranes were then placed in primary antibody (prepared in 5\% non-fat milk or BSA in TBST) overnight at $4{ }^{\circ} \mathrm{C}$. Membranes were then incubated with secondary antibody (prepared in 5\% non-fat milk or BSA in TBST) for one hour at room temperature and were washed several times with TBST. Post-secondary antibody incubation, blots were imaged using Chemiluminescent Detection with ECL Western Blotting Detection Reagent (BioRad). Western blot quantification was performed using ImageLab (BioRad).

The primary antibodies administered for Western blotting were rabbit antiphospho-p70 S6 Kinase (Cell Signaling), rabbit anti-p70 S6 Kinase (Cell Signaling), rabbit anti-Rab7a (Cell Signaling), rat anti-Lamp1 (Developmental Studies Hybridoma

Bank) rabbit anti-TBC1D15 (GeneTex), goat anti-actin (Santa Cruz Biotechnology) and rabbit anti-ubiquitin (Cell Signaling). These antibodies were all used at a 1:1000 dilution. Secondary antibodies were donkey anti-rabbit, donkey anti-goat, or donkey anti-rat, conjugated to horseradish peroxidase (HRP) (Bethyl Laboratories). These antibodies were used at a 1:10,000 dilution.

\subsubsection{PhosTag SDS-PAGE}

10\% SDS-PAGE gels with $50 \mu \mathrm{M}$ PhosTag reagent were prepared according to manufacturer's (Wako Laboratory Chemicals) instructions (30\% acrylamide solution, 1.5 $\mathrm{mM}$ Tris- $\mathrm{HCl}(\mathrm{pH} 8.8), 10 \mathrm{mM} \mathrm{MnCl} 2,10 \%$ SDS, TEMED and distilled water). Before 
transferring, gels were washed three times with transfer buffer supplemented with $1 \mathrm{mM}$ EDTA, to chelate $\mathrm{Mn}^{2+}$. This ensures optimal transfer of phosphorylated protein species. Protein identification was assessed using the "Western Blotting and SDS-PAGE" section outlined above.

\subsubsection{Subcellular fractionation assay}

RAW 264.7 macrophages were cultured on ten-centimeter dishes, treated with the corresponding mTOR inhibitor (200 nM torin or EBSS), where untreated cells served as control. Cells were scraped in $500 \mu \mathrm{L}$ of fractionation buffer $(20 \mathrm{mM}$ HEPES, $10 \mathrm{mM}$ $\mathrm{KCl}, 2 \mathrm{mM} \mathrm{MgCl}$, $1 \mathrm{mM}$ EDTA and $1 \mathrm{mM} \mathrm{EGTA),} \mathrm{and} \mathrm{placed} \mathrm{on} \mathrm{ice} \mathrm{for} \mathrm{fifteen}$ minutes. Cellular homogenate was passed through a $1 \mathrm{~mL}$ syringe (twenty-five gauge needle) ten times, facilitating lysis, and was left on ice for twenty minutes. Cells were then centrifuged for five minutes at $1500 \mathrm{xg}$, separating cellular nuclear components (pellet) from the cytosol (containing membrane and cytoplasmic material). The cytosolic supernatant was then centrifuged at $100,000 \mathrm{xg}$ for one hour. Four hundred microliters $(400 \mu \mathrm{L})$ of fractionation buffer was added to the pellet generated from this centrifugation and was then re-suspended using a 25-gauge needle. The re-suspended mixture was centrifuged again at $100,000 x g$ for 45 minutes. The supernatant generated from this fractionation is indicative of cellular cytosolic material. The pellet produced is reflective of membrane-bound material. The membrane-containing pellet was resuspended in $400 \mu \mathrm{L}$ of fractionation buffer, syringed using a 25-gauge needle and run on a denaturing SDS-PAGE (see Western Blotting and SDS-PAGE above). 


\subsubsection{Affinity Purification of GST-RILPc33}

BL21 Escherichia coli (E. coli) expressing Rab7-interacting lysosomal protein c33 (RILPc33) fused to the C-terminus of glutathione-s-transferase (GST) (RILPc33GST) and GST alone, were obtained from the lab of Dr. John Brumell at the Hospital for Sick Children. One colony of the aforementioned bacteria was inoculated in $50 \mathrm{~mL}$ of LB broth overnight (for sixteen hours) at $37^{\circ} \mathrm{C}$. One milliliter $(1 \mathrm{~mL})$ of overnight culture was added to $250 \mathrm{~mL}$ of $\mathrm{LB}$ broth and sub-cultured for four to six hours at $37^{\circ} \mathrm{C}$, until an OD of between 0.6 and 0.8 was reached. Isopropyl $\beta$-D-1-thiogalactopyranoside (IPTG) was added to the subculture at a final concentration of $0.5 \mathrm{mM}$ in order to initiate protein expression. This induced culture was grown at $26^{\circ} \mathrm{C}$ for sixteen hours. Post-induction, bacteria were centrifuged at $3000 \mathrm{xg}$ for ten minutes and washed using $4^{\circ} \mathrm{C}$ PBS. Bacteria were re-suspended in $5 \mathrm{~mL}$ of lysis buffer (containing $25 \mathrm{mM}$ Tris- $\mathrm{HCl}(\mathrm{pH} 7.4), 1 \mathrm{mM}$ DTT, $0.5 \mathrm{mM}$ EDTA, $1 \mathrm{M} \mathrm{NaCl}$ and protease inhibitors) and ground using a morter and pestle (using Celite 545, Sigma Aldrich). The ground product was centrifuged at 15000xg for 15 minutes (for separation of Celite 545 from lysate). Protein purification was accomplished with the addition of $200 \mu \mathrm{L}$ (with 50\% slurry) glutathione-Sepharose 4B beads (Life Technologies) to the ground bacterial product. Lysates were incubated with glutathione sepharose $4 \mathrm{~B}$ beads for two hours at $4{ }^{\circ} \mathrm{C}$, followed by two centrifugations.

\subsubsection{Affinity Precipitation of GTP-bound Rab7}

Concurrently, RAW 264.7 macrophages were seeded and treated with the corresponding mTOR inhibitor (either $200 \mathrm{nM}$ torin for two hours, $100 \mu \mathrm{M}$ A-769662 for two hours or EBSS for one hour or two hours). Cells were subsequently lysed in buffer 
(100 $\mathrm{mM} \mathrm{NaCl}, 20 \mathrm{mM}$ HEPES, $5 \mathrm{mM} \mathrm{MgCl}_{2}$ and protease inhibitors). Glutathione sepharose 4B beads were incubated (shaken) with lysates overnight at $4^{\circ} \mathrm{C}$. Approximately one milliliter $(1 \mathrm{~mL})$ of cell lysate was added to $200 \mu \mathrm{L}$ of glutathione sepharose 4B beads. After rotation, beads were washed with pull-down buffer and heated at $95^{\circ} \mathrm{C}$ for five minutes. Samples were run on a denaturing SDS-PAGE following the "Western Blotting and SDS-PAGE" information outlined previously, and levels of active Rab7 (Rab7-GTP) were evaluated.

\subsubsection{Immunoprecipitation}

The immunoprecipitation of TBC1D15 was performed first by seeding RAW 264.7 macrophages, treating with the corresponding mTOR inhibitor for two hours (200 $\mathrm{nM}$ torin, EBSS or $100 \mu \mathrm{M}$ A-769662), where untreated cells served as control. Following treatment aspiration cells were rinsed with ice-cold PBS and subsequently lysed in $500 \mu \mathrm{L}$ of ice-cold lysis buffer and incubated for five minutes. Cells were then scraped, sonicated on ice for five seconds and centrifuged at $14000 \mathrm{xg}$ at $4^{\circ} \mathrm{C}$ for ten minutes. TBC1D15 primary antibody was then added to the supernatant generated postcentrifugation (1:100 dilution relative to cellular supernatant volume) and samples were shaken overnight at $4{ }^{\circ} \mathrm{C}$. Twenty microliters $(20 \mu \mathrm{L})$ of Dynabeads ${ }^{\circledR}$ Protein $\mathrm{G}$ for Immunoprecipitation (Invitrogen) were added to this mixture (50\% slurry) and were shaken at $4{ }^{\circ} \mathrm{C}$ for four hours. Cells were then centrifuged at $4^{\circ} \mathrm{C}$ for thirty seconds and washed five times with $1 \mathrm{X}$ lysis buffer. Cells were re-suspended in $3 \mathrm{X}$ SDS sample buffer, vortexed and boiled at $95^{\circ} \mathrm{C}$ for five minutes. Samples were loaded on a denaturing SDS-PAGE, following "Western Blotting and SDSPAGE" protocol listed 
earlier.

\subsection{Functional Assays and Imaging}

\subsubsection{Fc $\gamma$-mediated endocytosis assay using aggregated IgG and immunofluorescence}

Aggregated IgG internalization was determined by heating $10 \mathrm{mg} / \mathrm{mL}$ human $\mathrm{IgG}$ (Sigma Aldrich) for twenty minutes at $62^{\circ} \mathrm{C}$. After heating, insoluble complexes were sedimented via centrifugation for ten minutes at $16000 \mathrm{xg}$ and $25^{\circ} \mathrm{C}$. Soluble aggregated IgG was added to cells at $1 \mathrm{mg} / \mathrm{mL}$ for fifteen minutes at $37^{\circ} \mathrm{C}$. Residual (un-internalized) aggregated IgG was removed by washing cells with PBS. Trafficking was assessed by incubating cells in DMEM at $37^{\circ} \mathrm{C}$ for four different time points $(0$ minutes, 15 minutes, 30 minutes and 60 minutes) after fifteen minutes of aggregated $\mathrm{IgG}$ exposure. Cells were then fixed with 4\% PFA for twenty minutes and quenched with $100 \mathrm{mM}$ glycine for twenty minutes. Cellular permeabilization was accomplished using $-20^{\circ} \mathrm{C}$ methanol for five minutes. $0.5 \%$ bovine serum albumin/PBS was used to wash cells prior to Lamp1 staining. Cells were exposed to rat anti-Lamp1 primary antibody for one hour at room temperature, at a 1:200 dilution. After this, Alexa 488 goat anti-rat secondary antibody (Bethyl Laboratories) was used at a dilution of 1:1000 for another hour at room temperature. Cells were then washed with $0.5 \%$ BSA/PBS every five minutes for another thirty minutes. Intracellular aggregated IgG was observed by staining $\operatorname{IgG}$ complexes with donkey anti-human Cy5-conjugated antibody (Cedarlane Laboratories). This was done at a 1:1000 dilution for one hour. Using spinning disc confocal microscopy, cells were examined for the presence of fluorochrome molecules (described below) and overlap between aggregated IgG and Lamp1 was quantified using a Pearson's Correlation 
Coefficient.

\subsubsection{Dye Quenched-Bovine Serum Albumin (DQ-BSA) proteolysis assay}

In order to assess lysosomal proteolytic capacity, cells were allowed to coendocytose $2 \mu \mathrm{M}$ Alexa 647 conjugated dextran alongside $10 \mu \mathrm{g} / \mathrm{mL}$ DQ-BSA Green for fifteen minutes at $37^{\circ} \mathrm{C}$. Cells were then exposed to dye-free DMEM for thirty minutes (chase period). Alexa 647 conjugated dextran was used in order to account for possible differences in endocytosis between untreated and mTOR-inhibited cells. Cells were fixed with 4\% PFA for twenty minutes and quenched with $100 \mathrm{mM}$ glycine for twenty minutes. Coverslips were then analyzed using spinning disc confocal microscopy (information below).

\subsubsection{Lysosomal labeling}

Lyosomal labeling involved the use of $2 \mu \mathrm{M}$ of a fluid-phase dextran molecule (either Alexa 488 conjugated dextran, Alexa 546 conjugated dextran or Alexa 647 conjugated dextran). This labeling occurred for thirty minutes at $37^{\circ} \mathrm{C}$. After dextraninduction, cells were washed three times with PBS in order to remove residual dextran. Cells were then placed in dextran-free media for a one-hour chase period at $37^{\circ} \mathrm{C}$.

\subsubsection{Spinning disc confocal microscopy and image quantification}

Confocal microscopy is an imaging modality that has the capacity to remove outof-focus light, gather information from a diminished focus depth and produce 3D images that are high in contrast. These features highlight the advantages of confocal microscopy 
compared to wide-field microscopy. Spinning disc confocal microscopy uses all of these features and allows for the illumination of a sample at many distinct locations simultaneously.

To quantify the membrane-to-cytosol abundance of Rab7, RILPc33 and DQ-BSA, cells were transfected with RFP-Rab7 and RILPc33-GFP plasmids or exposed to DQBSA Green and treated as described above. After image acquisition (single slice, 16-bit images) using spinning disc confocal microscopy, images were analyzed using ImageJ. This was done by thresholding the fluorescence of the lysosomal membrane-enclosed fluid-phase marker and creating a mask. The fluorescence intensity residing under this mask in the other channel (GFP/RFP) was then assessed using the Analyze Particle function. Following this calculation, background fluorescence was subtracted. Following this, the fluorescence intensity of the cytosol was calculated by outlining particular areas of the cytosol, followed by the subtraction of background fluorescence. This enabled the calculation of average membrane-bound to cytosolic fluorescence intensity.

\subsection{Statistical analyses}

All of the data presented in this dissertation were acquired through at least three independent trials. Results were normalized by comparing the mean of each treatment condition to the mean of the control condition. Data were subjected to analysis of variance (ANOVA) with Tukey's post-hoc test. A p value of less than $0.05(\mathrm{p}<0.05)$ was noted to be significant. All data are showcased as mean \pm standard error of the mean unless explicitly mentioned otherwise. 


\section{Results}

\subsection{Suppression of $\mathrm{mTOR}$ activity results in a significant reduction in levels of phosphorylated S6K}

To ensure that mTOR activity was suppressed, we examined levels of phosphorylated S6K, a protein phosphorylated by mTOR. Under conditions of mTOR inhibition, a significant reduction in phosphorylated S6K was observed (Figure 6A). This effect was present via direct pharmacological inhibition (through the use of $200 \mathrm{nM}$ torin) and by amino acid deprivation (using EBSS) (figure 6A). When EBSS was applied in conjunction with 5\% fetal bovine serum (FBS), levels of phosphorylated S6K were restored to basal conditions (Guertin \& Sabatini, 2009) (Figure 6A). Levels of total S6K have been used as a loading control for normalization purposes.

S6K is a substrate of mTOR phosphorylation, responsible for the induction of protein translation and ribosomal biogenesis (Jastrzebski, Hannan, Tchoubrieva, Hannan, \& Pearson, 2007). Optimal mTOR activity is reliant on ATP hydrolysis and amino acid abundance. Inhibiting the vital components required for kinase function and activity, serves to drastically diminish levels of a protein phosphorylated and subsequently regulated by mTOR (S6K), as evidenced in Figure 6. 


\section{Figure 6:}

A:

\section{Control 30min Torin $2 \mathrm{hr}$ Torin $2 \mathrm{hr}$ EBSS $2 \mathrm{hr}$ EBSS}

$+5 \% \mathrm{FBS}$

70 kDa

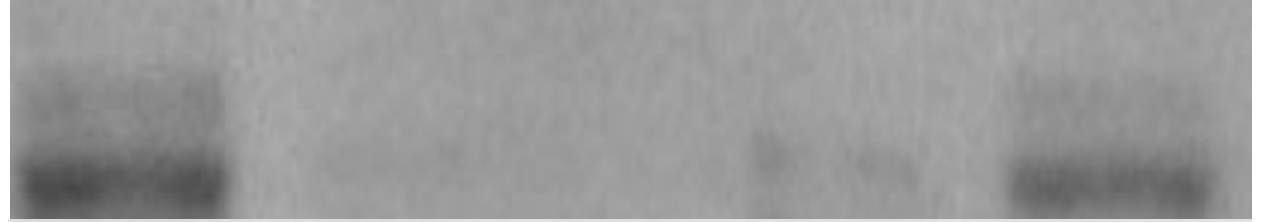

Phosphorylated S6K

70 kDa

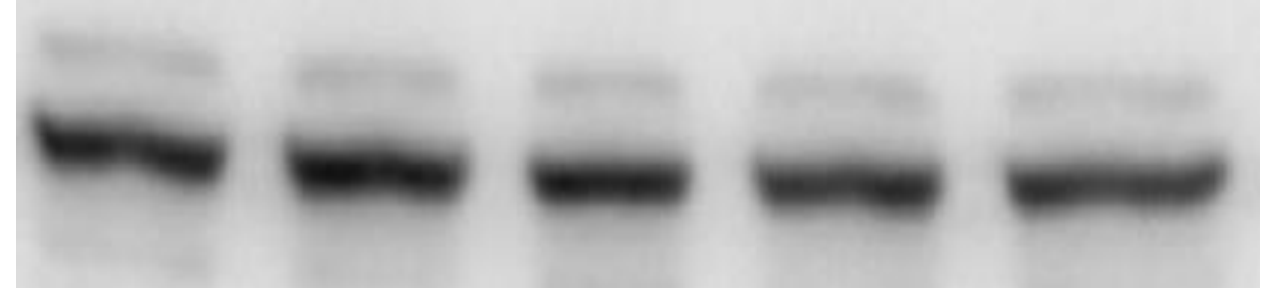

Total S6K

B:

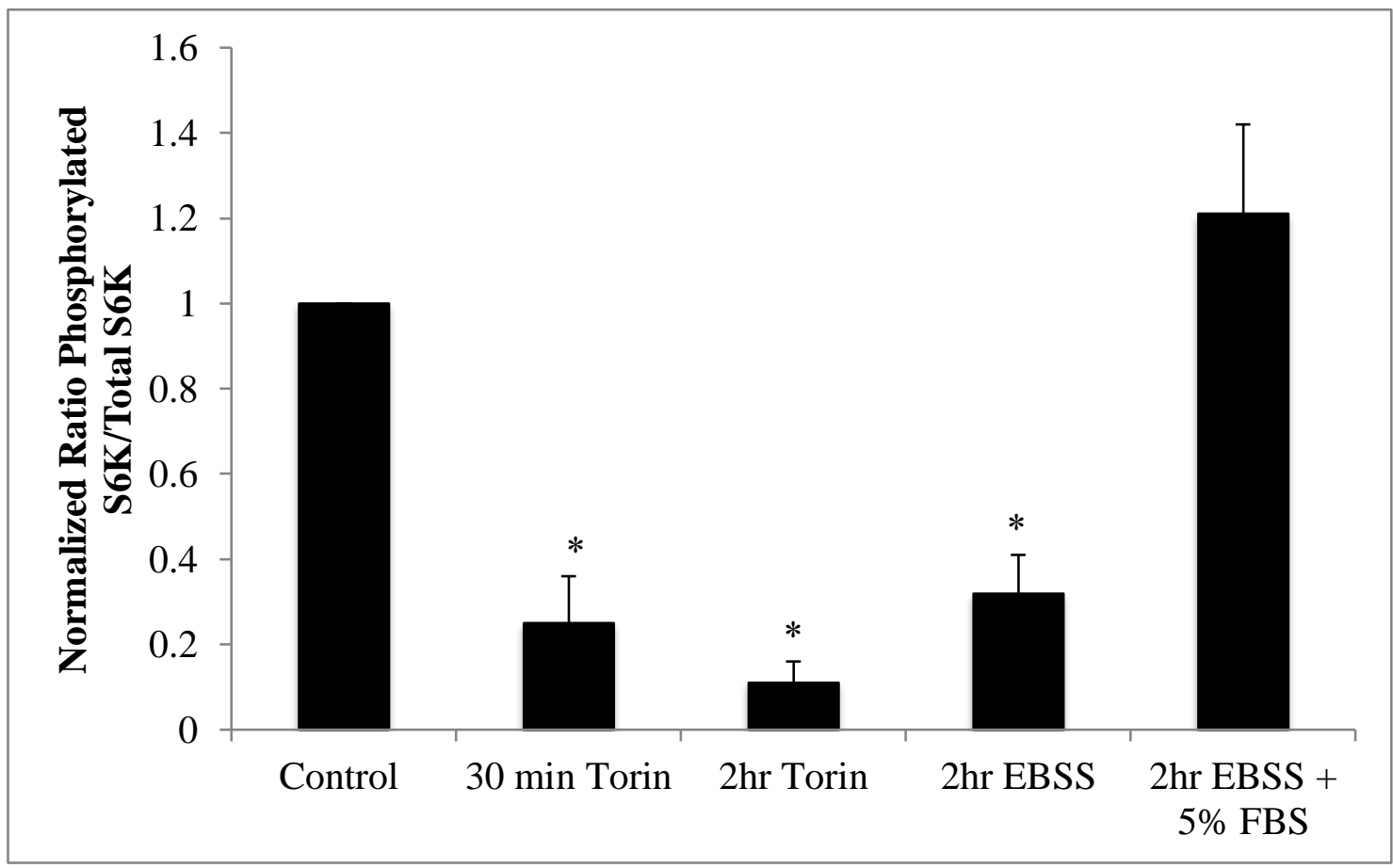

Figure 6. Suppression of $m$ TOR activity results in a significant reduction in levels of phosphorylated S6K: (A) Western blot depicting levels of phosphorylated S6K in control and mTOR-inhibited treatment conditions. Levels of phosphorylated S6K are significantly reduced upon mTOR inhibition. The use of EBSS in conjunction with 5\% FBS restores levels of phosphorylated S6K to basal conditions. Levels of total S6K serve as a loading control.

(B) Quantification of the results described in (A). Data was analyzed statistically by a one-way ANOVA, followed by Tukey's post hoc test $(\mathrm{p}<0.01)$. Data presented is representative of four independent trials and is presented as mean \pm SEM. 


\subsection{Lysosomal trafficking is upregulated under conditions of mTOR inhibition}

To begin assessing lysosomal function in amino acid-deprived conditions or in mTOR-suppressed cells, a trafficking assay was performed in which RAW 264.7 macrophages were pre-treated with $200 \mathrm{nM}$ torin or EBSS for two hours, where untreated cells served as a control. Cells were then exposed to aggregated IgG. Aggregated IgG is a cargo molecule that is internalized via Fc $\gamma$-mediated endocytosis (Indik, Park, Hunter, \& Schreiber, 1995). Upon its internalization, it is trafficked to the lysosome where it accumulates. Using immunofluorescence, the lysosomal population was labeled by probing for Lamp1 and aggregated IgG was identified using the marker Cy5. Under conditions of mTOR inhibition, a significant increase in colocalization was observed between aggregated IgG and Lamp1-positive structures, as calculated using a Pearson's Correlation Coefficient (Figure 7A and 7B). This indicates that under conditions of mTOR suppression, endocytic cargo is trafficked to the lysosome at an accelerated rate. 


\section{Figure 7:}

A:

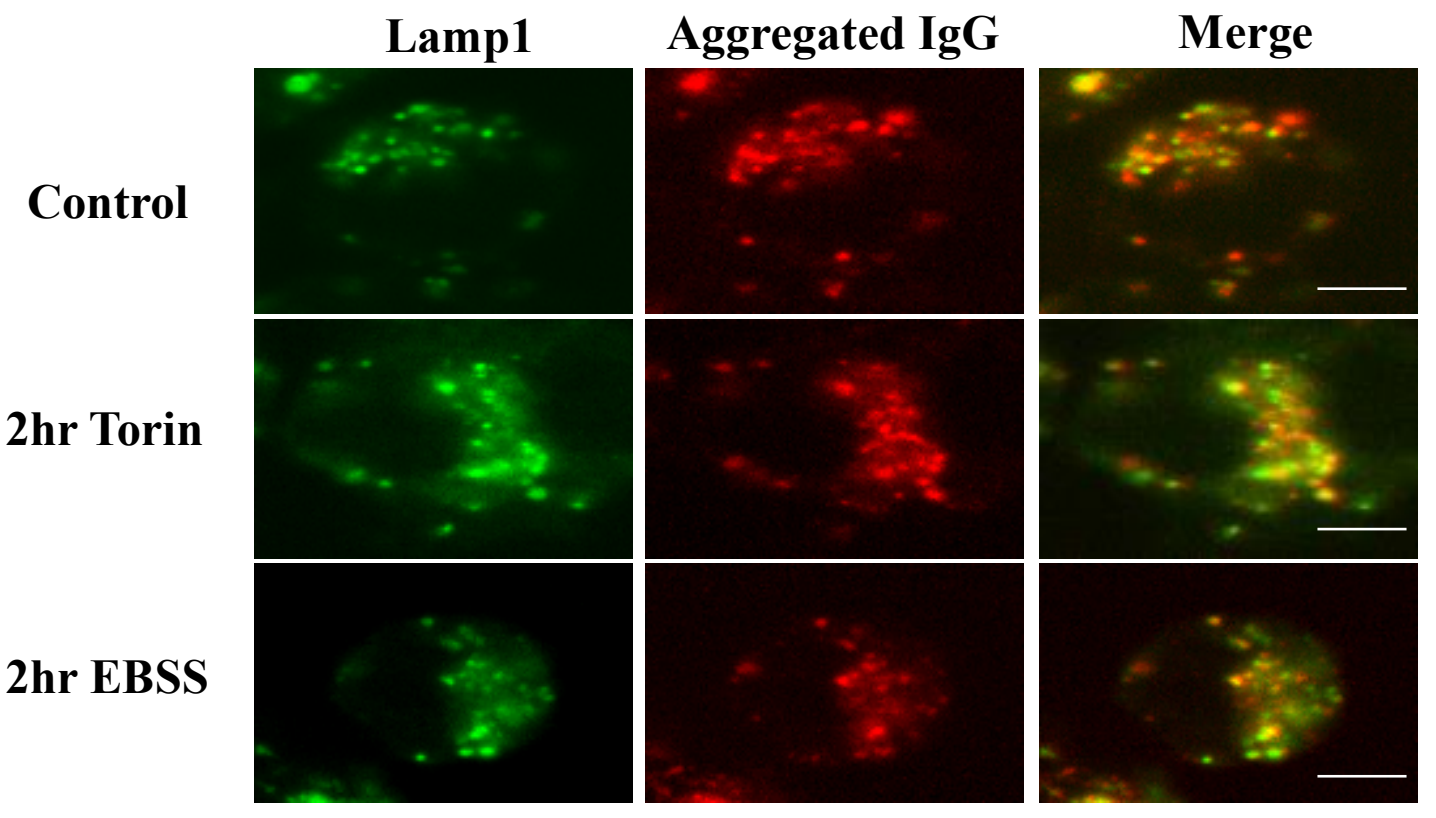

B:

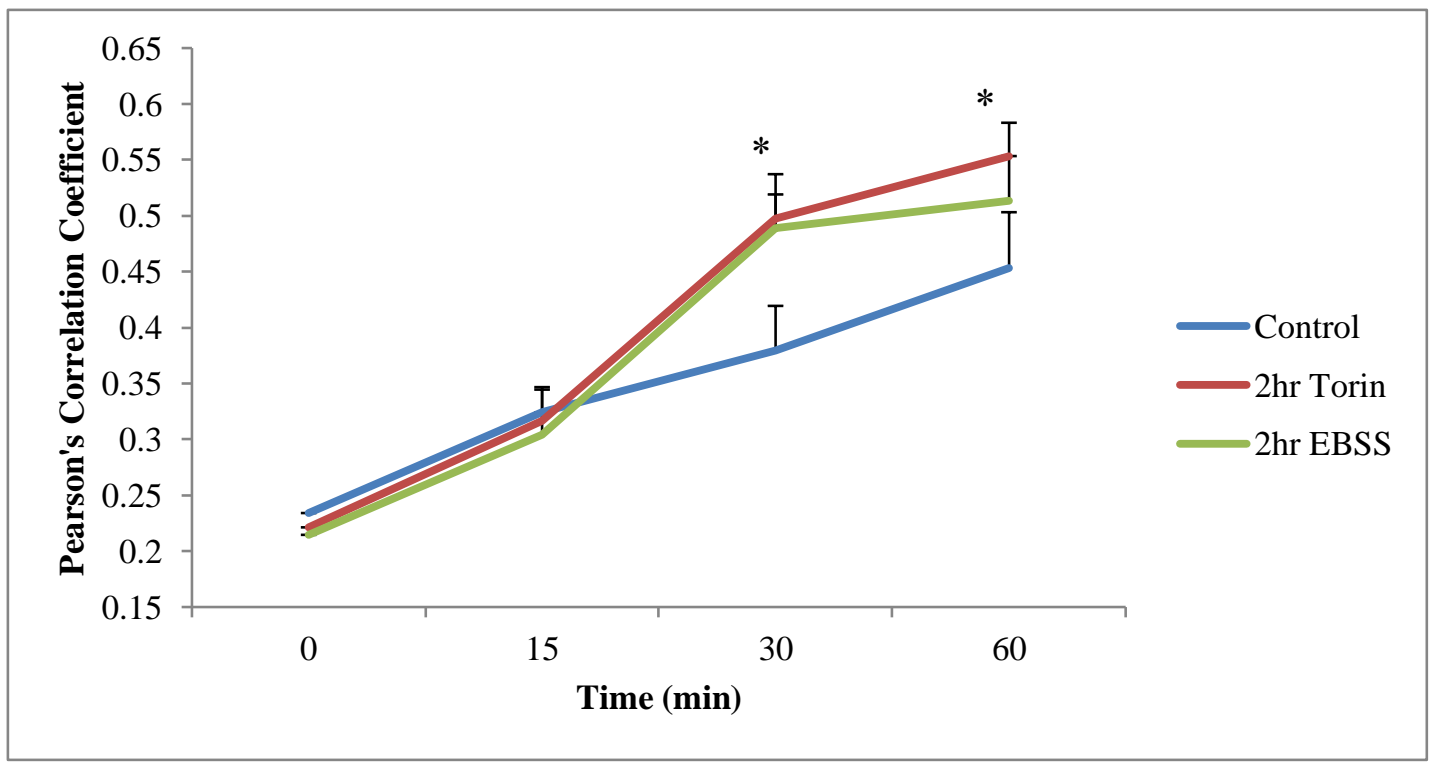

Figure 7. Trafficking to the lysosome is accelerated under conditions of mTOR inhibition:

(A) Spinning disc confocal microscopy showing the lysosomal population of RAW 264.7 macrophages labeled by probing for the lysosomal-associated membrane protein 1, Lamp1. Cells were pre-treated with $200 \mathrm{nM}$ torin or EBSS for two hours and then exposed to $1 \mathrm{mg} / \mathrm{mL}$ Aggregated IgG. Images presented are from thirty minutes post Aggregated IgG induction. Scale bar is equivalent to $10 \mu \mathrm{m}$. (B) Quantification of the microscopy images described in (A). Under conditions of mTOR inhibition, an increase in co-localization between Aggreggated IgG and Lamp1 is evident (assessed by a Pearson's Correlation Coefficient). This is indicative of accelerated trafficking to the lysosome in these treatment groups. Data was analyzed statistically by a one-way ANOVA, followed by Tukey's post hoc test $(\mathrm{p}<0.05)$. Data is representative of four independent trials and is presented as mean \pm SEM. At least thirty cells were analyzed per treatment condition. 


\subsection{Lysosomal proteolytic activity is enhanced by mTOR inhibition}

We next tested if amino acid depletion and/or mTOR suppression impacted lysosomal function by measuring proteolytic activity. To test this, we employed endocytosis and trafficking of Dye Quenched-Bovine Serum Albumin (DQ-BSA), which is BSA tagged with a high-density of BODIPY fluorochromes. This leads to fluorescence self-quenching. Upon cellular internalization, BSA is trafficked to lysosomes, where lysosomal hydrolases break it down into peptides, thus separating the BODIPY molecules and enhancing fluorescence. At the same time, the lysosomal population was co-labeled using the fluid-phase marker Alexa 647 conjugated dextran. Cells were pre-treated with $200 \mathrm{nM}$ torin or EBSS for two hours, where untreated cells served as a control. Normalized fluorescence intensity at the lysosome was assessed, using the Alexa 647 conjugated dextran signal as a mask (Figure 8A). Under conditions of mTOR inhibition there was a significant increase in the normalized fluorescence intensity at the lysosome (Figure 8B). This suggests that lysosomes are more proteolytic in mTOR-suppressed cells relative to mTOR-enabled cells. Overall, our data suggest that mTOR may modulate trafficking and/or lysosome activity. 


\section{Figure 8:}

A:

DQ-BSA Green Alexa 647 Dextran

Merge

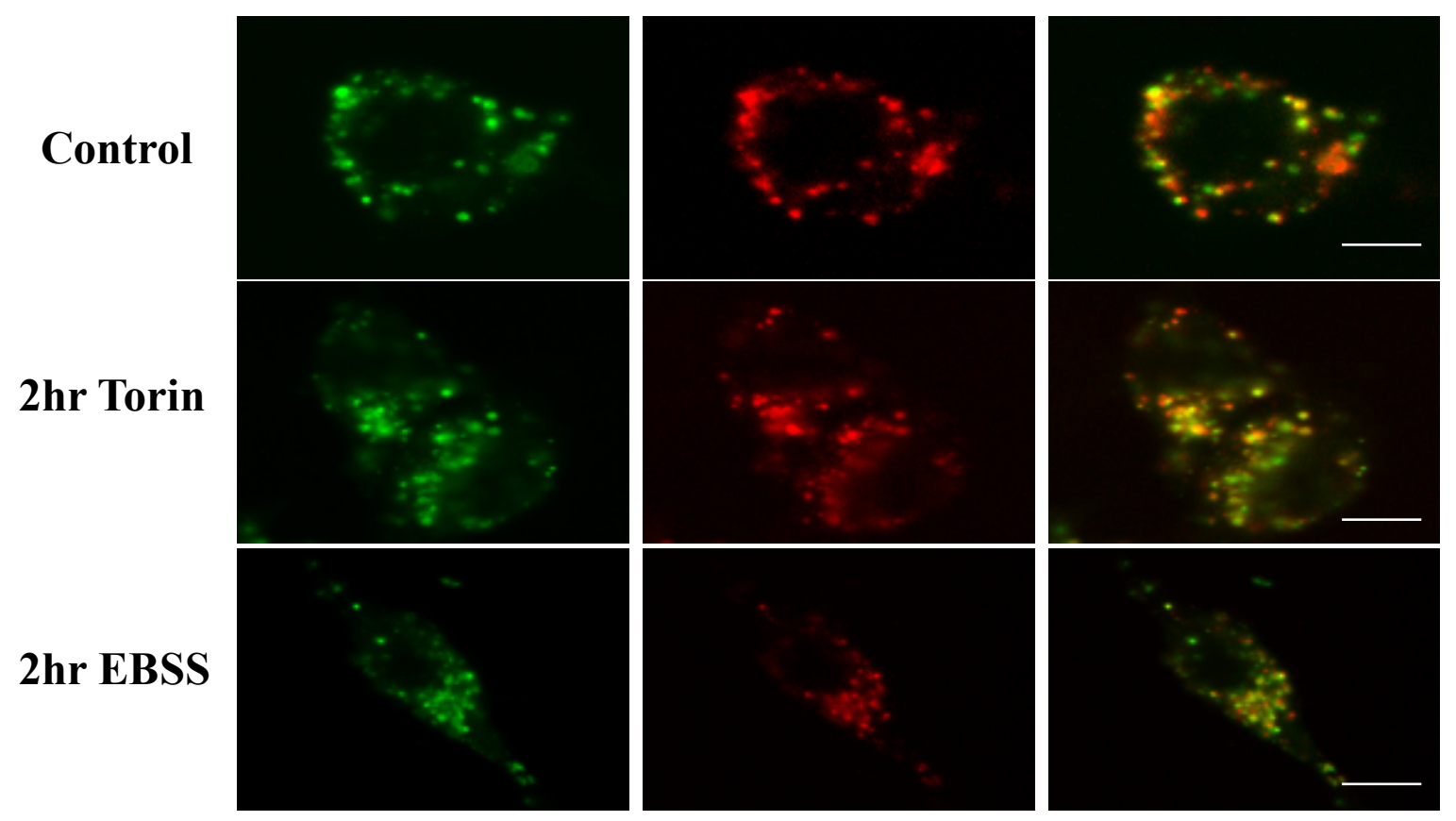

B:

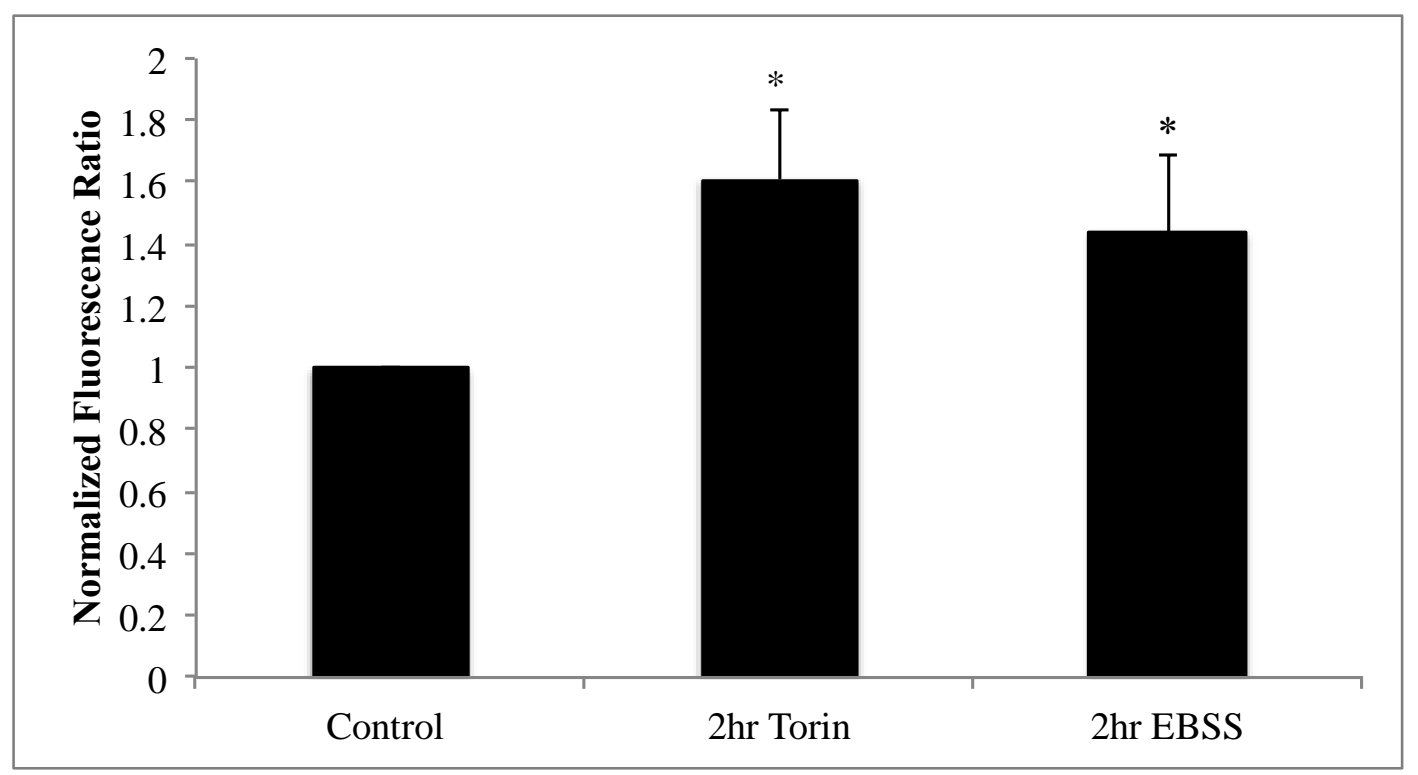

Figure 8. mTOR inhibition enhances lysosomal proteolytic activity: (A) Spinning disc confocal microscopy showing the lysosomal population of RAW 264.7 macrophages labeled with the fluidphase marker Alexa 647 conjugated dextran. Cells were pre-treated with $200 \mathrm{nM}$ torin or EBSS for two hours and were then exposed to DQ-BSA Green. Scale bar is equivalent to $10 \mu \mathrm{m}$. (B) Quantification of the microscopy images described in (A). A significant increase in normalized fluorescence intensity is present in cells with suppressed mTOR activity, meaning the lysosomal population is more proteolytic in nature. Data was analyzed statistically by a one-way ANOVA, followed by Tukey's post hoc test $(\mathrm{p}<0.05)$. Data presented is representative of three independent trials and is presented as mean \pm SEM. At least thirty cells were analyzed per treatment condition. 


\section{4. mTOR inhibition enhances total Rab7 lysosomal-membrane association}

To assess the effects of mTOR inhibition on levels of total Rab7 on the lysosomal membrane, a subcellular fractionation assay was employed. This technique uses the principles of differential ultracentrifugation to obtain a membrane-bound fraction and the cytosolic fraction from cell lysates. Cells were treated with the corresponding mTOR inhibitor (200 nM torin for two hours or EBSS for one hour or two hours) and spun using an ultracentrifuge. The membrane-bound fraction was harvested and subsequently run on a denaturing SDS-PAGE (Figure 9A). Rab7 levels were assessed, using Lamp1 as a loading control (Figure 9A). Under conditions of mTOR inhibition, a significant increase in levels of total Rab7 was observed (Figure 9B).

To corroborate the results of the subcellular fractionation assay, RAW 264.7 macrophages were transfected with RFP-Rab7 cDNA. The lysosomal population was labeled using the fluid-phase marker Alexa 488 conjugated dextran and cells were treated with the corresponding mTOR inhibitor (200 nM torin or EBSS for two hours) (figure 9C). Normalized fluorescence intensity at the lysosome was assessed, using the Alexa 488 conjugated dextran signal as a mask. Under conditions of mTOR inhibition, a significant elevation in levels of Rab7 on the lysosomal membrane was evident (Figure 9D). 


\section{Figure 9:}

A:

Control 2hr Torin $1 \mathrm{hr}$ EBSS 2hr EBSS

23

kDa

120

kDa
B:

Rab7

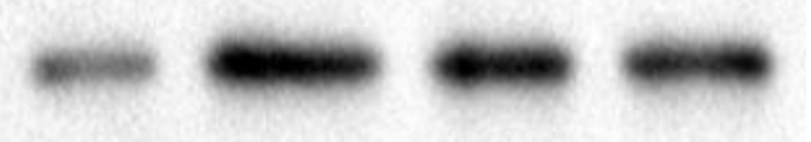

Lamp1

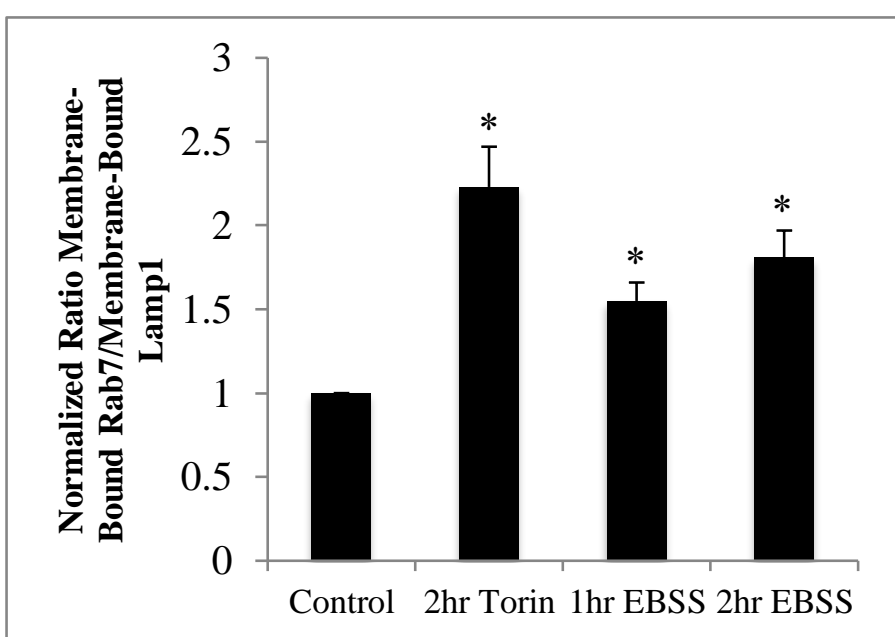

C:

D:
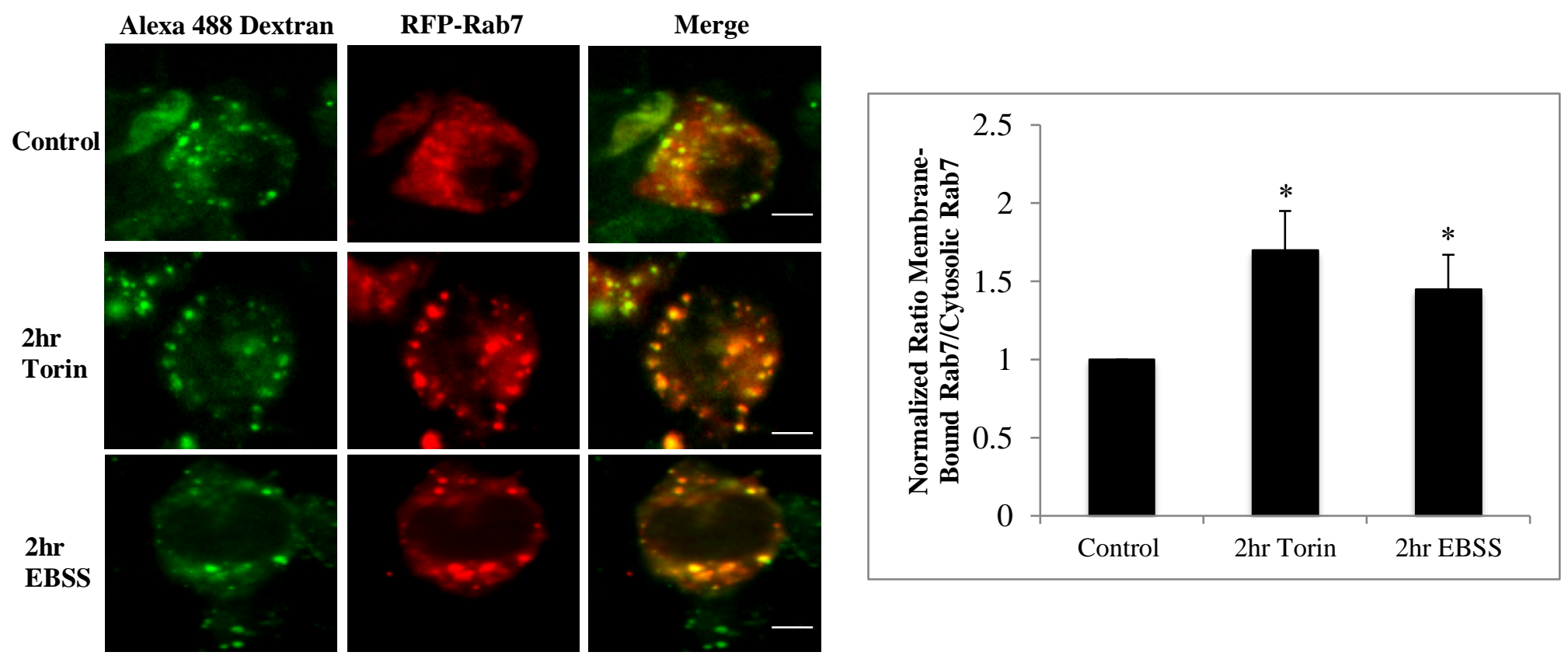

Figure 9. mTOR inhibition enhances total Rab7 lysosomal-membrane association: (A) Western blot depicting levels of total Rab7 present in the cellular membrane-bound fraction homogenate, post differential ultracentrifugation (subcellular fractionation assay). mTOR inhibition results in a striking increase in levels of total Rab7, being most potent in the $200 \mathrm{nM}$ torin treatment condition. Levels of Lamp1 serve as a loading control. (B) Quantification of the results described in (A). Data is presented as mean \pm SEM for five independent experiments. Data was subjected to statistical analysis using a one-way ANOVA, followed by Tukey's post hoc test, $(\mathrm{p}<0.05)$ between control and mTOR-inhibited treatment groups. Data is representative of five independent trials and is presented as mean \pm SEM. (C) Spinning disc confocal microscopy showing the lysosomal population of RAW 264.7 macrophages labeled with the fluid-phase marker Alexa 488 conjugated dextran. Cells were transfected with RFP-Rab7 and subsequently treated with $200 \mathrm{nM}$ torin or EBSS for two hours. Scale bar is equivalent to $10 \mu \mathrm{m}$. (D) Quantification of the microscopy images described in (C). A significant difference in total Rab7 membrane-association is present in cells lacking functional mTOR. Data was analyzed statistically by a one-way ANOVA, followed by Tukey's post hoc test $(\mathrm{p}<0.05)$. Data is representative of four independent trials and is presented as mean \pm SEM. At least thirty cells were analyzed per treatment condition61 


\section{5. mTOR inhibition increased levels of GTP-bound Rab7 on the lysosomal membrane}

Our observations suggest that mTOR inhibition increases total levels of Rab7 on the lysosome. To determine if elevated levels of active Rab7 are present when mTOR is inhibited, RAW 264.7 macrophages were transfected with RILPc33-GFP cDNA. RILPc33 is a truncated version of the Rab7 effector RILP, lacking its N-terminal half but maintaining a domain that specifically binds active Rab7 (Rab7-GTP). The truncated version of RILP was used as opposed to full-length RILP, because transfecting cells with full-length RILP induces perinuclear clustering of lysosomes. Lysosomes were subsequently labeled with the fluid-phase marker Alexa 546 conjugated dextran, and cells were exposed to the mTOR inhibitor torin for two hours or depleting cells from amino acids using EBSS, for two hours (Figure 10A). Normalized fluorescence intensity was evaluated at the lysosome, using the dextran signal as a mask. Under conditions of mTOR inhibition, there was a significant increase in levels of RILPc33 on the lysosomal membrane relative to control treatment (Figure 10B). This is indicative of the presence of more active Rab7 (Rab7-GTP). 


\section{Figure 10:}

A:

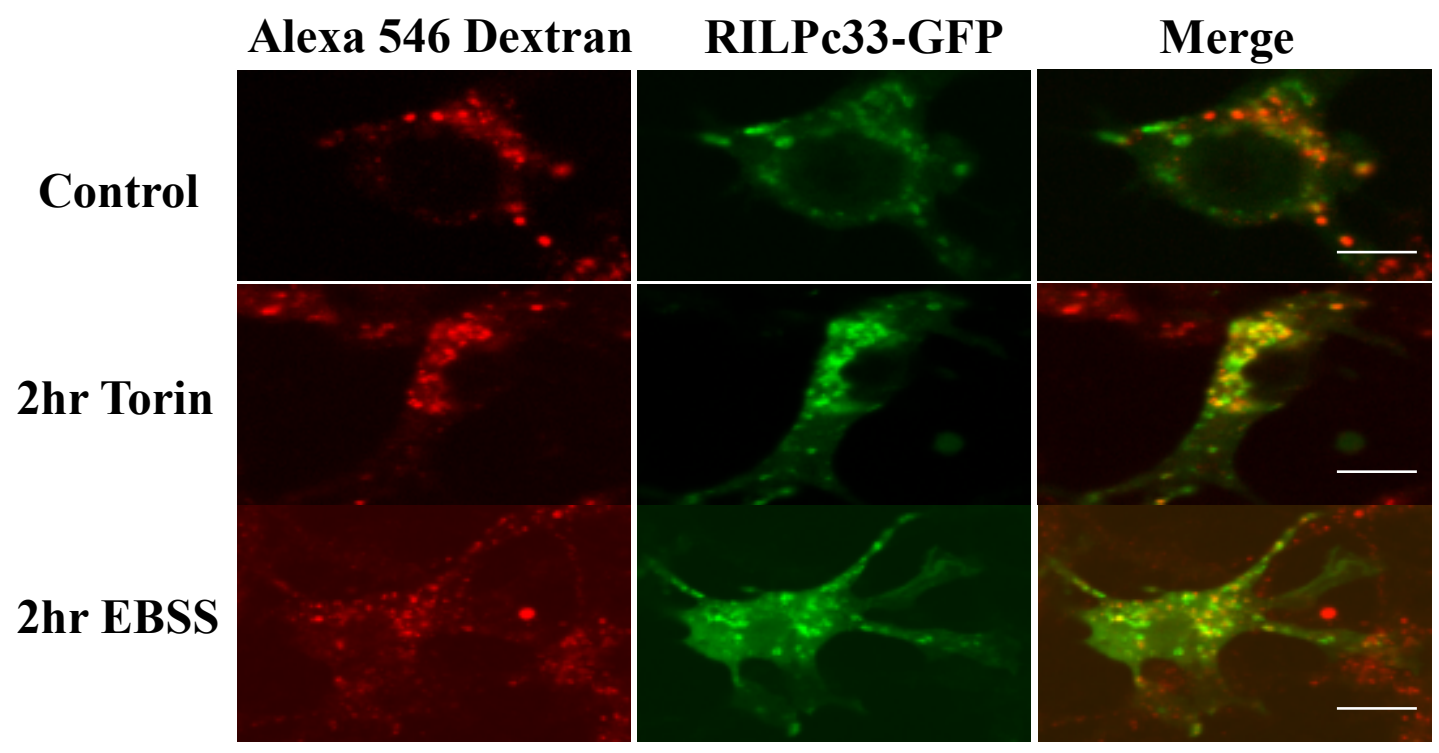

B:

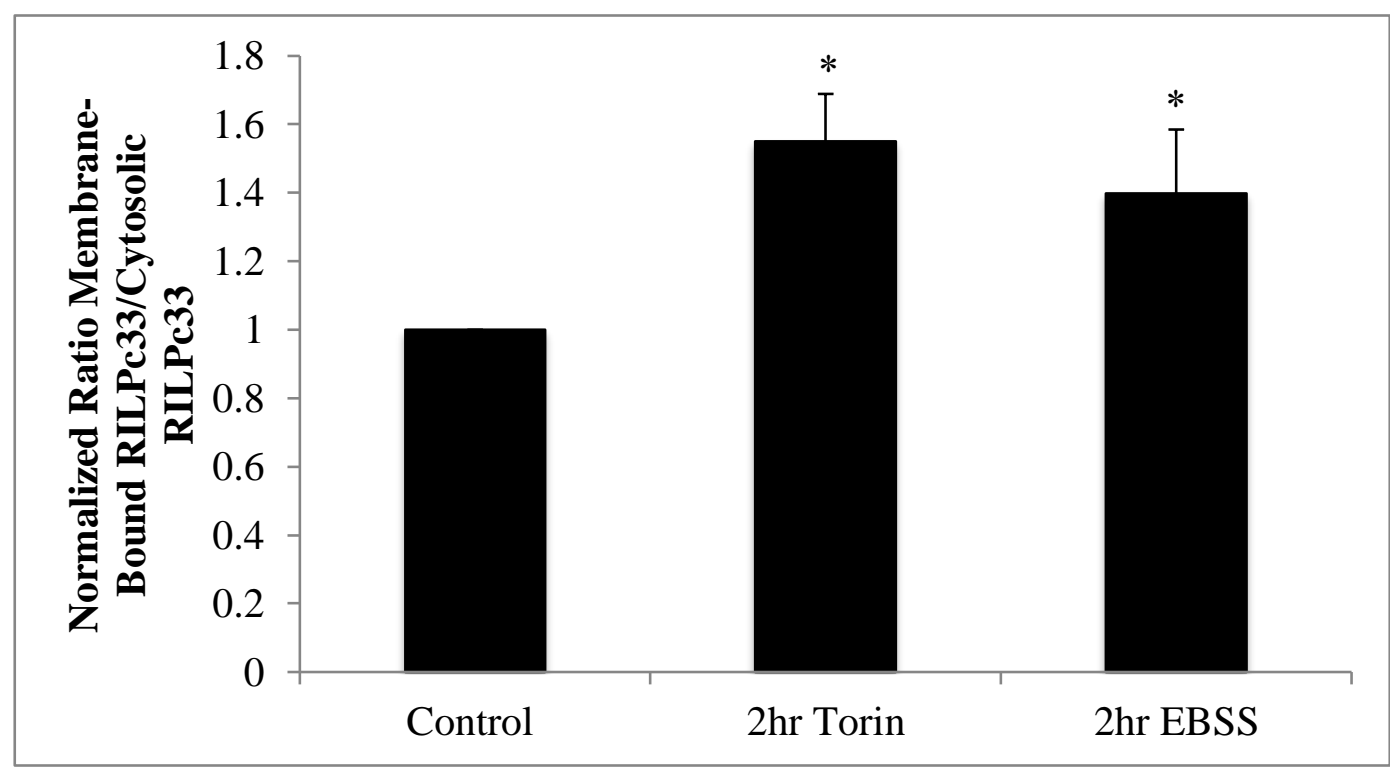

Figure 10. mTOR inhibition increases levels of RILPc33 (active Rab7) on the lysosomal membrane: (A) Spinning disc confocal microscopy showing the lysosomal population of RAW 264.7 macrophages labeled with the fluid-phase marker Alexa 546 conjugated dextran. Cells were transfected with RILPc33-GFP and subsequently treated with $200 \mathrm{nM}$ torin or EBSS for two hours. Scale bar is equivalent to $10 \mu \mathrm{m}$. (B) Quantification of the microscopy images described in (A). A significant increase in RILPc33 membrane-association is present in cells with inhibited mTOR activity. Data was analyzed statistically by a one-way ANOVA, followed by Tukey's post hoc test $(\mathrm{p}<0.05)$. Data presented is representative of three independent trials and is presented as mean \pm SEM. At least thirty cells were analyzed per treatment condition. 


\subsection{Inhibiting mTOR results in more GTP-bound, active Rab7}

To complement the results of the RILPc33 transfection, an affinity precipitation assay was performed ("Affinity precipitation of GTP-bound Rab7"). This technique uses GST-RILPc33 bound to glutathione-conjugated beads to precipitate GTP-bound Rab7. After cells were exposed to torin, EBSS or vehicle, cell lysates were exposed to GSTRILPc33 bound to sepharose beads. Precipitates were then eluted and analyzed by SDSPAGE and Western blotting as described in Materials and Methods. We observed a significant increase in Rab7 association with RILPc33-bound to beads in cells treated with torin and EBSS relative to control cells (Figure 11A and 11B). This recovery was specific to RILPc33-binding since GST alone did not recover any Rab7 (Figure 11A). In addition, we could account for differences in total lysate loading by blotting for total Rab7 (Figure 11A, bottom blot). This suggests that there is more active Rab7 (Rab7GTP) in cells suppressed of mTOR function.

\subsubsection{AMPK hyper-activation increased levels of active Rab7 (Rab7-GTP)}

AMP-activated Protein Kinase (AMPK) is an intracellular energy regulator and is activated under conditions of energy deprivation (low ATP), low oxygen (hypoxia), decreased glucose, tissue ischemia and mechanical stress (Tsou, Zheng, Hsu, Sasaki, \& Cantley, 2011). AMPK plays the reciprocal role to mTOR, which is potently activated under conditions of nutrient satiety (amino acids, growth factors, oxygen), resulting in the induction of cellular anabolic processes. AMPK has been shown to inhibit mTOR activity (Kimura et al., 2003). To assess the impact of AMPK activity on Rab7 activity, we employed affinity precipitation of GTP-bound Rab7 as described above using lysates 
from cells treated with $100 \mu \mathrm{M}$ A-769662 (an activator of AMPK) and $40 \mu \mathrm{M}$ Compound C (an AMPK inhibitor). When A-769662 was used, levels of active Rab7 on the lysosomal membrane significantly increased compared to control cells (Figure 11C and 11D). Conversely, the use of Compound $\mathrm{C}$ resulted in a non-significant change in levels of active Rab7, relative to control cells (Figure 11C and 11D). This suggests an interplay between mTOR, AMPK and Rab7. 


\section{Figure 11:}

A:

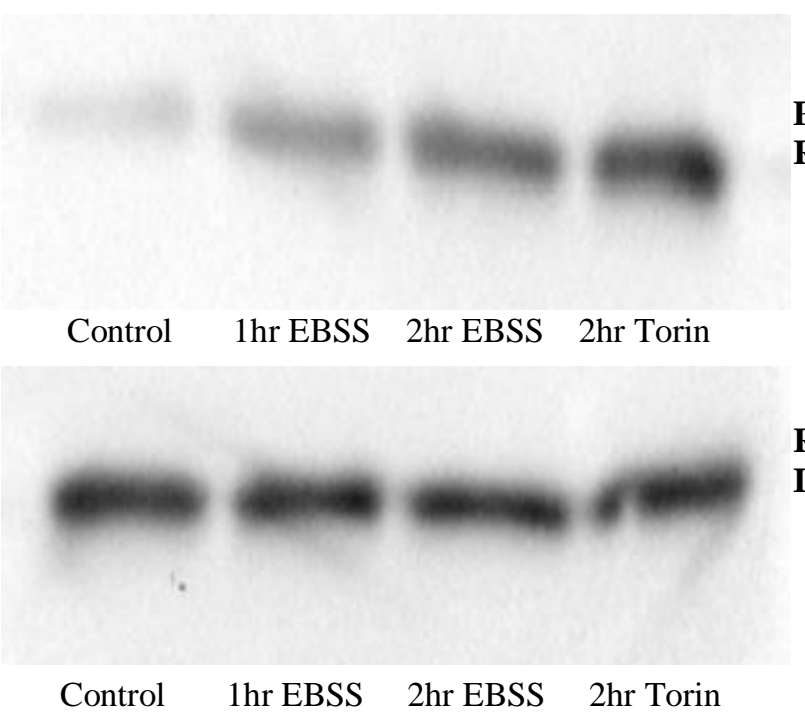

C:
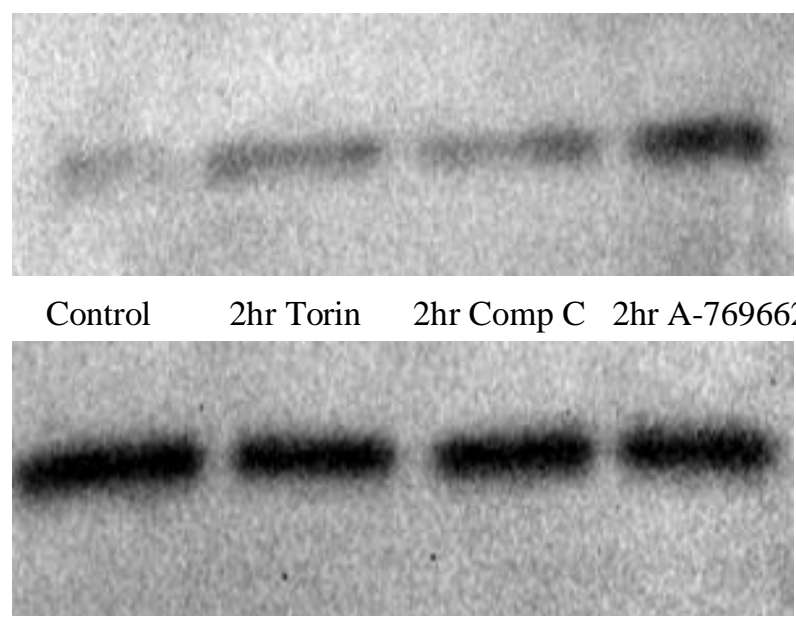

Control
Rab7

Input
B:

Precipitated
Rab7

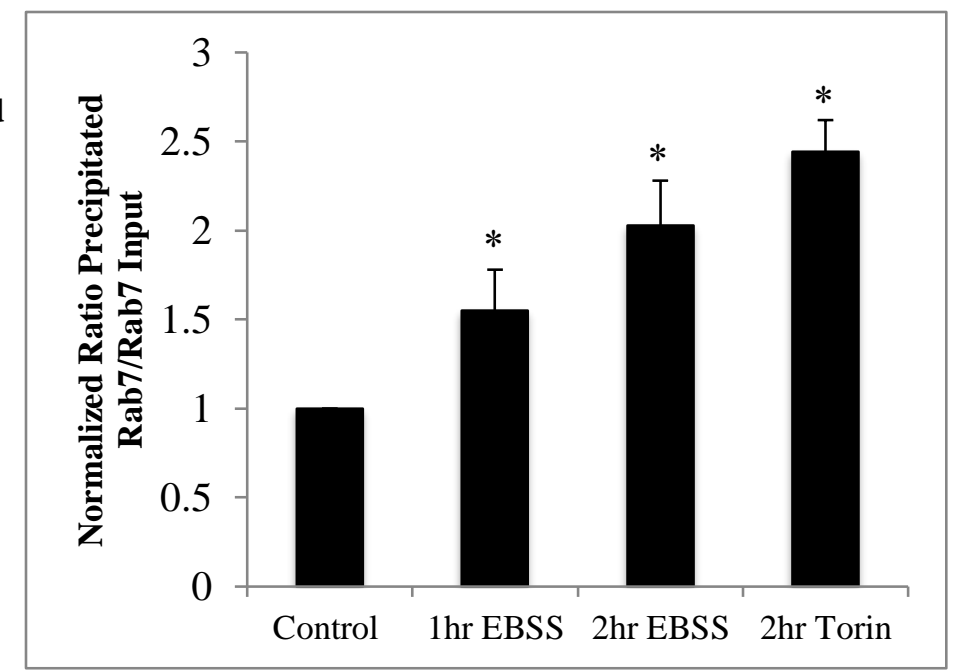

D:

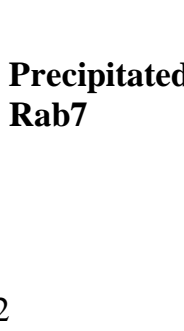

Rab7 Input

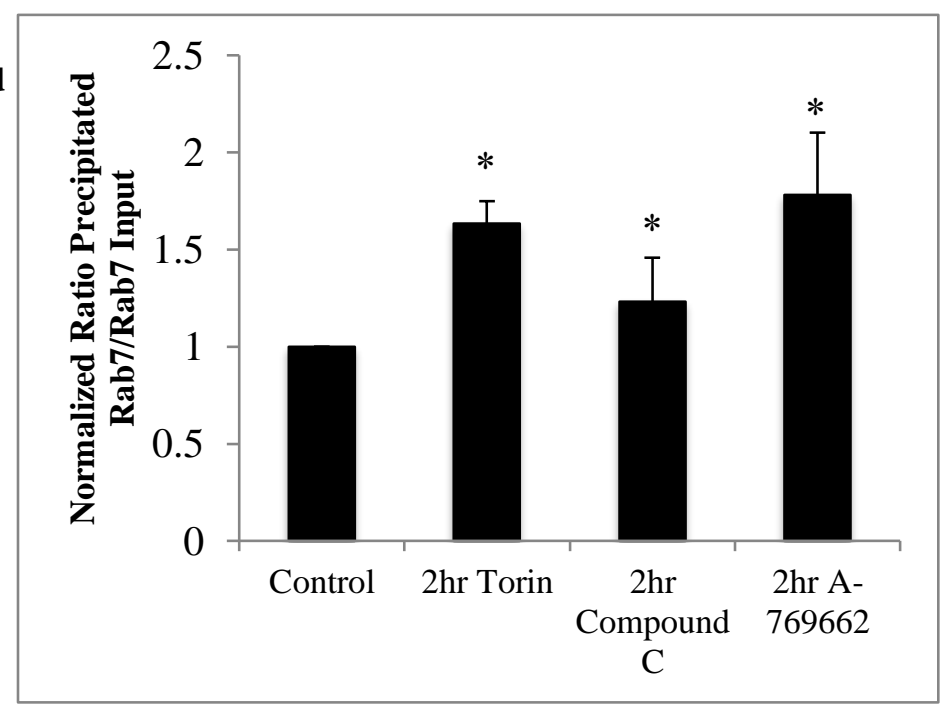

Figure 11. Inhibiting mTOR results in more active Rab7 (Rab7-GTP): (A) Western blot showcasing levels of active Rab7 bound to glutathione sepharose beads (Precipitated Rab7). Levels of Rab7 present in the whole cell lysate serve as a loading control. Conditions of mTOR inhibition result in a pronounced enhancement in levels of active Rab7 (Rab7-GTP), being most prominent in the $200 \mathrm{nM}$ torin treatment condition. (B) Quantification of the results described in (A). Data was analyzed statistically by a one-way ANOVA, followed by Tukey's post hoc test $(\mathrm{p}<0.05)$. Data presented is representative of three independent trials and is presented as mean \pm SEM. (C) Western blot illustrating proportion of active Rab7 attached to glutathione sepharose beads (Precipitated Rab7), under conditions of AMPK activation (A769662) and inhibition (Compound C). AMPK activation through A-769662 produces elevated levels of Rab7-GTP. Conversely, conditions of AMPK inhibition, using Compound C, mimic control conditions. (D) Quantification of the results described in (C). Data was analyzed statistically by a one-way ANOVA, followed by Tukey's post hoc test $(\mathrm{p}<0.05)$. Data presented is representative of three independent trials and is presented as mean $\pm \mathrm{SEM}$. 


\subsection{Increased levels of Rab7-GTP are specific to mTOR inhibition not AMPK activation}

Since mTOR and AMPK activities are reciprocally controlled, it remained unclear if elevated levels of active Rab7 are due to inhibition of mTOR activity or through reciprocal activation of AMPK activity. To differentiate between a direct role of AMPK versus mTOR in elevating GTP-bound Rab7 levels, we treated cells with $200 \mathrm{nM}$ torin in conjunction with $40 \mu \mathrm{M}$ compound $\mathrm{C}$ to inhibit both mTOR and AMPK in synchrony. We observed that inhibition of AMPK activity concurrent with mTOR suppression resulted in levels of active Rab7 similar to cells treated with torin-only (Figure 12A and 12B). This suggests GTP-Rab7 levels increase due to mTOR suppression independently of AMPK activity. In other words, AMPK activation is not required for elevated levels of Rab7-GTP. 


\section{Figure 12:}

A:

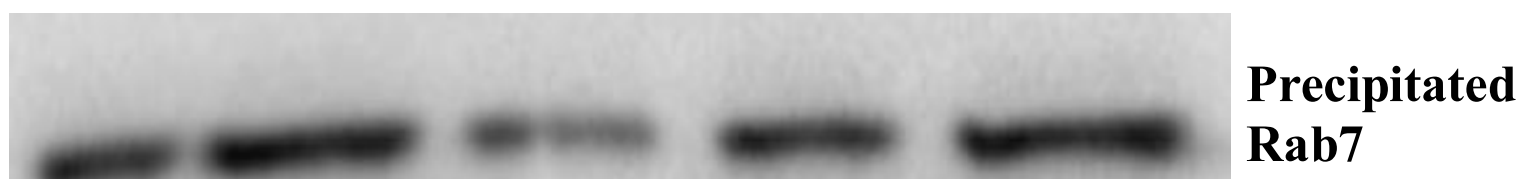

Control $2 \mathrm{hr}$ Torin $\quad 2 \mathrm{hr}$ Comp C 2hr A-769662 2hr Torin

+ Comp C

$23 \mathrm{kDa}$

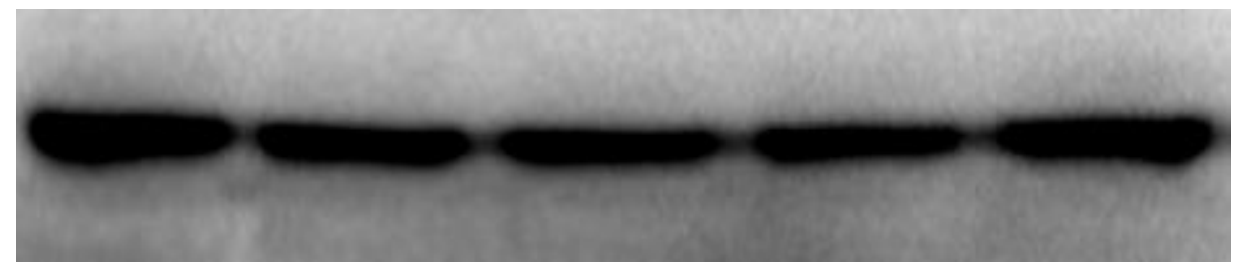

Input

Rab7

Control 2hr Torin $2 \mathrm{hr}$ Comp C 2hr A-769662 2hr Torin

+ Comp C

B:

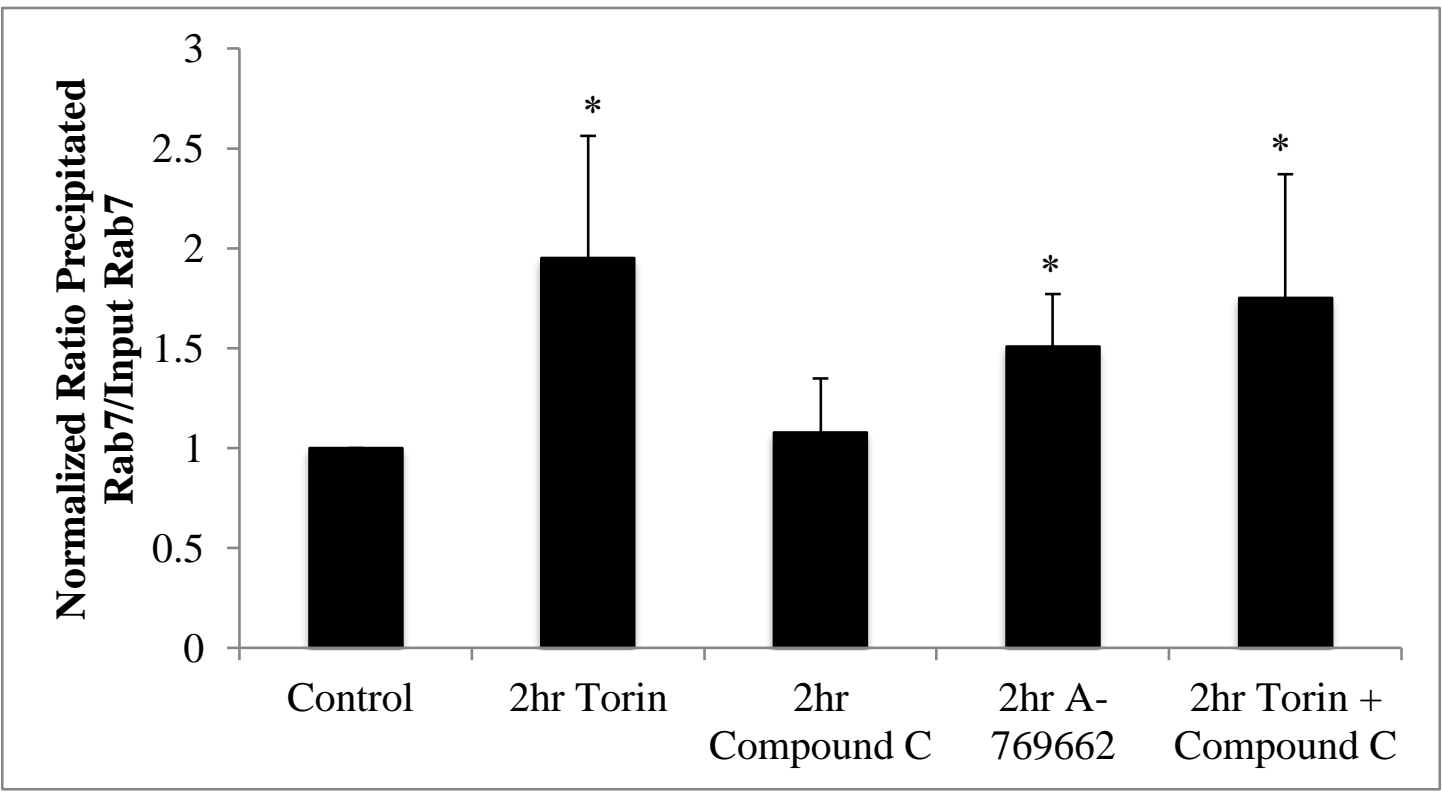

Figure 12. Increased levels of Rab7-GTP are specific to mTOR inhibition not AMPK activation: (A) Western blot illuminating levels of active Rab7 bound to glutathione sepharose beads (Precipitated Rab7). Levels of Rab7 present in the whole cell lysate serve as a loading control. The inhibition of mTOR and AMPK in synchrony (through torin and Compound $\mathrm{C}$ respectively) still results in an increase in active Rab7 (Rab7-GTP). This suggests that this signaling axis exists independently of AMPK, acting specifically through mTOR inhibition. (B) Quantification of the results described in (A). Data was analyzed statistically by a one-way ANOVA, followed by Tukey's post hoc test $(p<0.05)$. Data presented is representative of five independent trials and is presented as mean \pm SEM. 


\section{8. mTOR does not seem to directly phosphorylate Rab7}

mTOR is a serine/threonine kinase, responsible for phosphorylating a number of downstream targets, prompting the question, "does mTOR phosphorylate Rab7 directly?" To analyze this, a PhosTag experiment was performed. PhosTag is a SDS-PAGE and Western blotting-based method that can detect multiple phosphorylated species. The principle behind this technique is that a PhosTag reagent, contained in the separating gel, binds to phosphorylated forms of proteins, retarding their motion. This will result in phosphorylated species appearing at a higher molecular weight (than their conventional position) and/or as multiple distinct bands if proteins exist in multiple phosphorylation states. When control, $200 \mathrm{nM}$ torin-treated and EBSS samples were run on a denaturing PhosTag gel, no change in phosphorylation pattern was observed upon probing for Rab7 (Figure 13A). This suggests that mTOR is not responsible for directly phosphorylating Rab7.

\subsection{Two Rab7 GAPs and One Rab7 GEF contain the mTOR consensus sequence}

Since Rab7 may not be subjected to mTOR phosphorylation, we considered that mTOR may act on Rab7 regulators such as Rab7 GEF and GAP proteins. To begin, we examined these proteins for a mTOR consensus sequence. Research has shown that proteins phosphorylated by mTOR exhibit a mTOR consensus sequence consisting of $(\mathbf{R} / \mathbf{K}) \mathbf{X}(\mathbf{R} / \mathbf{K}) \mathbf{X X}(\mathbf{S} / \mathbf{T})$. Interestingly, two Rab7 GAPs and two components of one Rab7 GEF contain this consensus sequence. The mTOR consensus sequence present in these Rab7 GEFs and GAPs has been outlined below in Table 1 in red. 


\begin{tabular}{|c|c|}
\hline $\begin{array}{l}\text { Protein Name } \\
\text { (Amino acid } \\
\text { length): }\end{array}$ & $\begin{array}{l}\text { Sequence: } \\
\text { (mTOR consensus sequence has been outlined in red) }\end{array}$ \\
\hline $\begin{array}{l}\text { TBC1D15, } \\
\text { Rab7 GAP } \\
\text { (671 amino } \\
\text { acids) }\end{array}$ & $\begin{array}{l}\text { MAAAGVVSGKIIYEQEGVYIHSSCGKANDQDSLISGILRVLEKDAEVIVDWRPLDDALD } \\
\text { SSSILCAGKDSSSVVEWTQAPKERAHRGSDQQSSYEAEWDMVTTVSFKKKPHTNGDA } \\
\text { PGHRNGKSKWSFLFSLADLKSVKQSKEGMGWSYLVFCLKDDVMLPALHFHQGDSKLL } \\
\text { IESLEKYVVLCESPQDSRTLLVNCQNKSLSQSFENLLDEPAYGLIQKIKKDPYTATMVGF } \\
\text { SKVTNYIFDSLRGSDPSTHQRPPSEMADFLSDAIPGLKINQQEEPGFEVITRIDLGERPVV } \\
\text { QRREPVSLEEWNKSLDPEGRLVAVESMKQKIFRGGLSHSLRKQAWKFLLGYFPWDSTK } \\
\text { EERTQLQKQKTDEYFRMKLQWKSVSEAQEKRNSRLRDYRSLIEKDVNRTDRTNKFYE } \\
\text { GQDNPGLILLHDILMTYCMYDFDLGYVQGMSDLLSPLLYVMENEVDAFWCFASYMDQ } \\
\text { MHQNFEEQMQGMKTQLIQLSTLLRLLDSGFCSYLESQDSGYLYFCFRWLLIRFKREFSF } \\
\text { LDILRLWEVMWTELPCKNFHLLLCCAILESEKQQIMAKHYGFNEILKHINELSMKIDVE } \\
\text { DILCKAEAISLQMAQCKELPQAVCEILGLQDSEITTPDSDTDENVGSPCPVSAFPSSTLPIL } \\
\text { AASEAKDDSPTQTLASPNACRLTPA }\end{array}$ \\
\hline $\begin{array}{l}\text { TBC1D10, } \\
\text { Rab7 GAP } \\
\text { (508 amino } \\
\text { acids) }\end{array}$ & $\begin{array}{l}\text { MAKSNGENGPRAPAAGESLSGTRESLAQGPDAATTDELSSLGSDSEANGFAERRIDKFG } \\
\text { FIVGSQGAEGALEEVPLEVLRQRESKWLDMLNNWDKWMAKKHKKIRLRCQKGIPPSL } \\
\text { RGRAWQYLSGGKVKLQQNPGKFDELDMSPGDPKWLDVIERDLHRQFPFHEMFVSRGG } \\
\text { HGQQDLFRVLKAYTLYRPEEGYCQAQAPIAAVLLMHMPAEQAFWCLVQICEKYLPGY } \\
\text { YSEKLEAIQLDGEILFSLLQKVSPVAHKHLSRQKIDPLLYMTEWFMCAFSRTLPWSSVL } \\
\text { RVWDMFFCEGVKIIFRVGLVLLKHALGSPEKVKACQGQYETIERLRSLSPKIMQEAFLV } \\
\text { QEVVELPVTERQIEREHLIQLRRWQETRGELQCRSPPRLHGAKAILDAEPGPRPALQPSP } \\
\text { SIRLPLDAPLPGSKAKPKPPKQAQKEQRKQMKGRGQLEKPPAPNQAMVVAAAGDACP } \\
\text { PQHVPPKDSAPKDSAPQDLAPQVSAHHRSQESLTSQESEDTYL }\end{array}$ \\
\hline $\begin{array}{l}\text { HOPS } \\
\text { Tethering } \\
\text { Complex - } \\
\text { Vps11, } \\
\text { Rab7 GEF } \\
\text { (941 amino } \\
\text { acids) }\end{array}$ & $\begin{array}{l}\text { MAAYLQWRRFVFFEKELVKEPLGNDGAAPGAAPVSGSAASKFLCLPPGITVCDSGRGS } \\
\text { LVFGDMEGQIWFLPRSLQLTGFQAYKLRVTHLYQLKQHNILASVGEDEEGINPLVKIW } \\
\text { NLEKRDGGNPLCTRIFPAIPGTEPTVVSCLTVHENLNFMAIGFTDGSVTLNKGDITRDRH } \\
\text { SKTQILHKGNYPVTGLAFRQAGKTTHLFVVTTENVQSYIVSGKDYPRVELDTHGCGLR } \\
\text { CSALSDPSQDLQFIVAGDECVYLYQPDERGPCFAFEGHKLIVHWFRGYLVIVSRDRK VS } \\
\text { PKSEFTSRDSQNSDKQILNIYDLCNKFIAYSAGFEDIVDVLAEWGSLYVLTRDGRVHAL } \\
\text { QEKDTQTKLEMLFKKNLFEMAINLAKSQHLDSDGLAQIFMQYGDHLYSKGNHDGAVQ } \\
\text { QYIRTIGKLEPSYVIRKFLDAQRIHNLTAYLQTLHRQSLANADHTTLLLNCYTKLKDSS } \\
\text { KLEEFIKTKSESEVHFDVETAIKVLRQAGYYSHALYLAENHAHHEWYLKIQLEDIKNY } \\
\text { QEALRYIGKLPFEQAESNMKRYGKTLMHHIPEQTTQLLKGLCTDYRPSLEGRGDREALS } \\
\text { CRASSEEFIPIFANNPRELKAFLEHMSEVQPDSPQGIYDTLLELRLQNWAHEKDPQAKEK } \\
\text { LHAEAISLLKSGRFCDVFDKALVLCQMHDFQDGVLYLYEQGKLFQQIMHYHMQHEQY } \\
\text { RQVIAVCERHGEQEPSLWEQALSYFARKEEDCKEYVAAVLRHIENKSLMPPLLVVQTL } \\
\text { AHNSTATLSIIRDYLVQKLQKQSQQIAQDELRVRRYREETTRIRQEIQELKASPKIFQKTK } \\
\text { CSICNSALELPSVHFLCGHSFHQHCFESYSESDADCPTCLPENRKVMDMIRAQEQKRDL } \\
\text { HDQFQHQLKCSNDSFSVIADYFGRGVFNKLTLLTDPPTARLTPSLEAGLQRDLLMHSRR } \\
\text { GT }\end{array}$ \\
\hline $\begin{array}{l}\text { HOPS } \\
\text { Tethering } \\
\text { Complex - } \\
\text { Vps41, } \\
\text { Rab7 GEF }\end{array}$ & $\begin{array}{l}\text { MAEAEEQETESLEESTDESEEESEEEPKLKYERLSNGVTEILQKDAASCMTVHDKFLAL } \\
\text { GTHYGKVYLLDVQGNITQKFDVSPVKINQISLDDSGEHMGVCSEDGKLQVFGLYSGEE } \\
\text { FHETFDCPIKIIAVHPQFVRSSCKQFVTGGKKLLLFERTWMNRWKSSVLHEGEGNIRSV } \\
\text { KWRGHLIAWANNMGVKVFDITSKQRISNVPRDDISLRPDMYPCSLCWKDNVTLIIGWG } \\
\text { TSIKICSVKERHASEMRDLPSRYVEIVSQFETEFYISGLAPLCDQLVVLSYVKEVSEKTE }\end{array}$ \\
\hline
\end{tabular}


(853 amino acids)

REYCARPRLDIIQPLPETCEEISSDALTVRGFQENECRDYHLEYSEGESLFYVVSPRDVV
VAKERDQDDHIDWLLEKKKYEEALMAAEISQRNIKRHKILDIGLAYVNHLVERGEYDM
AARKCQKILGKNASLWEYEVYKFKEIGQLKAISPYLPRGDPVLKPLIYEMILHEFLESDY
EGFATLIREWPGDLYNNSVIVQAVRDHLKKDSQNKTLLKTLAELYTYDKNYGNALEIY
LTLRHKDVFQLIHKHNLFSSIKDKIVLLMDFDSEKAVDMLLDNEDKISIKKVVEELEDRP
ELQHVYLHKLFKRDHHKGQRYHEKQISLYAEYDRPNLLPFLRDSTHCPLEKALEICQQR
NFVEETVYLLSRMGNSRSALKMIMEELHDVDKAIEFAKEQDDGELWEDLILYSIDKPPF
ITGLLNNIGTHVDPILLIHRIKEGMEIPNLRDSLVKILQDYNLQILLREGCKKILVADSLSL
LKKMHRTQMKGVLVDEENICESCLSPILPTDAAKPFSVVVFHCRHMFHKECLPMPSMN
APAQYCNICSAKNRGPGSAILEMKK

Figure 14. Rab7 GEF and GAP amino acid sequences containing the mTOR consensus sequence

\subsection{0. mTOR does not seem to directly phosphorylate TBC1D15}

Considering some of the Rab7 GEFs and GAPs contain the mTOR consensus sequence, does mTOR phosphorylate any of these regulatory proteins/components? We began with a PhosTag analysis of TBC1D15 because of the commercial availability of anti-TBC1D15 antibodies. We observed that mTOR inhibition with $200 \mathrm{nM}$ torin or cell exposure to EBSS for two hours did not seem to change the PhosTag migration and pattern of TBC1D15 relative to control cells (Figure 13B), indicating that mTOR activity does not modify the phosphorylation of TBC1D15. 


\section{Figure 13:}

A:

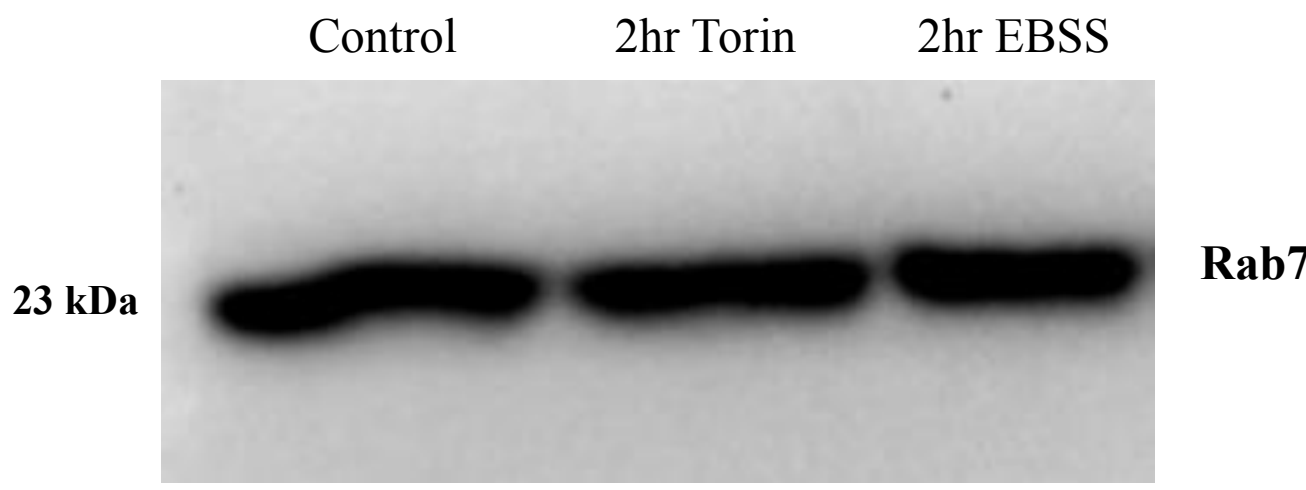

B:

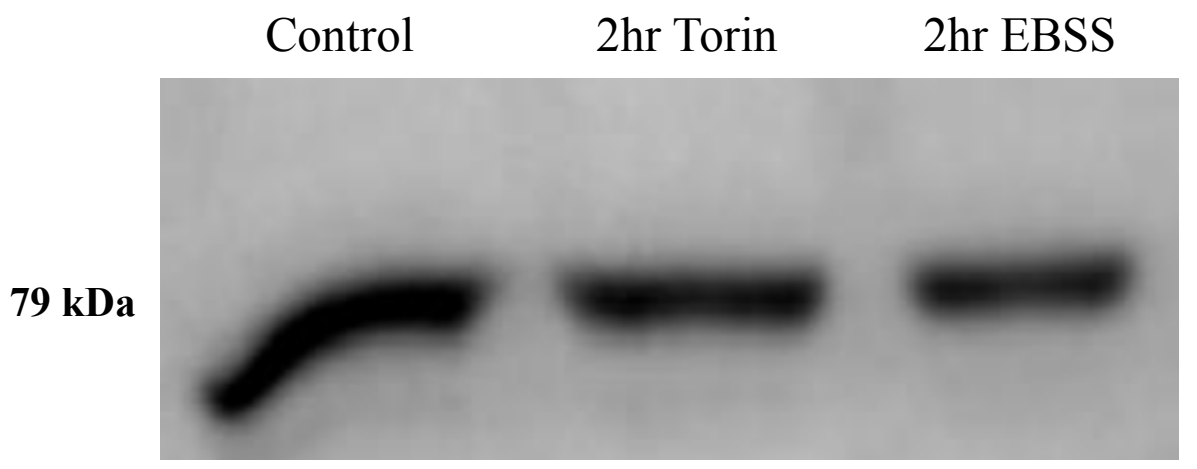

\section{TBC1D15}

Figure 13. mTOR does not directly phosphorylate Rab7 or TBC1D15: (A) Denaturing PhosTag showing no change in phosphorylation pattern of Rab7 between control and mTOR-inhibited treatment groups. Data presented is representative of three independent trials. (B) Denaturing PhosTag showing no change in phosphorylation pattern of TBC1D15 between control and conditions of mTOR suppression. 


\subsection{1. mTOR inhibition results in decreased levels of TBC1D15 and this depletion was restored via proteasome inhibition}

During PhosTag analysis of TBC1D15, we noted that the total levels of TBC1D15 seemed lower in mTOR-suppressed cells relative to control cells. To confirm this assertion, we assessed total TBC1D15 levels using Western blotting in control and mTOR-suppressed cells as before. We found that cells exposed to $200 \mathrm{nM}$ torin and EBSS did reduce TBC1D15 levels by 50\% relative to control cells (Figures 15A and 15B). We hypothesized that this decrease may be due to proteasome-mediated

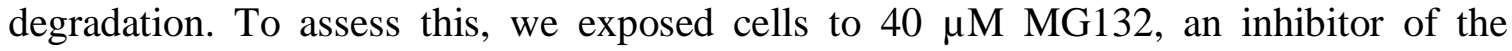
proteasome, in conjunction with $200 \mathrm{nM}$ torin. We observed that proteasome inhibition stabilized the levels of TBC1D15 in the presence of torin (Figures 15C and 15D), comparable to basal conditions. This suggests that torin results in TBC1D15s ubiquitination and targeting to the proteasome for degradation.

To test if mTOR inhibition increased the ubiquitination of TBC1D15, I employed an immunoprecipitation of TBC1D15 and blotted for co-immunoprecipitated ubiquitin. Cells were exposed for two hours to $200 \mathrm{nM}$ torin, EBSS or $100 \mu \mathrm{M}$ A-769662, where untreated cells served as control. As shown in Figure 16A, there was a significant reduction in the amount of immunoprecipitated TBC1D15 from cells inhibited for mTOR activity, consistent with reduced TBC1D15 levels. However, these same treatment conditions produced a significant enrichment when blots were exposed to anti-ubiquitin antibodies, suggesting enhanced ubiquitin association with TBC1D15 in mTOR suppressed cells (Figure 16A and 16B). This suggests that TBC1D15 is ubiqutinated in mTOR-suppressed cells consistent with a proteasome-dependent decrease in TBC1D15 levels. 


\section{Figure 15:}

A:

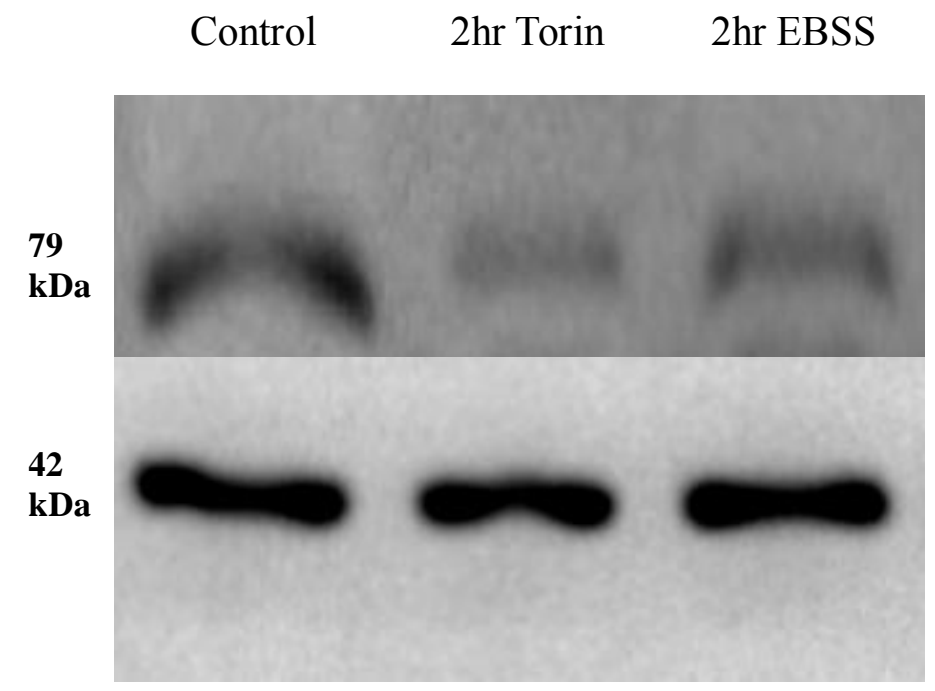

C:

Control 2hr Torin 1hr EBSS 2hr EBSS 2hr MG132 2hr MG132

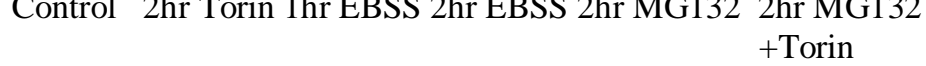

\section{9}

kDa

42

kDa
B:

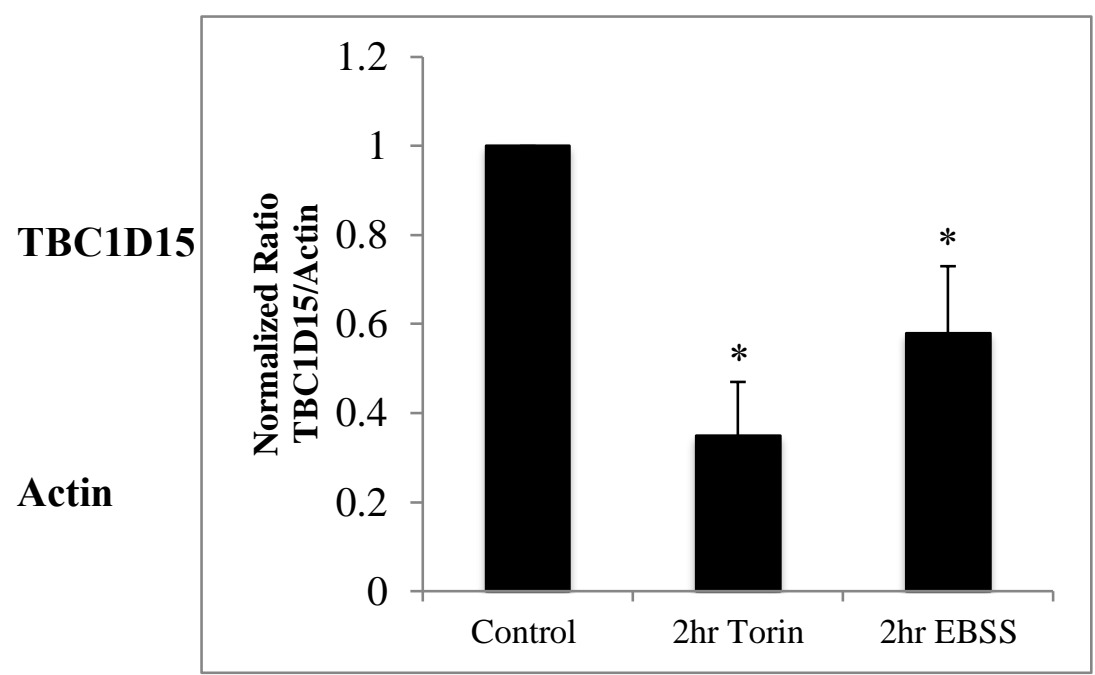

D:

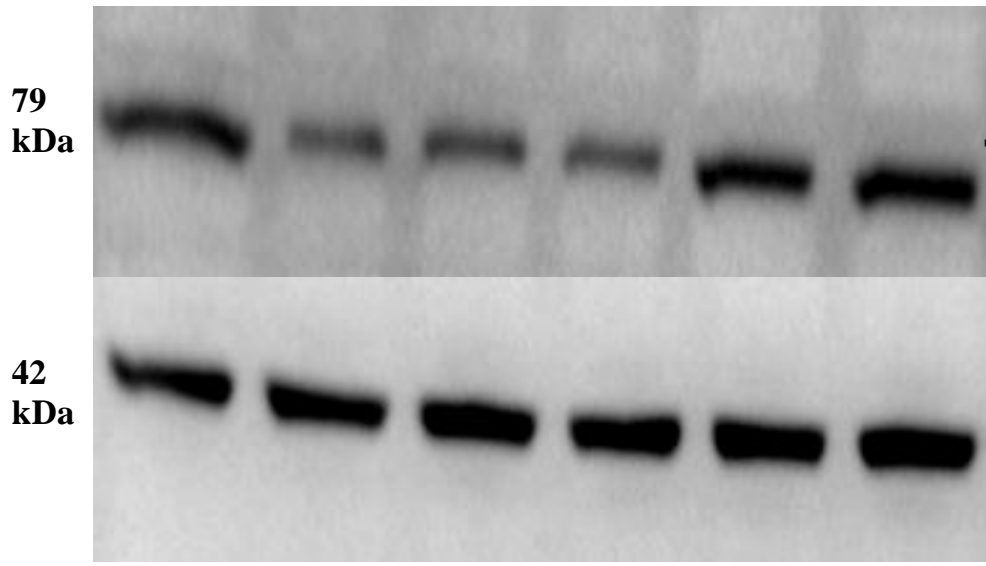

TBC1D15

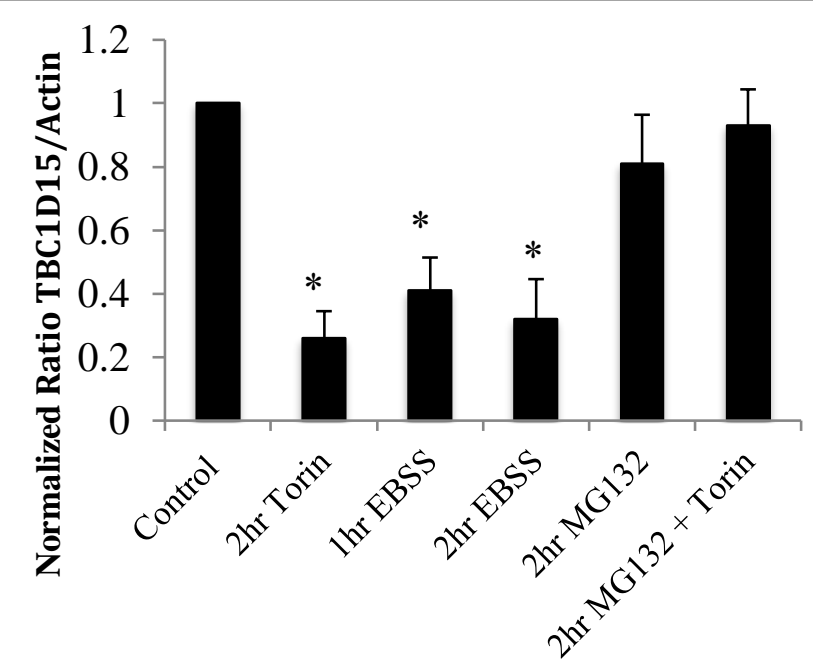

Figure 15. mTOR inhibition results in decreased levels of TBC1D15, which can be restored upon inhibition of the 26S Proteasome: (A) Western blot depicting levels of TBC1D15 in control and mTORinhibited treatment conditions. Levels of TBC1D15 are significantly reduced upon mTOR inhibition. The most exaggerated reduction is observed in the $200 \mathrm{nM}$ torin treatment condition. Levels of actin serve as a loading control. (B) Quantification of the results described in (A). Data was analyzed statistically by a oneway ANOVA, followed by Tukey's post hoc test $(p<0.01)$. Data presented is representative of four independent trials and is presented as mean \pm SEM. (C) Western blot depicting levels of TBC1D15 in control, mTOR-inhibited treatment conditions and conditions where the $26 \mathrm{~S}$ proteasome is inhibited. Similar to above, levels of TBC1D15 are significantly reduced upon mTOR inhibition. However, the use of torin in conjunction with the proteasomal inhibitor MG132, restores levels of TBC1D15 to basal conditions. Levels of actin serve as a loading control. (D) Quantification of the results described in (C). Data was analyzed statistically by a one-way ANOVA, followed by Tukey's post hoc test $(\mathrm{p}<0.01)$. Data presented is representative of four independent trials and is presented as mean \pm SEM. 


\section{Figure 16:}

A:

$79 \mathrm{kDa}$

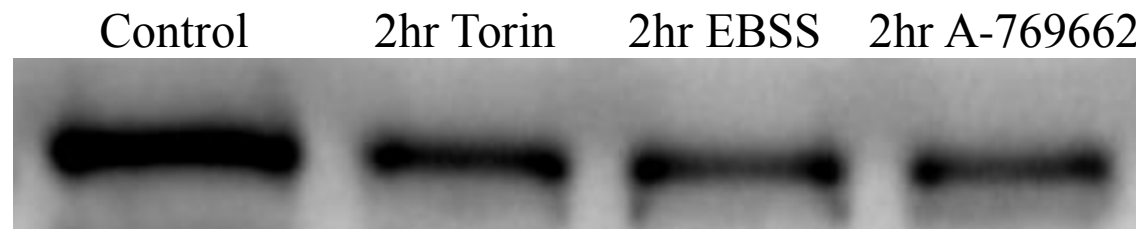

\section{IP}

AntiTBC1D15

Control 2hr Torin 2hr EBSS 2hr A-769662

$79 \mathrm{kDa}$

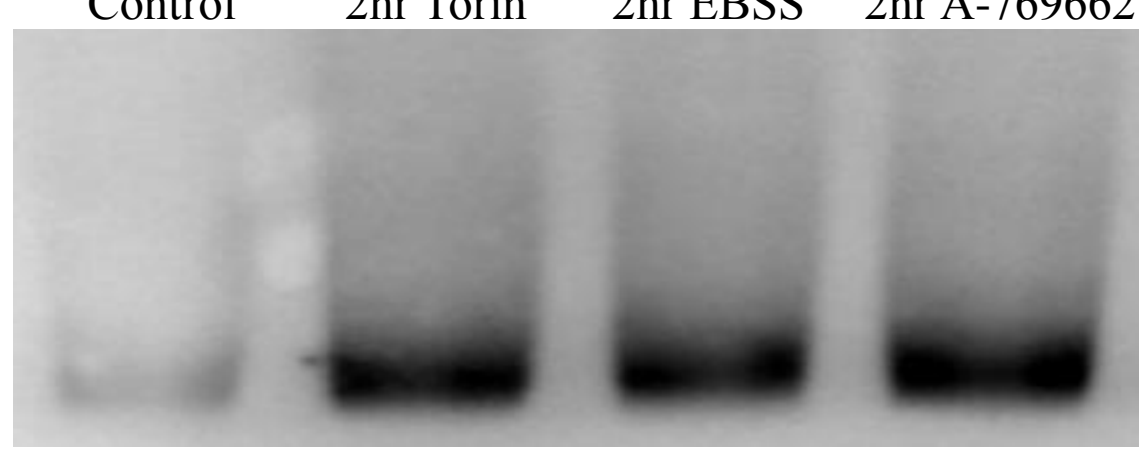

Blot AntiUbiquitin

B:

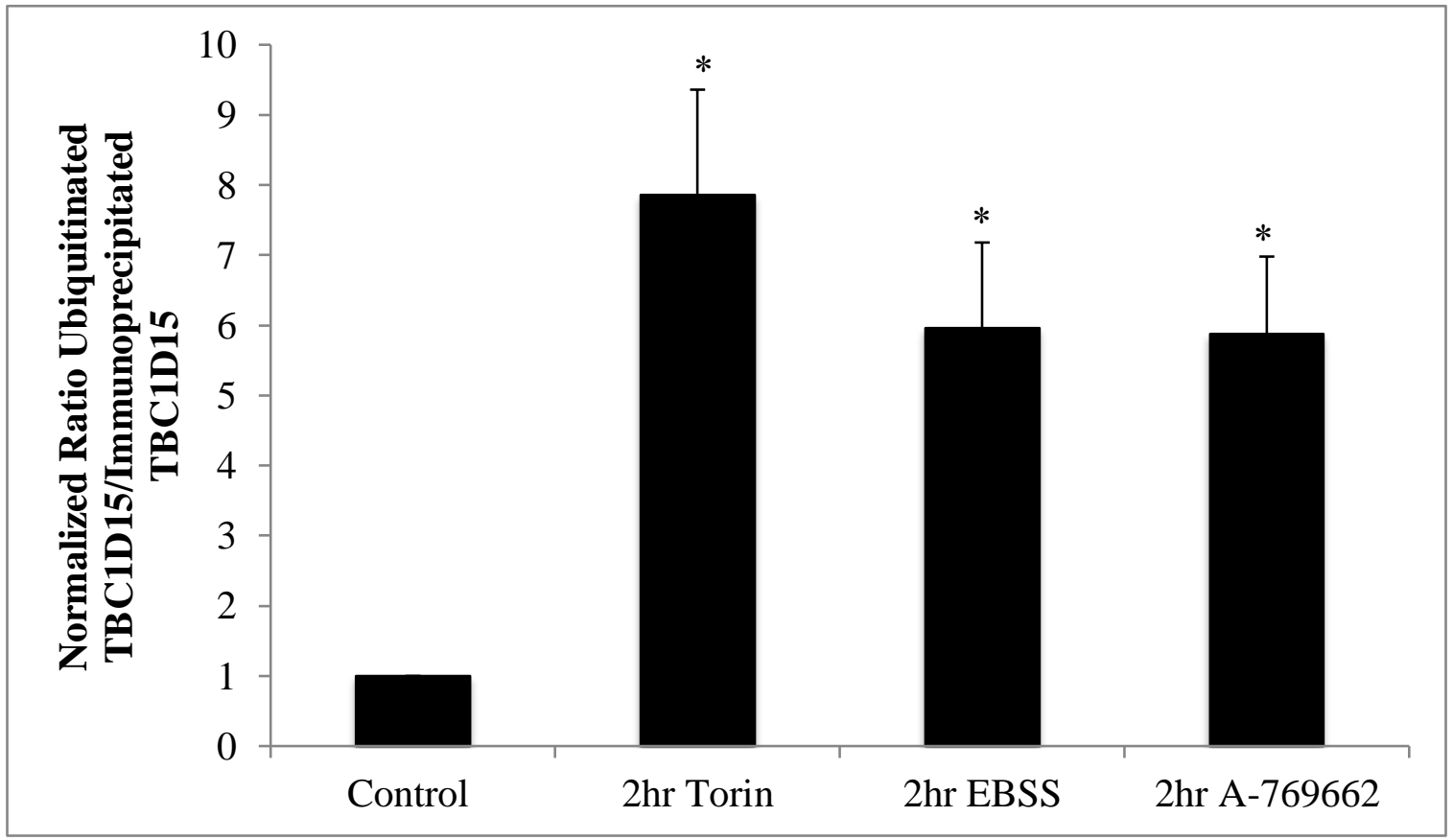

Figure 16. mTOR inhibition results in enhanced ubiquitination of TBC1D15:

(A) Levels of TBC1D15 generated from an immunoprecipitation. Significantly less TBC1D15 is recovered in conditions where mTOR activity is suppressed (top blot). Interestingly, conditions of mTOR inhibition produce a marked enhancement in levels of ubiquitinated TBC1D15 (bottom blot). (B) Quantification of the results described in (A). Data was analyzed statistically by a one-way ANOVA, followed by Tukey's post hoc test $(p<0.01)$. Data presented is representative of three independent trials and is presented as mean $\pm \mathrm{SEM}$. 


\section{Discussion and Future Directions}

\subsection{Summary of findings}

The research presented in this dissertation suggests that the inhibition of mTOR functionally modulates lysosome activity and function. Notably, mTOR suppression seems to enhance trafficking of material towards the lysosome and increases lysosomemediated proteolysis. These functional implications are a consequence of elevated Rab7 activity (more Rab7-GTP). In turn, enhanced levels of active Rab7 may be the result of reduced levels of the Rab7 GAP, TBC1D15, through ubiquitin and proteasomedependent degradation.

\subsection{Role of Rab7 in autophagy}

During the process of autophagy, damaged proteins and organelles, or ones that are deemed no longer necessary by the cell are sequestered into a structure known as an autophagosome (Mizushima, 2007). This autophagosome goes through a series of maturation steps (acquiring several distinct markers including LC3, Atg13 and GABARAP) eventually fusing with the lysosome, forming a hybrid organelle known as an autolysosome (Carlsson \& Simonsen, 2015). The autolysosome facilitates the degradation of delivered components. This process is essential for the clearance of cellular debris and the maintenance of cellular homeostasis. mTOR, specifically mTOR Complex 1 (mTORC1) is physically located on the lysosomal surface, at the Ragulator docking site. During conditions of mTOR inhibition (through starvation or the use of pharmacological treatments) autophagy is initiated, a process that terminates at the lysosome. This research sought to determine if crucial energy-detecting pathways 
(involving mTOR and AMPK) were involved in synchronizing cargo trafficking to the lysosome, providing nutrient release for usage in alternate pathways. In addition to autophagy, cells may derive energy and nutrients by increasing endocytosis and trafficking of endocytic material to lysosomes for digestion. Thus, we looked to see if endocytic trafficking to lysosomes was enhanced, along with lysosomal activity.

\subsection{The Rab7 GAP TBC1D2A, is involved in autophagy maintenance}

mTOR inhibition results in the induction of autophagy, a process which terminates at the lysosome. The research in this dissertation has shown that conditions of mTOR inhibition through pharmacological treatment (200 nM torin) or amino acid depletion (EBSS application), result in accelerated trafficking of a surrogate cargo molecule, aggregated IgG, to lysosomes. This is likely the result of elevated levels of active Rab7 (Rab7-GTP).

TBC1D2A, a Rab7 GAP conventionally known as Armus, has been studied in the context of autophagy. A physical connection between Leucine-Rich Repeat Kinase 1 (LRRK1), VAMP7 (a SNARE on the lysosomal membrane) and TBC1D2A, is necessary for activation of GAP activity (Toyofuku et al., 2015). Functional Rab7 GTP-hydrolysis is essential for autophagosome-lysosome fusion and autophagic flux (Toyofuku et al., 2015). LRRK1-silenced cells contain enlarged autophagosome-lysosome hybrids and delayed autophagic turnover (Toyofuku et al., 2015). Similarly, research done by Bernadette Carroll and colleagues has shown that Armus depletion impairs autophagic competence while Armus overexpression enlarges the autophagosomal population (Bernadette Carroll et al., 2013). The aforementioned information showcases the 
importance of functional Armus, a regulator of Rab7 activity, in autophagy progression. Additionally, autophagy induced by acute starvation results in a transient increase in levels of Rab7-GTP (Bernadette Carroll et al., 2013). This is consistent with the results previously outlined.

\subsection{The effects of starvation on endocytosis}

Our findings suggest that the suppression of mTOR activity accelerates the trafficking of material towards the lysosome. Enhanced trafficking may allow for faster nutrient liberation and recycling for re-use.

There is a paucity of knowledge when it comes to the relationship between starvation, nutrient turnover and trafficking. Potentially, increasing the activity of the Rab7 GTPase, the canonical mediator of lysosomal trafficking, tethering and fusion, may accelerate the trafficking of material towards the lysosome, facilitating nutrient replenishment for additional usage. This can be done either by delivering autophagosomes and/or endocytic cargo rapidly to lysosomes in order to accelerate degradation and the release of nutrients.

Conditions of lowered energy abundance induce upregulation of AMP-activated protein kinase (AMPK). AMPK activation has been shown to differentially regulate the trafficking of a subset of proteins, promoting pathways that increase energy accrual, while inhibiting pathways that consume energy. However, the connection between AMPK and regulation of the cell surface proteome remains to be understood. An important study that connects AMPK and energy-status of the cell to endocytosis and membrane remodeling, came from Eden Ross and colleagues (lab of Dr. Costin 
Antonescu) in 2015. This research showed that the treatment of retinal pigment epithelial (RPE) cells with the AMPK activator A-769662 caused a drastic reduction in the number of proteins on the cell surface (Ross et al., 2015). This suggests that conditions of energy deprivation cause changes in rates of endocytosis.

The model organism Dictyostelium has been used to examine the consequences of starvation on components of the endocytic pathway. In conditions of acute starvation (under four hours in duration), the kinetics of endocytosis are altered (E. W. E. W. Smith, Lima, Charette, \& Cosson, 2010). Notably, the ingestion of fluid phase material, postlysosome exocytosis and the translocation of material from the lysosome to the postlysosome were accelerated (E. W. E. W. Smith et al., 2010). This pinpoints starvation as a process capable of tempering rates of endocytosis and activity of endocytic machinery.

Glucose starvation appears to play a similar role in Saccharomyces cerevisiae, causing an increase in protein transport to the yeast vacuole, while preventing the backflux of proteins to the plasma membrane (Lang et al., 2014). The inhibition of recycling is a direct consequence of depleted cellular energy levels (low ATP) due to acute starvation. This research postulates that enhanced endocytosis coupled with reduced recycling functions to increase the import and trafficking of amino acids and lipids from the plasma membrane (Lang et al., 2014). Ultimately, this provides crucial resources for cellular survival. Collectively, the work presented here and work done in other model systems, suggest that endocytosis and endosomal trafficking can be tailored to meet the energy status of a cell. 


\subsection{Lysosomes act as bi-directional signaling platforms}

This work has shown that mTOR has the ability to control lysosome function. The inhibition of mTOR functionally modulates the lysosomal population of RAW 264.7 macrophages twofold. The proteolytic capacity of lysosomes is enhanced in addition to increased molecular trafficking. This represents another layer in an evolving story of how mTOR controls lysosome activity.

mTOR plays a crucial role in the regulation of lysosomal activity and function, bidirectionally. Lysosomes act as a scaffolding platform for mTOR signaling (serving as a docking site for mTORC1) and mTOR can mechanistically influence lysosomal activity, specifically through the transcription factors TFEB and TFE3 (Raben \& Puertollano, 2016). mTOR, particularly mTOR complex 1 (mTORC1) is as a regulator of TFEB localization through phosphorylation of specific residues on the surface of TFEB (Sardiello, 2016). Nutrient-rich conditions lead to the phosphorylation of TFEB by mTORC1. This phosphorylation facilitates an interaction between TFEB and 14-3-3 proteins, localizing TFEB to the cytosol (Napolitano \& Ballabio, 2016). Conversely, starvation conditions, which impair mTORC1 activity, prevent the phosphorylation of TFEB. This allows TFEB to translocate to the nucleus, initiating the transcription of lysosomal genes involved in catabolism (Napolitano \& Ballabio, 2016). TFEB serves as a master regulator of lysosome biogenesis, autophagy, macromolecular degradation and lysosomal exocytosis (Sardiello, 2016). This showcases the importance of mTOR (and TFEB) in adapting the lysosomal population to changing environmental statuses/situations. 


\section{6. mTOR inhibition and protein degradation}

The inhibition of mTOR leads to the depletion of TBC1D15, a Rab7 GAP, through a proteasome-dependent pathway via its ubiquitination. This illustrates a connection between mTOR activity and proteolysis. Protein production is enhanced under conditions of nutrient satiety and growth factor presence. These conditions are diametrically opposed to conditions promoting protein degradation, including serum deprivation, starvation and low energy. Recent research has sought to investigate whether degradation by the $26 \mathrm{~S}$ proteasome is upregulated when mTOR activity is suppressed. When mTOR is inhibited using rapamycin or torin, the degradation of long-lived proteins is dramatically enhanced within thirty minutes post-mTOR inhibition (Zhao, Zhai, Gygi, \& Goldberg, 2015). This increase is marked by a significant enhancement in Lysine 48 (K-48) ubiquitin-linkages, not Lysine 63 (K-63) ubiquitin-linkages (Zhao et al., 2015). An increase in protein degradation persists for several hours and is heavily reliant on the inhibition of mTORC1 not mTORC2. Interestingly, new protein synthesis is not essential for this phenotype or the phosphorylation of crucial mTOR targets (Ulks, 4E-BPs or S6Ks) (Zhao et al., 2015). This study also identified several proteins that were rapidly ubiquitinated and degraded. These data show that the inhibition of mTOR serves to rapidly increase the ubiquitin proteasome system, resulting in the ubiquitination of proteins implicated in anabolism (Zhao et al., 2015). The degradation of TBC1D15 may be part of a larger reorganization of the cell. This provides a link between the loss of mTOR activity and protein destruction. 


\subsection{E3 ubiquitin ligases and endo-lysosomal function}

The pronounced ubiquitination of TBC1D15 under conditions of mTOR suppression is likely important for the degradation of TBC1D15. Ubiquitination occurs through the activity of an E3 ubiquitin ligase, which covalently ligates ubiquitin to target proteins. The identity of the E3 ubiquitin ligase responsible for this is unclear, considering hundreds of genes encoding E3s exist.

Several E3 ubiquitin ligases are linked to endosomal and lysosomal function, including Parkin. However, not all ubiquitination events are linked to proteasomedepended degradation. For example, Parkin was shown to ubiquitinate the Rab7 GTPase at lysine 38 (K-38), and the absence of functional Parkin decreased the stability of Rab7 (Song, Trajkovic, Tsunemi, \& Krainc, 2016). Parkin-deficient fibroblasts showed diminished levels of Rab7 Interacting Lysosomal Protein (RILP) bound to Rab7 and this phenotype was restored upon overexpression of wild-type RILP (Song et al., 2016). Thus, in this case, Rab7 ubiquitination by Parkin interferes with the binding of protein effectors, the recruitment of Rab7 to membranes and consequently, Rab7 stability (Song et al., 2016).

Canonical Rab GTPase biology places vital importance on GEFs for Rab protein activation (GDP $\rightarrow$ GTP) and subsequent effector binding. This research highlights a connection between Rab GTPase regulation and Parkin-mediated ubiqutination.

The activity of several E3 ubiquitin ligases impinge on the lysosome. The RING domain E3 ubiquitin ligase Deltex-3-like (DTX3L) is involved in the sorting of the chemokine receptor CXCR4 from early endosomes to lysosomes (Holleman \& Marchese, 2014). The E3 ubiquitin ligase Rabring7 associates with lysosomes, mediating sorting of 
the epidermal growth factor receptor (EGFR) (C. J. Smith, Berry, \& McGlade, 2013). A series of Culin-RING E3 ubiquitin ligases are implicated in autophagy regulation, a process that terminates at the lysosome (Cui, Xiong, \& Zhao, 2016). All of this data suggests that the lysosome may serve as a signaling hub for E3 ubiquitin ligase activity and subsequent regulation.

\section{Future Directions}

\subsection{E3 ubiquitin ligase identification}

Approximately seven hundred putative E3 ubiquitin ligases have been identified in literature. E3 ubiquitin ligases are responsible for catalyzing the covalent addition of ubiquitin to lysine residue(s) on target proteins, resulting in protein shuttling to the $26 \mathrm{~S}$ proteasome for degradation (Berndsen \& Wolberger, 2014). Future research would aim to determine the E3 ubiquitin ligase responsible for the ubiquitination of TBC1D15. To investigate this, a BioID could be employed. The attachment of BirA, a biotin ligase, to TBC1D15 in control and mTOR-inhibited cells, will cause the biotinylation of proteins in close proximity to TBC1D15 (Fairhead \& Howarth, 2015). Upon biotinylation, protein purification will be accomplished using streptavidin, and protein interaction partners will be identified using mass spectrometry. This has the potential to illuminate any E3 ubiquitin ligases that interface with TBC1D15, and presumably the phospho-regulation of these E3 ubiquitin ligases by mTOR.

\subsection{Identification of ubiquitination site(s) on TBC1D15}

TBC1D15 is a 691 amino acid protein with the sequence: 
MAAAGVVSGKIIYEQEGVYIHSSCGKANDQDSLISGILRVLEKDAEVIVDWRPLD DALDSSSILCAGKDSSSVVEWTQAPKERAHRGSDQQSSYEAEWDMVTTVSFKK KPHTNGDAPGHRNGKSKWSFLFSLADLKSVKQSKEGMGWSYLVFCLKDDVML PALHFHQGDSKLLIESLEKYVVLCESPQDSRTLLVNCQNKSLSQSFENLLDEPAY GLIQKIKKDPYTATMVGFSKVTNYIFDSLRGSDPSTHQRPPSEMADFLSDAIPGL KINQQEEPGFEVITRIDLGERPVVQRREPVSLEEWNKSLDPEGRLVAVESMKQKI FRGGLSHSLRKQAWKFLLGYFPWDSTKEERTQLQKQKTDEYFRMKLQWKSVS EAQEKRNSRLRDYRSLIEKDVNRTDRTNKFYEGQDNPGLILLHDILMTYCMYDF DLGYVQGMSDLLSPLLYVMENEVDAFWCFASYMDQMHQNFEEQMQGMKTQL IQLSTLLRLLDSGFCSYLESQDSGYLYFCFRWLLIRFKREFSFLDILRLWEVMWTE LPCKNFHLLLCCAILESEKQQIMAKHYGFNEILKHINELSMKIDVEDILCKAEAIS LQMAQCKELPQAVCEILGLQDSEITTPDSDTDENVGSPCPVSAFPSSTLPILAASE AKDDSPTQTLASPNACRLTPA

Forty-four lysine residues (K) have been identified in the sequence above (bolded in the sequence above). All of these residues are potential ubiquitination sites. Using the program "UbPred: Predictor of Protein Ubiquitination Sites", six of these lysine residues were identified as potential ubiquitination sites, one with high confidence (represented in red), three with medium confidence (represented in blue) and two with low confidence (represented in green). To determine the location of TBC1D15s ubiqutination, site directed mutagenesis would be employed at these six ubiqutination sites (K (lysine) $\rightarrow \mathrm{R}$ (arginine)). Post-mutation, RAW 264.7 macrophages will be treated with the corresponding mTOR inhibitor (torin, EBSS and A-769662) and total levels of TBC1D15 will be assessed using SDS-PAGE and Western Blotting. Traditionally, upon mTOR inhibition, a significant reduction in TBC1D15 is observed. Upon mutating one of these crucial lysine residues, are levels of TBC1D15 restored to basal conditions? If levels of mutated TBC1D15 mimic control conditions, this implicates that particular lysine amino acid as the linkage for poly-ubiquitination and targeting to the $26 \mathrm{~S}$ proteasome for degradation.

To complement these results, both endogenous TBC1D15 and mutated TBC1D15 
(at each of the six identified lysine residues) could be synthesized (GenScript) and inserted into a mammalian expression vector. The creation of these constructs would enable determination of the lysine linkage targeting TBC1D15 to the $26 \mathrm{~S}$ proteasome during mTOR inhibition. Lysine 48 linkages serve a degradative role whereas Lysine 63 linkages function to change protein localization, not destruction. Identifying the lysine linkage present would make for a more comprehensive story.

Expression of mutated forms of TBC1D15 may not result in a change in phenotype (still producing reduced total levels upon mTOR inhibition). Several explanations may account for this. First, a mutation at one "predicted" ubiquitination site may shift equilibrium/ubiquitination to an alternate lysine residue. This functional redundancy has been shown in the epidermal growth factor receptor (EGFR), which requires all lysine residues in its $\mathrm{C}$-terminus to be mutated to ablate degradation. Potentially, all six predicted ubiquitination locations may need to be mutated to inhibit protein destruction. Additionally, multiple signals may be required to induce the degradation of TBC1D15, for instance, phosphorylation followed by ubiquitination. This sequential cascade has the potential to further complicate this pathway.

\subsection{Functional implications of TBC1D15 silencing}

TBC1D15 is a Rab7 GAP responsible for hydrolyzing GTP to GDP $\left(\mathrm{GTP}+\mathrm{H}_{2} \mathrm{O}\right.$

$\rightarrow \mathrm{GDP}+\mathrm{Pi}$ ), rendering Rab7 inactive and leading to its dissociation off the lysosomal membrane. Future experiments could test if TBC1D15 silencing results in more active Rab7 (Rab7-GTP). This would be assessed by transfecting TBC1D15-silenced RAW 264.7 macrophages with RILPc33-GFP and analyzing fluorescence intensity at the 
lysosome. Victoria Hipolito, PhD candidate in the lab of Dr. Roberto Botelho, has performed preliminary experiments. These experiments show elevated levels of RILPc33 (more active Rab7) in TBC1D15-silenced cells. To complement this, levels of active Rab7 (Rab7-GTP) could be determined post-TBC1D15 silencing via affinity precipitation of GTP-bound Rab7 using GST-RILPc33. Additionally, TBC1D15 silencing (more active Rab7) should accelerate the trafficking of material towards the lysosome. This could be assessed by measuring the rates of endocytosis and trafficking as was done for the trafficking of Aggregated IgG and Immunofluorescence. Victoria Hipolito, PhD candidate in the lab of Dr. Roberto Botelho, has performed preliminary experiments, which show accelerated trafficking in TBC1D15-silenced cells.

\subsection{Proteasome inhibition and levels of active Rab7 (Rab7-GTP)}

A significant reduction in total levels of TBC1D15 is evident when mTOR activity is suppressed. This reduction is recovered when torin is used with MG132, an inhibitor of the $26 \mathrm{~S}$ proteasome. Basal levels of TBC1D15 in the "torin + MG132" treatment group should produce reduced levels of active Rab7 (Rab7-GTP). To test if this is the case, we could employ affinity precipitation of GTP-bound Rab7 using GSTRILPc33 as described above. Low levels of Rab7-GTP in this treatment group would provide further evidence that TBC1D15 acts as a Rab7 GAP. Heightened levels of this protein promote accelerated GTP hydrolysis and Rab7 inactivation. 


\subsection{Additional Functional Tests}

\subsubsection{Using peroxisomes as a cargo "molecule" as opposed to aggregated IgG}

To assess the trafficking of material towards the lysosome, aggregated IgG was used as a cargo molecule. An alternate method to analyze trafficking is to track the movement of the peroxisomal population toward the lysosome under starvation conditions (pexophagy). The goal of this experiment is to enhance the work done using aggregated $\mathrm{IgG}$, potentially providing more of a functional basis for molecular trafficking during starvation.

\subsubsection{Magic Red cathepsin substrate assay}

Dye Quenched-Bovine Serum Albumin (DQ-BSA) was performed to measure the proteolytic activity of the lysosomal population upon mTOR inhibition. To complement these results, a Magic Red Cathepsin Substrate Assay could be employed. This assay quantitatively assesses the activity of lysosomal hydrolases over a pre-determined time period. Magic Red is a substrate conjugated to a fluorescent cresyl violet probe. Amide linkages present in the Magic Red substrate keep the cresyl violet probe in its nonfluorescent state. Magic Red is trafficked to the lysosome, where it is cleaved by lysosomal hydrolases. Cleavage of the amide linkage by lysosomal hydrolases results in fluorescence. A greater fluorescence intensity signal at the lysosome is indicative of a lysosomal population with enhanced cathepsin activity, thus being more degradative in nature. This is the phenotype expected when mTOR is inhibited using torin and EBSS. 


\section{Concluding statements}

The data presented in this dissertation shows that when mTOR is directly inhibited using torin (potent mTORC1 and mTORC2 inhibitor) or indirectly through AMPK activation with A-769662, or by amino acid deprivation through the use of EBSS, levels of active Rab7 (Rab7-GTP) increase on the lysosomal membrane. This seems to occur mechanistically through the depletion of TBC1D15 via its ubiquitination, leading to increased GTP-bound Rab7, which likely accelerates trafficking of material toward the lysosome and enhances lysosomal proteolysis. We predict that this process aids in nutrient replenishment. This has implications for what occurs when nutrient homeostasis is perturbed and how that imbalance can be offset. This may provide insight into several metabolic pathways and may impact processes like protein metabolism, lipid metabolism, carbohydrate metabolism and immunity (Figure 17). 


\section{Figure 17:}

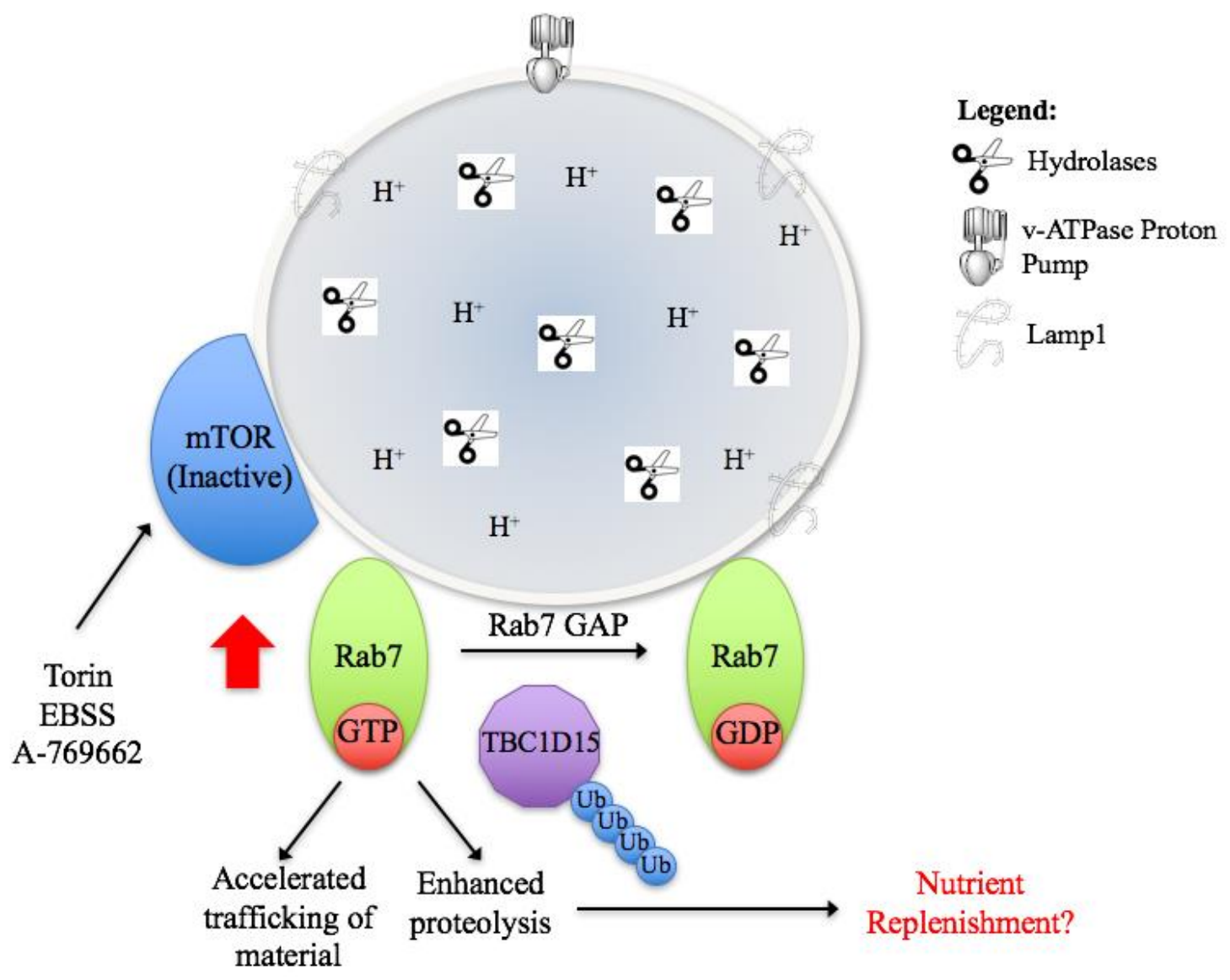

Figure 17. Overall model of research dissertation: Pharmacological inhibition of mTOR (through torin or A-769662) or amino acid deprivation (through EBSS), results in enhanced levels of active Rab7 (Rab7-GTP) on the lysosomal membrane. This phenomena occurs mechanistically through a reduction in levels of TBC1D15 (a Rab7 GAP) by ubiquitination. This phenotype has certain functional implications including material being trafficked to the lysosome at an accelerated rate and an increase in the degradative potential of the lysosomal population. These functional modulations have the potential to allow for nutrient replenishment for re-use. This novel signaling axis could be implicated in the disease states of several metabolic and immune diseases including certain cancer subtypes. 


\section{References}

Alory, C., \& Balch, W. E. (2000). Molecular basis for Rab prenylation. Journal of Cell Biology, 150(1), 89-103. https://doi.org/10.1083/jcb.150.1.89

An, Y., Shao, Y., Alory, C., Matteson, J., Sakisaka, T., Chen, W., ... Balch, W. E. (2003). Geranylgeranyl switching regulates GDI-Rab GTPase recycling. Structure, 11(3), 347-357. https://doi.org/10.1016/S0969-2126(03)00034-0

Auffarth, K., Arlt, H., Lachmann, J., Cabrera, M., \& Ungermann, C. (2014). Tracking of the dynamic localization of the Rab-specific HOPS subunits reveal their distinct interaction with Ypt7 and vacuoles. Cellular Logistics, 4(2), e29191. https://doi.org/10.4161/cl.29191

Banchereau, J., \& Steinman, R. M. (1998). Dendritic cells and the control of immunity. Nature, 392(March), 245-252. https://doi.org/10.1038/32588

Barr, F., \& Lambright, D. G. (2010). Rab GEFs and GAPs. Current Opinion in Cell Biology. https://doi.org/10.1016/j.ceb.2010.04.007

Berndsen, C. E., \& Wolberger, C. (2014). New insights into ubiquitin E3 ligase mechanism. Nature Structural \& Molecular Biology, 21(4), 301-307. https://doi.org/10.1038/nsmb.2780

Botelho, R. J., \& Grinstein, S. (2011). Phagocytosis. Current Biology: CB, 21(14), R533-R538. https://doi.org/10.1016/j.cub.2011.05.053

Byles, V., Covarrubias, A. J., Ben-Sahra, I., Lamming, D. W., Sabatini, D. M., Manning, B. D., \& Horng, T. (2013). The TSC-mTOR pathway regulates macrophage polarization. Nature Communications, 4. https://doi.org/10.1038/ncomms3834

Carlsson, S. R., \& Simonsen, A. (2015). Membrane dynamics in autophagosome 
biogenesis. Journal of Cell Science, 128(2), 193-205.

https://doi.org/10.1242/jcs.141036

Carroll, B., Mohd-Naim, N., Maximiano, F., Frasa, M., McCormack, J., Finelli, M., Thoresen, S., Perdios, L., Daigaku, R., Francis, R., Futter, C., Dikic, I., \& Braga, V. (2013). The TBC/RabGAP Armus Coordinated Rac1 and Rab7 Fucntions during Autophagy. Developmental Cell, 25(1), 15-28.

https://doi.org/10.1016/j.devcel.2013.03.005

Cogli, L., Piro, F., \& Bucci, C. (2009). Rab7 and the CMT2B disease. Biochemical Society Transactions, 37(Pt 5), 1027-31. https://doi.org/10.1042/BST0371027

Cox, D., Lee, D. J., Dale, B. M., Calafat, J., \& Greenberg, S. (2000). A Rab11-containing rapidly recycling compartment in macrophages that promotes phagocytosis. Proceedings of the National Academy of Sciences of the United States of America, 97(2), 680-5. https://doi.org/10.1073/pnas.97.2.680

Cui, D., Xiong, X., \& Zhao, Y. (2016). Cullin-RING ligases in regulation of autophagy. Cell Division, 11(1), 8. https://doi.org/10.1186/s13008-016-0022-5

Da Fonseca, P. C. A., He, J., \& Morris, E. P. (2012). Molecular Model of the Human 26S Proteasome. Molecular Cell, 46(1), 54-66. https://doi.org/10.1016/j.molcel.2012.03.026

Dazert, E., \& Hall, M. N. (2011). MTOR signaling in disease. Current Opinion in Cell Biology. https://doi.org/10.1016/j.ceb.2011.09.003

de Duve, C., Pressman, B. C., Gianetto, R., Wattiaux, R., \& Appelmans, F. (1955). Tissue fractionation studies. 6. Intracellular distribution patterns of enzymes in ratliver tissue. Biochemical Journal, 60(4), 604-617. 
https://doi.org/10.1042/bj0600604

De Luca, M., Cogli, L., Progida, C., Nisi, V., Pascolutti, R., Sigismund, S., ... Bucci, C. (2015). RILP regulates vacuolar ATPase through interaction with the V1G1 subunit. Journal of Cell Science, 128(14), 2565-2565. https://doi.org/10.1242/jcs.175323

Deshaies, R. J., \& Joazeiro, C. A. P. (2009). RING Domain E3 Ubiquitin Ligases. Annual Review of Biochemistry, 78(1), 399-434. https://doi.org/10.1146/annurev.biochem.78.101807.093809

Dirac-Svejstrup, A. B., Sumizawa, T., \& Pfeffer, S. R. (1997). Identification of a GDI displacement factor that releases endosomal Rab GTPases from Rab-GDI. EMBO Journal, 16(3), 465-472. https://doi.org/10.1093/emboj/16.3.465

Dunkelberger, J. R., \& Song, W. C. (2010). Complement and its role in innate and adaptive immune responses. Cell Research, 20(1), 34-50. https://doi.org/10.1038/cr.2009.139

Ebner, M., Sinkovics, B., Szczygieł, M., Ribeiro, D. W., \& Yudushkin, I. (2017). Localization of mTORC2 activity inside cells. Journal of Cell Biology, 216(2), 343353. https://doi.org/10.1083/jcb.201610060

Fairhead, M., \& Howarth, M. (2015). Site-Specific biotinylation of purified proteins using BirA. In Site-Specific Protein Labeling: Methods and Protocols (pp. 171184). https://doi.org/10.1007/978-1-4939-2272-7_12

Feldman, D. E., Chen, C., Punj, V., \& Machida, K. (2013). The TBC1D15 Oncoprotein Controls Stem Cell Self-Renewal through Destabilization of the Numb-p53 Complex. PLoS ONE, 8(2). https://doi.org/10.1371/journal.pone.0057312

Flannagan, R. S., Jaumouillé, V., \& Grinstein, S. (2012). The Cell Biology of 
Phagocytosis. Annual Review of Pathology: Mechanisms of Disease, 7(1), 61-98. https://doi.org/10.1146/annurev-pathol-011811-132445

Gallastegui, N., \& Groll, M. (2010). The 26S proteasome: assembly and function of a destructive machine. Trends in Biochemical Sciences. https://doi.org/10.1016/j.tibs.2010.05.005

Ganz, T. (2012). Macrophages and systemic iron homeostasis. Journal of Innate Immunity. https://doi.org/10.1159/000336423

Girard, E., Chmiest, D., Fournier, N., Johannes, L., Paul, J. L., Vedie, B., \& Lamaze, C. (2014). Rab7 is functionally required for selective cargo sorting at the early endosome. Traffic, 15(3), 309-326. https://doi.org/10.1111/tra.12143

Glick, B. S. (2000). Organization of the Golgi apparatus. Current Opinion in Cell Biology. https://doi.org/10.1016/S0955-0674(00)00116-2

Grant, B. D., \& Donaldson, J. G. (2009). Pathways and mechanisms of endocytic recycling. Nature Reviews Molecular Cell Biology, 10(9), 597-608. https://doi.org/10.1038/nrm2755

Guerra, F., \& Bucci, C. (2016). Multiple Roles of the Small GTPase Rab7. Cells, 5(3), 34. https://doi.org/10.3390/cells5030034

Guertin, D. A., \& Sabatini, D. M. (2009). The Pharmacology of mTOR Inhibition. Science Signaling, 2(67), pe24-pe24. https://doi.org/10.1126/scisignal.267pe24

Gyparaki, M. T., \& Papavassiliou, A. G. (2014). Lysosome: The cell's "suicidal bag" as a promising cancer target. Trends in Molecular Medicine. https://doi.org/10.1016/j.molmed.2014.01.009

Hara, K., Yonezawa, K., Kozlowski, M. T., Sugimoto, T., Andrabi, K., Weng, Q. P., ... 
Avruch, J. (1997). Regulation of eIF-4E BP1 phosphorylation by mTOR. Journal of Biological Chemistry, 272(42), 26457-26463.

https://doi.org/10.1074/jbc.272.42.26457

Hartmann-Petersen, R., Seeger, M., \& Gordon, C. (2003). Transferring substrates to the 26S proteasome. Trends in Biochemical Sciences. https://doi.org/10.1016/S09680004(02)00002-6

Harvey, B. P., Gee, R. J., Haberman, A. M., Shlomchik, M. J., \& Mamula, M. J. (2007). Antigen presentation and transfer between B cells and macrophages. European Journal of Immunology, 37(7), 1739-1751. https://doi.org/10.1002/eji.200636452

Henne, W. M., Buchkovich, N. J., \& Emr, S. D. (2011). The ESCRT Pathway. Developmental Cell. https://doi.org/10.1016/j.devcel.2011.05.015

Holleman, J., \& Marchese, A. (2014). The ubiquitin ligase deltex-31 regulates endosomal sorting of the G protein-coupled receptor CXCR4. Molecular Biology of the Cell, 25(12), 1892-1904. https://doi.org/10.1091/mbc.E13-10-0612

Huang, K., \& Fingar, D. C. (2014). Growing knowledge of the mTOR signaling network. Seminars in Cell and Developmental Biology. https://doi.org/10.1016/j.semcdb.2014.09.011

Huang, W., Zhu, P. J., Zhang, S., Zhou, H., Stoica, L., Galiano, M., ... Costa-Mattioli, M. (2013). mTORC2 controls actin polymerization required for consolidation of longterm memory. Nature Neuroscience, 16(4), 441-448. https://doi.org/10.1038/nn.3351

Huotari, J., \& Helenius, A. (2011). Endosome maturation. The EMBO Journal, 30(17), 3481-500. https://doi.org/10.1038/emboj.2011.286 
Hutagalung, A. H., \& Novick, P. J. (2011). Role of Rab GTPases in Membrane Traffic and Cell Physiology. Physiological Reviews, 91(1), 119-149. https://doi.org/10.1152/physrev.00059.2009

Indik, Z. K., Park, J., Hunter, S., \& Schreiber, A. D. (1995). The Molecular Dissection of Fcy Receptor Mediated Phagocytosis. Blood, 86(12), 1109-1124. https://doi.org/10.1080/01621459.1952.10483441

Jacobson, A. D., Zhang, N. Y., Xu, P., Han, K. J., Noone, S., Peng, J., \& Liu, C. W. (2009). The lysine 48 and lysine 63 ubiquitin conjugates are processed differently by the 26 S proteasome. Journal of Biological Chemistry, 284(51), 35485-35494. https://doi.org/10.1074/jbc.M109.052928

Jastrzebski, K., Hannan, K. M., Tchoubrieva, E. B., Hannan, R. D., \& Pearson, R. B. (2007). Coordinate regulation of ribosome biogenesis and function by the ribosomal protein S6 kinase, a key mediator of mTOR function. Growth Factors (Chur, Switzerland), 25(4), 209-226. https://doi.org/10.1080/08977190701779101

Jordens, I., Fernandez-Borja, M., Marsman, M., Dusseljee, S., Janssen, L., Calafat, J., ... Neefjes, J. (2001). The Rab7 effector protein RILP controls lysosomal transport by inducing the recruitment of dynein-dynactin motors. Current Biology, 11(21), 16801685. https://doi.org/10.1016/S0960-9822(01)00531-0

Kimura, N., Tokunaga, C., Dalal, S., Richardson, C., Yoshino, K., Hara, K., ... Yonezawa, K. (2003). A possible linkage between AMP-activated protein kinase (AMPK) and mammalian target of rapamycin (mTOR) signalling pathway. Genes to Cells : Devoted to Molecular \& Cellular Mechanisms, 8(1), 65-79. https://doi.org/10.1007/s00441-012-1491-8 
Komander, D., \& Rape, M. (2012). The Ubiquitin Code. Annual Review of Biochemistry, 81(1), 203-229. https://doi.org/10.1146/annurev-biochem-060310-170328

Lang, M. J., Martinez-Marquez, J. Y., Prosser, D. C., Ganser, L. R., Buelto, D., Wendland, B., \& Duncan, M. C. (2014). Glucose starvation inhibits autophagy via vacuolar hydrolysis and induces plasma membrane internalization by downregulating recycling. Journal of Biological Chemistry, 289(24), 16736-16747. https://doi.org/10.1074/jbc.M113.525782

Laplante, M., \& Sabatini, D. M. (2012a). mTOR signaling. Cold Spring Harbor Perspectives in Biology, 4(2). https://doi.org/10.1101/cshperspect.a011593

Laplante, M., \& Sabatini, D. M. (2012b). MTOR signaling in growth control and disease. Cell. https://doi.org/10.1016/j.cell.2012.03.017

Long, X., Lin, Y., Ortiz-Vega, S., Yonezawa, K., \& Avruch, J. (2005). Rheb binds and regulates the mTOR kinase. Current Biology, 15(8), 702-713. https://doi.org/10.1016/j.cub.2005.02.053

Lübke, T., Lobel, P., \& Sleat, D. E. (2009). Proteomics of the lysosome. Biochimica et Biophysica Acta - Molecular Cell Research. https://doi.org/10.1016/j.bbamcr.2008.09.018

Luzio, J. P.; Rous, B. A.; Bright, N. A.; Pryor, P. R.; Mullock, B. M. and Piper, R. C. (2000). Lysosome-endosome fusion and lysosome biogenesis. Journal of Cell Science, 113 ( Pt 9, 1515-1524. https://doi.org/10.1093/emboj/18.2.297

Magnuson, B., Ekim, B., \& Fingar, D. C. (2012). Regulation and function of ribosomal protein S6 kinase (S6K) within mTOR signalling networks. The Biochemical Journal, 441(1), 1-21. https://doi.org/10.1042/BJ20110892 
Mantegazza, A. R., Magalhaes, J. G., Amigorena, S., \& Marks, M. S. (2013).

Presentation of Phagocytosed Antigens by MHC Class I and II. Traffic. https://doi.org/10.1111/tra.12026

Mihaylova, M. M., \& Shaw, R. J. (2011). The AMPK signalling pathway coordinates cell growth, autophagy and metabolism. Nature Cell Biology, 13(9), 1016-1023. https://doi.org/10.1038/ncb2329

Mishev, K., Dejonghe, W., \& Russinova, E. (2013). Small molecules for dissecting endomembrane trafficking: A cross-systems view. Chemistry and Biology. https://doi.org/10.1016/j.chembiol.2013.03.009

Mizushima, N. (2007). Autophagy: Process and function. Genes and Development. https://doi.org/10.1101/gad.1599207

Morita, M., Gravel, S. P., Hulea, L., Larsson, O., Pollak, M., St-Pierre, J., \& Topisirovic, I. (2015). MTOR coordinates protein synthesis, mitochondrial activity. Cell Cycle. https://doi.org/10.4161/15384101.2014.991572

Morreale, F. E. ster, \& Walden, H. (2016). Types of Ubiquitin Ligases. Cell, 165(1), 248-248. https://doi.org/10.1016/j.cell.2016.03.003

Mukherjee, S., Ghosh, R. N., \& Maxfield, F. R. (1997). Endocytosis. Physiol Rev, 77(3), 759-803. Retrieved from internal-pdf://759.full0480312877/759.full.pdf\%5Cnhttp://www.ncbi.nlm.nih.gov/pubmed/9234965\%5Cn internal-pdf://mukherjee-1997-endocytosis-2762107437/Mukherjee-1997Endocytosis.pdf internal-pdf://Mukherjee-1997-Endocytosis11000512045/Mukherjee-1997-Endoc

Napolitano, G., \& Ballabio, A. (2016). TFEB at a glance. Journal of Cell Science, 
129(13), 2475-2481. https://doi.org/10.1242/jcs.146365

Narita, M., \& Inoki, K. (2012). Rags connect mTOR and autophagy. Small GTPases, 3(2), 111-114. https://doi.org/10.4161/sgtp.19422

Nordmann, M., Cabrera, M., Perz, A., Bröcker, C., Ostrowicz, C., Engelbrecht-Vandré, S., \& Ungermann, C. (2010). The Mon1-Ccz1 complex is the GEF of the late endosomal Rab7 homolog Ypt7. Current Biology, 20(18), 1654-1659. https://doi.org/10.1016/j.cub.2010.08.002

Palacios, C. (2006). The Role of Nutrients in Bone Health, from A to Z. Critical Reviews in Food Science and Nutrition, 46(8), 621-628. https://doi.org/10.1080/10408390500466174

Pang, G., Xie, J., Chen, Q., \& Hu, Z. (2014). Energy intake, metabolic homeostasis, and human health. Food Science and Human Wellness, 3(3-4), 89-103. https://doi.org/10.1016/j.fshw.2015.01.001

Peralta, E. R., Martin, B. C., \& Edinger, A. L. (2010). Differential effects of TBC1D15 and mammalian Vps39 on Rab7 activation state, lysosomal morphology, and growth factor dependence. Journal of Biological Chemistry, 285(22), 16814-16821. https://doi.org/10.1074/jbc.M110.111633

Pfeffer, S., \& Aivazian, D. (2004). Targeting Rab GTPases to distinct membrane compartments. Nature Reviews Molecular Cell Biology, 5(11), 886-896. https://doi.org/10.1038/nrm1500

Pfeffer, S. R. (2005). Structural clues to rab GTPase functional diversity. Journal of Biological Chemistry. https://doi.org/10.1074/jbc.R500003200

Polak, P., \& Hall, M. N. (2006). mTORC2 Caught in a SINful Akt. Developmental Cell. 
https://doi.org/10.1016/j.devcel.2006.09.005

Porta, C., Paglino, C., \& Mosca, A. (2014). Targeting PI3K/Akt/mTOR Signaling in Cancer. Frontiers in Oncology, 4. https://doi.org/10.3389/fonc.2014.00064

Poteryaev, D., Datta, S., Ackema, K., Zerial, M., \& Spang, A. (2010). Identification of the switch in early-to-late endosome transition. Cell, 141(3), 497-508. https://doi.org/10.1016/j.cell.2010.03.011

Poüs, C., \& Codogno, P. (2011). Lysosome positioning coordinates mTORC1 activity and autophagy. Nature Cell Biology, 13(4), 342-344. https://doi.org/10.1038/ncb0411-342

Progida, C., Malerod, L., Stuffers, S., Brech, A., Bucci, C., \& Stenmark, H. (2007). RILP is required for the proper morphology and function of late endosomes. Journal of Cell Science, 120(21), 3729-3737. https://doi.org/10.1242/jcs.017301

Pu, J., Schindler, C., Jia, R., Jarnik, M., Backlund, P., \& Bonifacino, J. S. (2015). BORC, a Multisubunit Complex that Regulates Lysosome Positioning. Developmental Cell, 33(2), 176-188. https://doi.org/10.1016/j.devcel.2015.02.011

Puertollano, R. (2014). mTOR and lysosome regulation. F1000Prime Reports, 6. https://doi.org/10.12703/P6-52

Raben, N., \& Puertollano, R. (2016). TFEB and TFE3: Linking Lysosomes to Cellular Adaptation to Stress. Annual Review of Cell and Developmental Biology, 32(1), 255-278. https://doi.org/10.1146/annurev-cellbio-111315-125407

Reggiori, F., \& Ungermann, C. (2017). Autophagosome Maturation and Fusion. Journal of Molecular Biology. https://doi.org/10.1016/j.jmb.2017.01.002

Rocha, N., Kuijl, C., Van Der Kant, R., Janssen, L., Houben, D., Janssen, H., ... Neefjes, 
J. (2009). Cholesterol sensor ORP1L contacts the ER protein VAP to control Rab7RILP-p150Glued and late endosome positioning. Journal of Cell Biology, 185(7), 1209-1225. https://doi.org/10.1083/jcb.200811005

Romero, R. K., Peralta, E. R., Guenther, G. G., Wong, S. Y., \& Edinger, A. L. (2009). Rab7 activation by growth factor withdrawal contributes to the induction of apoptosis. Molecular Biology of the Cell, 20(12), 2831-40. https://doi.org/10.1091/mbc.E08-09-0911

Ross, E., Ata, R., Thavarajah, T., Medvedev, S., Bowden, P., Marshall, J. G., \& Antonescu, C. N. (2015). AMP-activated protein kinase regulates the cell surface proteome and integrin membrane traffic. PLoS ONE, 10(5). https://doi.org/10.1371/journal.pone.0128013

Rotin, D., \& Kumar, S. (2009). Physiological functions of the HECT family of ubiquitin ligases. Nature Reviews Molecular Cell Biology, 10(6), 398-409. https://doi.org/10.1038/nrm2690

Rubinsztein, D. C., Shpilka, T., \& Elazar, Z. (2012). Mechanisms of autophagosome biogenesis. Current Biology. https://doi.org/10.1016/j.cub.2011.11.034

Sancak, Y., Bar-Peled, L., Zoncu, R., Markhard, A. L., Nada, S., \& Sabatini, D. M. (2010). Ragulator-rag complex targets mTORC1 to the lysosomal surface and is necessary for its activation by amino acids. Cell, 141(2), 290-303. https://doi.org/10.1016/j.cell.2010.02.024

Sardiello, M. (2016). Transcription factor EB: from master coordinator of lysosomal pathways to candidate therapeutic target in degenerative storage diseases. Annals of the New York Academy of Sciences, 1371(1), 3-14. 
https://doi.org/10.1111/nyas.13131

Saric, A., Hipolito, V. E. B., Kay, J. G., Canton, J., Antonescu, C. N., \& Botelho, R. J. (2016). mTOR controls lysosome tubulation and antigen presentation in macrophages and dendritic cells. Molecular Biology of the Cell, 27(2), 321-333. https://doi.org/10.1091/mbc.E15-05-0272

Schumacher, K., \& Krebs, M. (2010). The V-ATPase: Small cargo, large effects. Current Opinion in Plant Biology. https://doi.org/10.1016/j.pbi.2010.07.003

Scott, C. C., Vacca, F., \& Gruenberg, J. (2014). Endosome maturation, transport and functions. Seminars in Cell and Developmental Biology. https://doi.org/10.1016/j.semcdb.2014.03.034

Seabra, M. C. (1996). Nucleotide dependence of rab geranylgeranylation rab escort protein interacts preferentially with GDP-bound Rab. Journal of Biological Chemistry, 271(24), 14398-14404. https://doi.org/10.1074/jbc.271.24.14398

Shock, H. (2005). AMPK Signaling. Cell, (April 2006), 2005.

Silva, M. T., \& Correia-Neves, M. (2012). Neutrophils and macrophages: The main partners of phagocyte cell systems. Frontiers in Immunology, 3(JUL). https://doi.org/10.3389/fimmu.2012.00174

Smalle, J., \& Vierstra, R. D. (2004). THE UBIQUITIN 26S PROTEASOME PROTEOLYTIC PATHWAY. Annual Review of Plant Biology, 55(1), 555-590. https://doi.org/10.1146/annurev.arplant.55.031903.141801

Smith, C. J., Berry, D. M., \& McGlade, C. J. (2013). The E3 ubiquitin ligases RNF126 and Rabring7 regulate endosomal sorting of the epidermal growth factor receptor. Journal of Cell Science, 126(Pt 6), 1366-80. https://doi.org/10.1242/jcs.116129 
Smith, E. W. E. W., Lima, W. C. W. C., Charette, S. J. S. J., \& Cosson, P. P. (2010). Effect of starvation on the endocytic pathway in Dictyostelium cells. Eukaryotic Cell, 9(3), 387-392. https://doi.org/10.1128/EC.00285-09

Solinger, J. A., \& Spang, A. (2013). Tethering complexes in the endocytic pathway: CORVET and HOPS. FEBS Journal. https://doi.org/10.1111/febs.12151

Song, P., Trajkovic, K., Tsunemi, T., \& Krainc, D. (2016). Parkin Modulates Endosomal Organization and Function of the Endo-Lysosomal Pathway. Journal of Neuroscience, 36(8), 2425-2437. https://doi.org/10.1523/JNEUROSCI.256915.2016

Steinberg, G. R., \& Kemp, B. E. (2009). AMPK in Health and Disease. Physiological Reviews, 89(3), 1025-1078. https://doi.org/10.1152/physrev.00011.2008

Stenmark, H. (2009). Rab GTPases as coordinators of vesicle traffic. Nature Reviews Molecular Cell Biology, 10(8), 513-525. https://doi.org/10.1038/nrm2728

Swatek, K. N., \& Komander, D. (2016). Ubiquitin modifications. Cell Research, 26(4), 399-422. https://doi.org/10.1038/cr.2016.39

Tanida, I., Ueno, T., \& Kominami, E. (2008). LC3 and autophagy. Methods in Molecular Biology, 445, 77-88. https://doi.org/10.1007/978-1-59745-157-4-4

Toyofuku, T., Morimoto, K., Sasawatari, S., Kumanogoh, A., (2015). Leucine-Rich Repeat Kinase 1 Regulates Autophagy through Turning On TBC1D2-Dependent Rab7 Inactivation. Molecular and Cellular Biology, 35(17), 3044-3058. https://doi.org/10.1128/mcb.00085-15

Tsou, P., Zheng, B., Hsu, C. H., Sasaki, A. T., \& Cantley, L. C. (2011). A fluorescent reporter of AMPK activity and cellular energy stress. Cell Metabolism, 13(4), 476- 
486. https://doi.org/10.1016/j.cmet.2011.03.006

Ungewickell, E. J., \& Hinrichsen, L. (2007). Endocytosis: clathrin-mediated membrane budding. Current Opinion in Cell Biology. https://doi.org/10.1016/j.ceb.2007.05.003

Vanlandingham, P. A., \& Ceresa, B. P. (2009). Rab7 regulates late endocytic trafficking downstream of multivesicular body biogenesis and cargo sequestration. Journal of Biological Chemistry, 284(18), 12110-12124. https://doi.org/10.1074/jbc.M809277200

Voges, D., Zwickl, P., \& Baumeister, W. (1999). The 26S Proteasome: A Molecular Machine Designed for Controlled Proteolysis. Annual Review of Biochemistry, 68(1), 1015-1068. https://doi.org/10.1146/annurev.biochem.68.1.1015

Wang, X., \& Proud, C. G. (2011). MTORC1 signaling: What we still dont know. Journal of Molecular Cell Biology. https://doi.org/10.1093/jmcb/mjq038

Xiao, B., Sanders, M. J., Underwood, E., Heath, R., Mayer, F. V., Carmena, D., ... Gamblin, S. J. (2011). Structure of mammalian AMPK and its regulation by ADP. Nature, 472(7342), 230-233. https://doi.org/10.1038/nature09932

Xu, H., \& Ren, D. (2015). Lysosomal Physiology. Annual Review of Physiology, 77(1), 57-80. https://doi.org/10.1146/annurev-physiol-021014-071649

Yamano, K., Fogel, A. I., Wang, C., van der Bliek, A. M., \& Youle, R. J. (2014). Mitochondrial Rab GAPs govern autophagosome biogenesis during mitophagy. eLife, 3, e01612. https://doi.org/10.7554/eLife.01612

Yang, Q., \& Guan, K.-L. (2007). Expanding mTOR signaling. Cell Research, 17(8), 666681. https://doi.org/10.1038/cr.2007.64

Ye, Y., \& Rape, M. (2009). Building ubiquitin chains: E2 enzymes at work. Nature 
Reviews Molecular Cell Biology, 10(11), 755-764. https://doi.org/10.1038/nrm2780

Zerial, M., \& McBride, H. (2001). Rab proteins as membrane organizers. Nature Reviews. Molecular Cell Biology, 2(2), 107-117. https://doi.org/10.1038/35052055

Zhang, M., Chen, L., Wang, S., \& Wang, T. (2009). Rab7: roles in membrane trafficking and disease. Bioscience Reports, 29(3), 193. https://doi.org/10.1042/BSR20090032

Zhang, X. M., Walsh, B., Mitchell, C. A., \& Rowe, T. (2005). TBC domain family, member 15 is a novel mammalian Rab GTPase-activating protein with substrate preference for Rab7. Biochemical and Biophysical Research Communications, 335(1), 154-161. https://doi.org/10.1016/j.bbrc.2005.07.070

Zhao, J., Zhai, B., Gygi, S. P., \& Goldberg, A. L. (2015). mTOR inhibition activates overall protein degradation by the ubiquitin proteasome system as well as by autophagy. Proceedings of the National Academy of Sciences, 112(52), 1579015797. https://doi.org/10.1073/pnas.1521919112 